\title{
It takes a town to build a trail: Relationships between nonprofit organizations and local governments in rail-trail and greenway development in three West Virginia communities
}

\author{
Kelly L. Pack \\ West Virginia University
}

Follow this and additional works at: https://researchrepository.wvu.edu/etd

\section{Recommended Citation}

Pack, Kelly L., "It takes a town to build a trail: Relationships between nonprofit organizations and local governments in rail-trail and greenway development in three West Virginia communities" (2006). Graduate Theses, Dissertations, and Problem Reports. 2469.

https://researchrepository.wvu.edu/etd/2469

This Thesis is protected by copyright and/or related rights. It has been brought to you by the The Research Repository @ WVU with permission from the rights-holder(s). You are free to use this Thesis in any way that is permitted by the copyright and related rights legislation that applies to your use. For other uses you must obtain permission from the rights-holder(s) directly, unless additional rights are indicated by a Creative Commons license in the record and/ or on the work itself. This Thesis has been accepted for inclusion in WVU Graduate Theses, Dissertations, and Problem Reports collection by an authorized administrator of The Research Repository @ WVU. For more information, please contact researchrepository@mail.wvu.edu. 


\title{
It Takes a Town to Build a Trail:
}

Relationships between Nonprofit Organizations and Local Governments in Rail-Trail and Greenway Development in Three West Virginia Communities

\author{
Kelly L. Pack \\ Thesis submitted to the \\ Davis College of Agriculture, Forestry \& Consumer Sciences \\ at West Virginia University \\ in partial fulfillment of the requirements \\ for the degree of \\ Master of Science \\ in \\ Recreation, Parks, and Tourism Resources
}

\author{
Steve Selin, Ph.D., Chair \\ Jaci Webb-Dempsey, Ph.D. \\ Peggy Pings, M.S. \\ Division of Forestry \\ Morgantown, West Virginia \\ 2006
}

Keywords: Rail-Trail, Greenway, Nonprofit Organizations, Social Capital, Public-Private Partnerships, Networks, Capacity Building Qualitative Methods Copyright 2006 Kelly L. Pack 


\section{Abstract \\ It Takes a Town to Build a Trail: Relationships between Nonprofit Organizations and Local Governments in Rail-Trail and Greenway Development in Three West Virginia Communities Kelly L. Pack}

As more communities across the country are developing rail-trails and greenways, relationships among community-based nonprofit organizations and local government entities evolve during trail development. Twenty-three participants from the nonprofit and local government sectors in three West Virginia municipalities were interviewed about their relationships and experience in rail-trail and greenway development. This qualitative analysis employs a grounded theory framework and reveals several practical and theoretical findings. Perceived benefits and costs of trail development reported by participants provided a context for how participants relayed experiences indicative of their political and built environments. Factors that constrain or facilitate relationship building between nonprofit organizations and local government entities, as well as the role of community involvement, leadership, attitudes, and planning principles and processes were categories that emerged to support the importance of individual and organizational level social capital in exploring nonprofit and local government relations in rail-trail and greenway development. 


\section{Dedication}

This research is dedicated to all of the champions and torch carriers of rail-trail and greenway development throughout the country. It is also my small contribution to the community members of Charleston, Morgantown, and Wheeling, West Virginia who contributed to this study. Their shared experiences taught me so much about what it means to belong to a community, and to continually improve community welfare through service and stewardship. 


\section{Acknowledgements}

I would like to thank the members of my committee:

Peggy Pings, who graciously agreed to include me in a project that was the seed of this entire study, and who has been a teacher and a mentor through my graduate education. Dr. Jaci Webb-Dempsey, who opened my eyes to the world of qualitative research, and supported my work with her encouraging words.

Dr. Steve Selin, who guided me through the research process and remained confident in my ability to endeavor into somewhat unknown territory.

I would also like to thank my family, Mark, Frances, and Nikki Pack, for all of their love and support throughout the many stages of my life, and for sharing their love of rail-trails with me.

I have so much gratitude for the constant encouragement of my boyfriend, Michael Miller, and his mother, Connie who have so often shared my joys and frustrations as their own.

Lastly, I will be forever grateful to all of the people in Morgantown who work relentlessly to make it the vibrant community that it is. 


\section{Table of Contents}

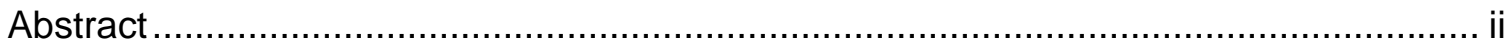

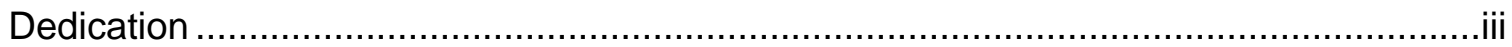

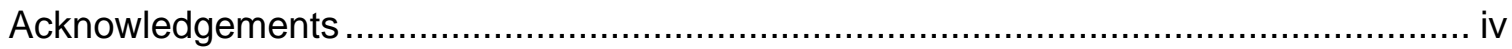

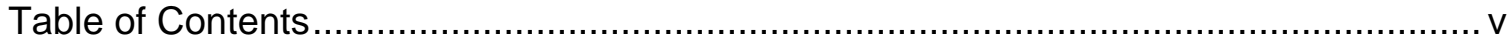

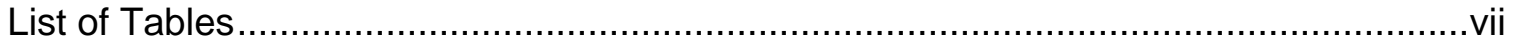

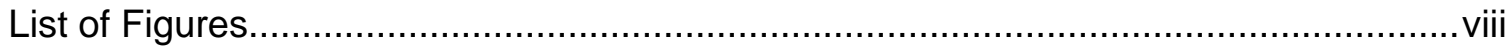

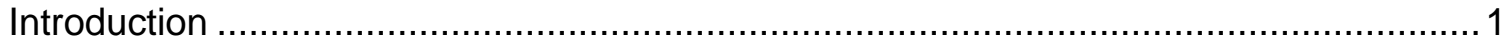

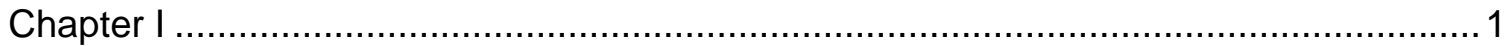

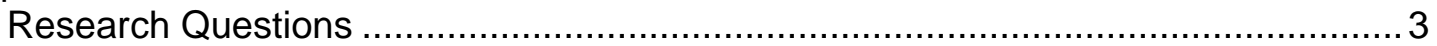

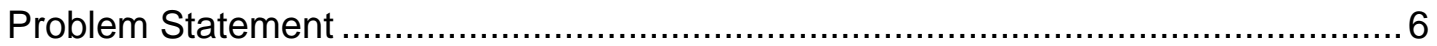

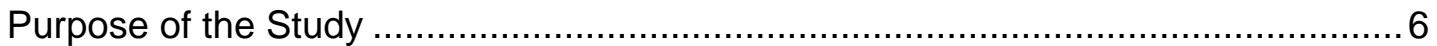

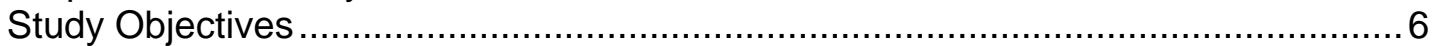

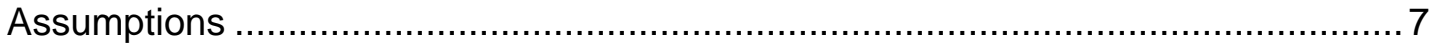

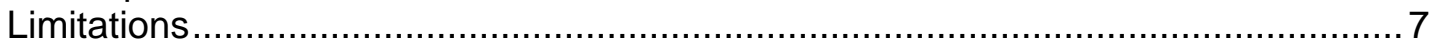

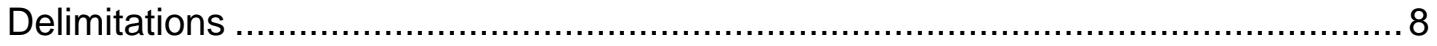

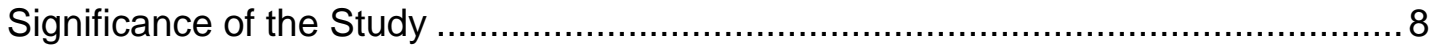

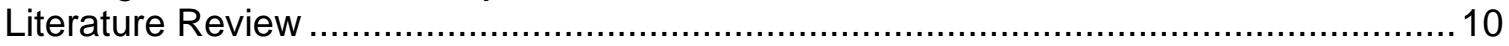

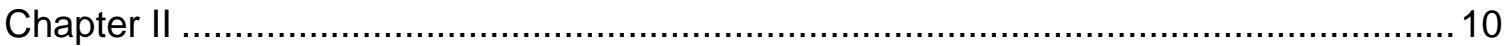

Rail-Trails and Greenways ...................................................................... 10

Partnerships, Collaboration, and Community Involvement .................................. 12

Nonprofit Organizations and Local Government .................................................17

Social Capital Theory Implications ..............................................................19

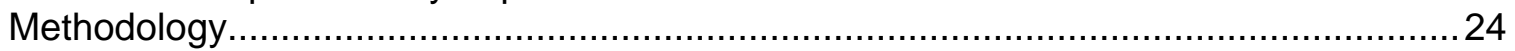

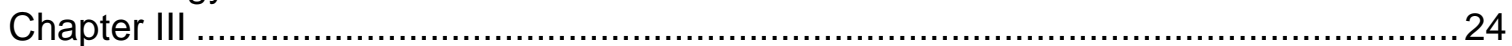

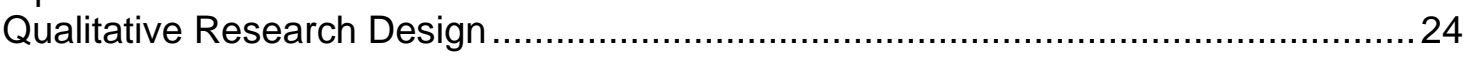

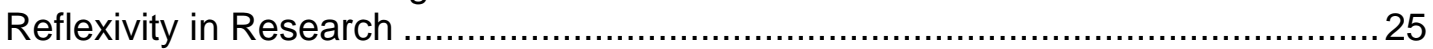

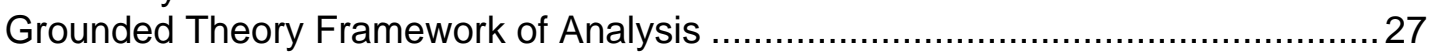

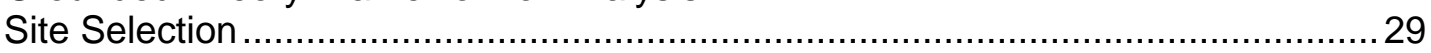

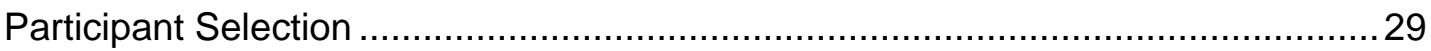

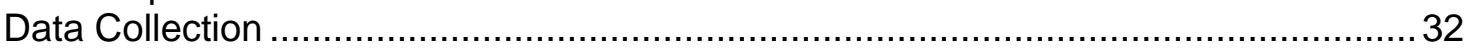

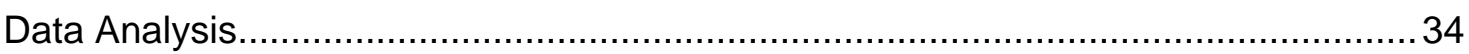

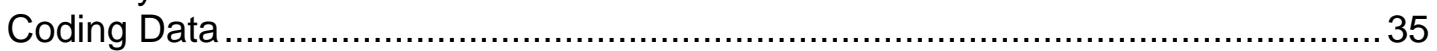

Developing themes and categories and moving toward theorization.......................37

Study Completion ........................................................................................ 38

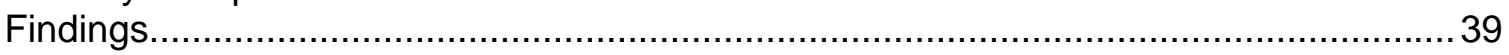

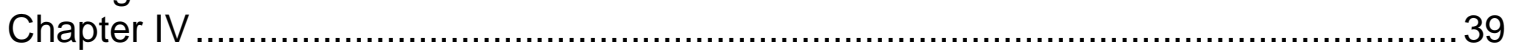

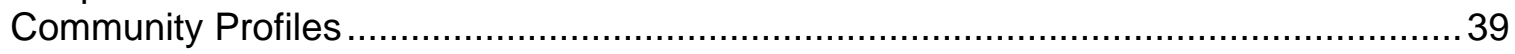

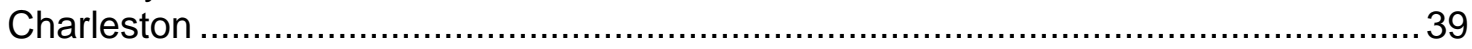

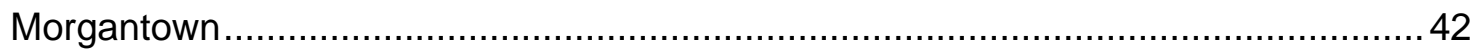

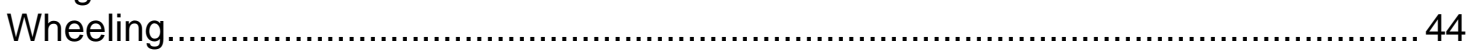

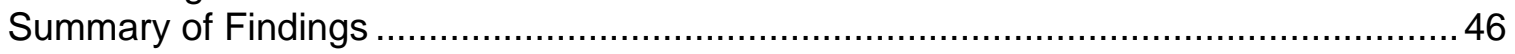

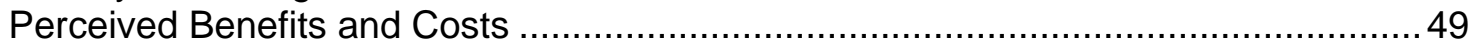

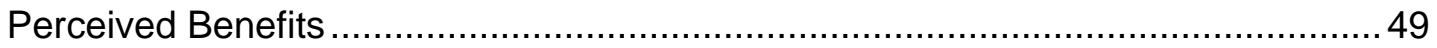

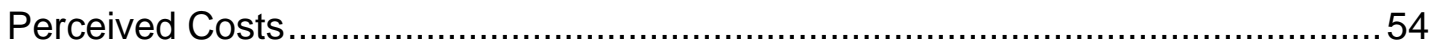

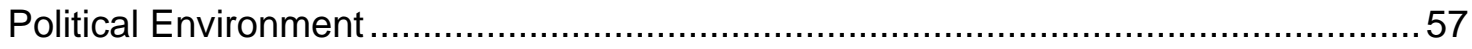

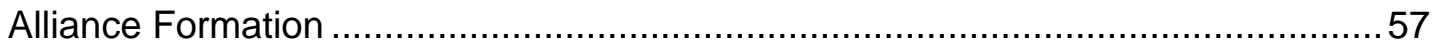

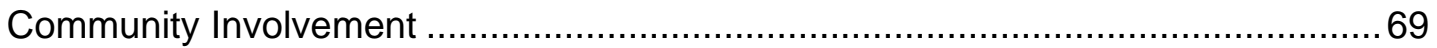

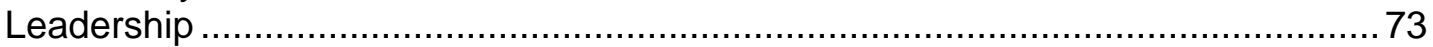

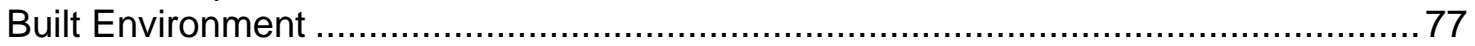




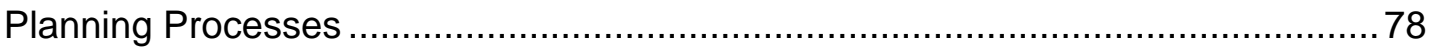

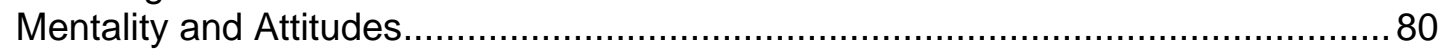

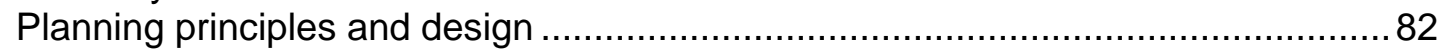

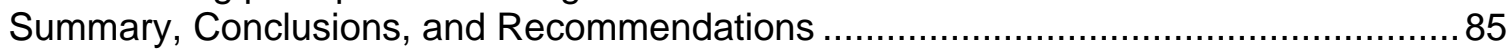

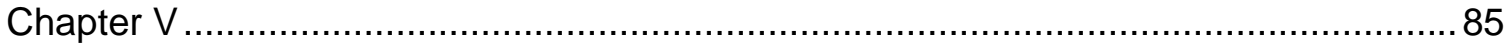

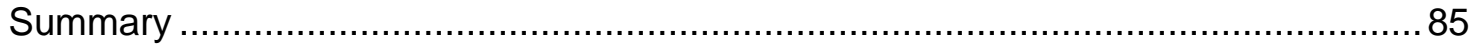

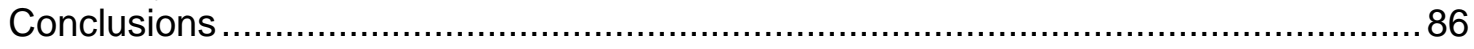

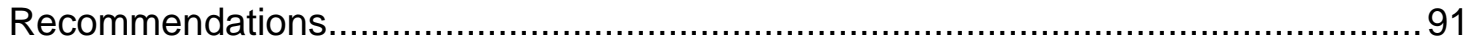

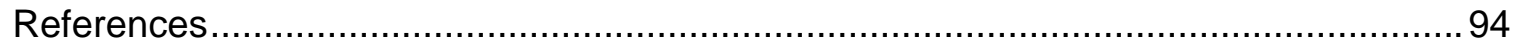

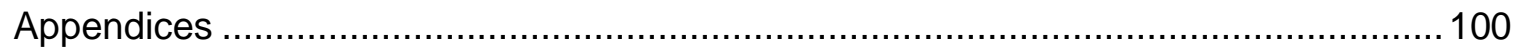

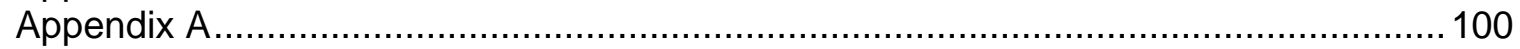

Interview Guide Questions ............................................................................. 100

Questions for participants representing nonprofit organizations:........................ 100

Questions for participants representing local government: ................................. 100

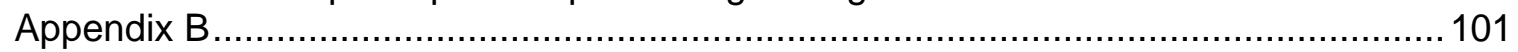

Themes, Categories, and Subcategories within the Findings ............................... 101

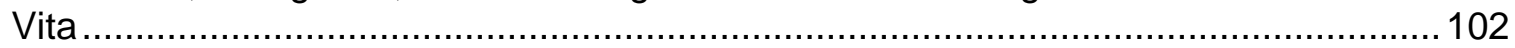




\section{List of Tables}

Table 1. Interview Participants .......................................................................... 31

Table 2. Perceived Benefits of Rail-Trails and Greenways Ranked by Response .........50 


\section{List of Figures}

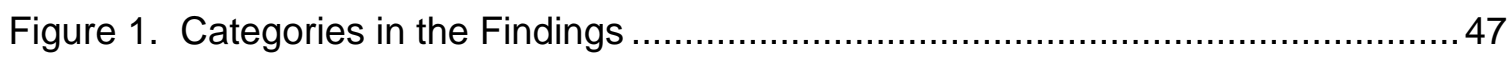




\section{Introduction}

\section{Chapter I}

"When a piece of work gets done in the world, who actually does it? Whose eyes and ears do the perceiving, whose cortex does the thinking, who has the feeling that motivates, the will that overcomes obstacles?"

-Aldous Huxley

Without much notice, old railroad lines began to change. In a few mid-western towns in the 1960s, people began using abandoned railroad tracks for recreation. Where trains once sped past towns carrying passengers and cargo, people were walking, jogging, biking, and horseback riding along old rail corridors. Users began calling the abandoned tracks "rails-to-trails," and over time, the idea of converting old rail lines into usable recreation amenities spread across the country ${ }^{1}$. It has been over 40 years since the first railroad right-of-way was converted into a rail-trail in a suburb of Chicago. Citizens formed groups to address the potential of a "footpath" where the old railroad tracks existed. From the onset, community members posed questions addressing the logistics of creating a trail, recognizing that "the enthusiasm [for trail building] was fine, but how [do we] make the path idea WORK? Where and how do we begin?"2 Eventually, community members formed committees with representatives from several local groups and were able to work together with developers and local government officials to create the Illinois Prairie Path. Today, a nonprofit trail advocacy group for the Illinois Prairie Path continues working with local governments and other civic groups to maintain the 61 mile trail system in northeastern Illinois.

More cities and towns across America began realizing the potential for rail-trails as the miles of abandoned railroad tracks began to increase in the late twentieth century, and the passage of the Intermodal Surface Transportation Efficiency Act (ISTEA) in 1991 provided new federal legislation that remains the "largest source of funding ever approved for trails and other non-highway transportation routes" (Flink, Olka, \& Searns, 2001). These factors, along with growing support of grassroots groups that garnered attention to this new phenomenon, brought attention to the quality of life benefits of multi-use trails in communities all over the United States. Communities with rail-trails

\footnotetext{
${ }^{1}$ The Rails-to-Trails Conservancy offers a brief history of rail-trails in the United States on the webpage entitled "History of the Rail-Trail Movement" http://www.railtrails.org/about/history.asp

2 The Illinois Prairie Path non-for-profit corporation (IPPC) website includes a documented oral history of the development of the rail-trail and the trail advocacy organization. (www.ipp.org)
} 
and greenways offer recreational, commuting, and fitness opportunities that attract business and help spur economic development (Howser, 1997). By 2004, the total mileage of rail-trails in the nation grew to 12,650 with another 14,000 miles under development (Rails-to-Trails Conservancy, 2004). West Virginia, with its abundance of abandoned tracks and scenic beauty, is an ideal home to rail-trails. In 1995, the Mountain State reported 223 miles of rail-trails (Hartman, Proud, \& Weirick, 1995). Currently, the national Rails-to-Trails Conservancy (RTC) reports 36 trails in West Virginia, totaling 416 miles $^{3}$.

Some of the trails included in the RTC survey may not be trails built on abandoned railroad right-of-ways, but share similar characteristics with rail-trails. The term 'greenway' is used to describe a variety of multi-use trails that are natural or manmade linear corridors used for recreation (Little, 1990). Another important aspect that is inherent to greenways is that they often link urban and rural landscapes as accessible open spaces close to communities where people live (Hoover \& Shannon, 1995). Using the terms "rail-trail" and "greenway" help identify the types of recreational amenities described in this thesis. The three communities examined in this study have existing or are developing plans for rail-trails. However, the three communities are home to greenway initiatives that look at how additional open space linkages within and between neighborhoods could enhance the value of the rail-trail while providing more access to communities.

The beginning of the twenty-first century brought a new awareness of rail-trail and greenway issues in West Virginia. The West Virginia Statewide Trail Plan (Pathways to the Future: The West Virginia Statewide Trail Plan, 2002) shed light on the need for a more focused effort at addressing trail issues in the state by highlighting existing trails and promoting the development of new and addition to existing multi-use trails. In fact, the 2002 Statewide Comprehensive Outdoor Recreation Plan (SCORP) for the state of West Virginia illuminated the need for implementing suggestions brought forth in the Statewide Trail Plan:

The most consistent recreational preference by and between residents and officials was an interest in trails, either for hiking, walking, or bicycling. This particular interest is significant not only for its consistency across all regions of the state, but also because it was the highest facility preference expressed in the last Statewide Comprehensive Outdoor Recreation Plan in 1993.

\footnotetext{
${ }^{3}$ RTC maintains a website (www.traillink.com) that serves as an inventory and database for rail-trails and greenways in the United States.
} 
The culmination of these two Plans presents a clear need for increased attention to further develop rail-trail and greenway systems throughout the state.

Some communities like Morgantown, WV already know the social, economic, and health benefits produced through rail-trail development. Home to the Mon River Rail Trail system, Morgantown holds a unique community asset in the form of a 51-mile railtrail. Other cities like Charleston, WV that lack such a developed trail system are home to growing support for greenways and rail-trails. The efforts of small community-based nonprofits, along with local government initiatives ${ }^{4}$ have encouraged Charleston residents to notice the possibilities that exist within their riverfront community. The West Virginia cities of Morgantown and Wheeling have different stories of rail-trail development, but both initiatives started with a few interested community members or government officials who wanted to make their city a better, more livable place. These small groups of people must have also posed the same questions as those working on developing the Illinois Prairies Path 40 years ago: how will the idea of building a rail-trail be implemented? Where and how does it all begin?

\section{Research Questions}

Learning more about West Virginia communities' experience with rail-trail and greenway development could enhance the potential for increasing the state's infrastructure of trails. I began my research with a desire to reflect community experience by engaging in discourse with several individuals who could shed light on the following research questions:

- What is the nature of relationships between nonprofit organizations (NPOs) and local governments? How do relationships form and function?

- How do these groups perceive the benefits of rail-trail/greenway development to the community?

- What factors facilitate or constrain developing constructive relationships and in turn, the ability to complete rail-trail and greenway projects?

- Why have some West Virginia communities seen the benefits of rail-trails and greenways while other communities with supportive infrastructures have yet to develop these amenities?

Before I could begin exploring these questions more fully, I had to identify participants who are knowledgeable and invested in rail-trail and greenway development in their communities.

\footnotetext{
4 In 2005, the City of Charleston contracted with the national planning and development firm, Sasaki Associates, Inc., to develop a comprehensive plan for the riverfront area that included consideration for recreational trails. (www.cityofcharleston.org/riverfront/Charleston Riverfron1.pdf)
} 
In an age of devolution, state and federal governments shift control of planning and policy initiatives to local governments and members of the third sector, or nonprofit organizations, empowering more localized efforts to carry out social programs and services (De Vita, 1999; Snavely \& Desai, 2000). This shift has encouraged local governments and nonprofit organizations to form alliances in order to initiate programs and development. By exploring several different community-based nonprofits in West Virginia and their respective local governments, I understand more about how both groups function as 'change agents,' turning community dreams into reality, while also placing the phenomena, experience, and dialogue of community-based nonprofits and local governments into a context that might better illustrate the nature of these relationships and how they facilitate or inhibit rail-trail/greenway development.

This thesis explores the relationship between community-based nonprofit organizations and local municipalities in an effort to examine the aforementioned questions as they apply to three different communities in West Virginia. Rail-trail and greenway development relies on many different factors, and differs from site to site:

The genesis of a trail project may occur in a number of different ways. The route may be identified in a statewide, regional, or local master plan. It may be a specific corridor designated by a community group, or it could be the result of a serendipitous opportunity created by rail abandonment. (Flink et al., 2001, p. 6)

I wanted to gain a deep understanding of how individuals and groups of people spawn the genesis of a trail project. In order to learn more about the people behind trail development, I had to go beyond websites and guidebooks and speak to a wide variety of individuals who have contributed to their communities in a multitude of ways. I interviewed local elected officials, nonprofit executive directors, community members involved in grassroots efforts, and many others in order to discover the interwoven connections that are the heart of rail-trail and greenway development in Charleston, Morgantown, and Wheeling, West Virginia.

I draw from several disciplines and areas of research to shape and give context to my study. The body of knowledge pertaining to rail-trails and greenways emerged in the latter part of the twentieth century from the fields of planning, landscape architecture, and recreation and leisure studies, and continues to grow as more communities develop these amenities. Most of the existing literature is quantitative, seeking to promote railtrail and greenway development in the face of opposition by providing evidence to support the benefits of trail development (Moore \& Graefe, 1993; Moore, Graefe, 
Gitelson, \& Porter, 1992; Sederelis \& Moore, 1995; Turco, Gallager, \& Lee, 1998). Disciplines like public administration, political science, and sociology contribute to the bourgeoning literature pertaining to relationships between community-based nonprofit organizations and local governments (De Vita, 1999; Salamon, 1995; Smith, 2003; Snavely \& Desai, 2000). The intersection of rail-trail/greenway development and nonprofit/government relations research is most closely tied to studies that examine partnerships and collaborative efforts in park planning (Hou \& Rios, 2003; Pincetl, 2003), and collaboration in natural resource or public lands management (Collins, Constantz, Hunter, \& Selin, 1998; Selin \& Myers, 1995). Although there is little, if any, research examining nonprofit/government relations in rail-trail and greenway building efforts, the existing literature provides related research that allowed me to build a foundation for giving context to the phenomenon.

Using qualitative research methods gave me the opportunity to conduct an exploratory analysis; I wanted to discover the different dimensions that emerged from the data and explore their interrelationships instead of testing a hypothesis formed from prior assumptions (Patton, 2002). Like any groups involved in community-wide projects, those who are integral to rail-trail and greenway development have unique and differing perspectives regarding their experiences. Since language helps shape experience, I pursued my inquiry through conversation. The participants in my research relayed information to me during personal interviews. By working closely with the data, I identified emerging patterns and themes from the dialogue through a grounded theory approach by interview coding and inductive analysis (Glaser \& Strauss, 1967; Patton, 2002). Defined by Glaser and Strauss (1967) as "discovery of theory from data," grounded theory emerges from data and is subsequently illustrated by distinctive examples of data; in this way, grounded theory differs significantly from the hypotheses testing approach to research, where theories are used as the primary investigative foundation. A grounded theory framework enabled me to constantly examine and compare my data to produce relevant findings that connect with my research goals. Although I am not attempting to theorize, this framework allows me to examine the three communities within a context, holding them as representative forms of where the phenomenon of rail-trail and greenway development exist, while understanding more about the characteristics of effective relationship building between the public and nonprofit sectors. 


\section{Problem Statement}

While there is a large body of work pertaining to rail-trails and greenways, as well as research examining relationships between nonprofit organizations and local governing bodies, there is little empirical research that attempts to link the two. Also, historical accounts of rail-trail and greenway community initiatives in Wheeling, Charleston, and Morgantown, are relatively non-existent, although the communities' experience may be beneficial in understanding how, why, and under what circumstances such initiatives can be challenging and successful in West Virginia.

\section{Purpose of the Study}

As more communities in the country seek to develop rail-trails and greenways to improve quality of life, it is important to recognize the significance of such relationships in the several phases of planning, construction on on-going maintenance of rail-trails and greenways. Under this pretense, the purpose of my study is to explore the nature of relationships that exist between community-based nonprofits and local government entities working on rail-trail and greenway development in order to better understand what factors contribute to building effective relationships that facilitate or constrain railtrail and greenway development.

One of my goals was to explore different approaches to community-led rail-trail and greenway development efforts and is built upon a pilot study that I conducted examining the attitudes and perceptions of the Mon River Rail Trail (Pack, 2005). The principle findings of the study, entitled "Making Connections: Knowledge, Attitudes, and Beliefs of the Mon River Rail-Trail System", suggest the importance of rail-trails as agents of economic development, partnership builders, benefactors to quality-of-life, and promoters of alternative transportation. Expanding on this research is an opportunity to give a representative voice to a collective group of individuals that play a critical role in enhancing West Virginia communities by further developing opportunities for rail-trail and greenway development.

\section{Study Objectives}

- To identify individuals that work on rail-trail and greenway development and engage them in a dialogue that contributes to the knowledge of how development efforts occur.

- To illuminate the unique relationships formed out of a desire to enhance a community through rail-trail and greenway development. 
- To gain a better understanding of how relationships between and among nonprofit organizations and local government involved in rail-trail and greenway development form and function.

- To provide nested cases representative of rail-trail and greenway development progress in West Virginia.

\section{Assumptions}

Since my sample selection is relatively small $(n=23)$, I assume that my research design and methods account for adequate participant diversity and representation. I trusted that my research participants understood the context of my study, and answered questions or relayed information that was honest and accurate according to each individual's experience. I also chose three different sites from which to select a participant sample. Another assumption that I made is that the three different sites, or cases, are comparable based on the following characteristics: population, geography, and existing or developing experience with rail-trail and greenway development. The final assumption that I must make in undertaking a solely qualitative study is that I, as the researcher, am able to provide an accurate and largely unbiased account of the phenomenon by combining a rigorous and thorough mining of my data with document analysis and an in-depth survey of relative literature to build a supportive theoretical framework.

\section{Limitations}

In qualitative research, findings, or the understanding and representation of the phenomenon of interest, become "the researcher's interpretation of participants' interpretations" of reality (Merriam, 2002, p. 25). Instead of using a quantifiable instrument to support findings, I am the instrument that will collect and analyze the data. The validity of my research rests on my ability to present information rich cases (Patton, 2002) with a combination of document analysis and a review of supporting literature. Nonetheless, the findings produced are based on my representation of the data, as well as the nature of participants' response. Using an interview guide gives a level of consistency to the data, but the semi-structured nature of interviews provide for variance in understanding and interpretation of the phenomenon.

Other limitations exist in my sample. I chose to interview individuals that are involved or associated with community-based nonprofit organizations, as well as representatives from the three municipalities. Although rail-trail and greenway issues could be explored on a more regional basis to include perspectives from the state or county level, time permitted my ability to reach an appropriate level of saturation if I were 
to extend my study beyond the municipal level.

Time is another consideration important to the validity of my research. Community building and development projects are often lengthy, sometimes spanning decades of planning and building phases. My research provides only a glimpse into the efforts that form broader community histories; the dialogue is situated in one moment in time, of which each community is at a different phase in rail-trail and greenway development.

\section{Delimitations}

At the heart of all research, whether quantitative or qualitative, lies a very basic question: to what extent can the findings of a study be applied to other situations? (Merriam, 2002). In qualitative research, purposeful sample selection might be seen to limit a study's generalizability. Instead of being able to statistically generalize, I want to provide a rich description of a particular phenomenon, namely relationships that develop between community-based nonprofits and municipal officials or personnel involved in rail-trail and greenway development in the cities of Charleston, Morgantown, and Wheeling, West Virginia. The analysis and synthesis of data I collected in the spring of 2006 is presented to provide a substantial amount of thick descriptive information so that readers can determine how closely their situations match, in order to consider the relativity or transferability of the findings (Merriam, 2002).

\section{Significance of the Study}

Examining the implications of effective relationship building between communitybased nonprofits and local government entities might help illuminate sound practices while more broadly providing a basis for developing policy or legislation that could enhance the way communities are able to effectively build and maintain rail-trails or greenways. Patton (2002) suggests that:

...there is a very practical side to qualitative methods that simply involves asking open-ended questions of people and observing matters of interest in real-world settings in order to solve problems, improve programs, or develop policies. (p. 136)

Conducting research for this thesis provided me the personal opportunity to learn more about the people who are involved with the real work and obstacles in rail-trail and greenway development. I hope that the culmination of my research, as a representation of their collective story, is useful to other communities in West Virginia and across the country that are seeking innovative ways of solving problems, improving programs, or 
developing policies that enable relationship building among community based nonprofits and local governments, while providing an avenue of exploration for the expansion of rail-trail and greenway development in communities everywhere. 


\section{Literature Review}

\section{Chapter II}

In order to understand the social phenomena surrounding the relationships fostered by rail-trail and greenway development efforts in West Virginia, I draw from several areas of literature. First and foremost, examining research on rail-trails and greenways illustrates their growing presence as established community amenities and support their important role in reshaping cities and neighborhoods. Research in the nonprofit sector, especially as it applies to the working relationships of nonprofit organizations and local governments, sheds light on the existing knowledge of how and under what circumstances these two sectors serve the public. A close look at the literature pertaining to theories like collaboration, partnerships, and social capital also offers a way to link the two areas of research and support a means for placing value on examining how relationships between nonprofits and local government form and effectively function to work on rail-trail and greenway building efforts.

\section{Rail-Trails and Greenways}

Every rail-trail and greenway is unique to the community or region of its location, and can be managed as linear state parks, or maintained by local governments or recreation and parks entities (Flink et al., 2001; Little, 1990). Funding for rail-trail and greenway projects comes largely from federal dollars allocated to state departments of highways and transportation under legislation that includes provisions for programs that support nonmotorized travel. Introduced in 1991 as the Intermodal Surface Transportation Efficiency Act (ISTEA), the legislation has been reauthorized twice as the Transportation Enhancement Act for the $21^{\text {st }}$ Century (TEA-21) in 1998, and most recently as the Safe, Accountable, Flexible, Efficient Transportation Equity Act: A Legacy for Users (SAFETEA-LU) in 2005 (Replogle, 2006). Most of the federal grants funneled through the state are based on an "80/20 match," meaning that government monies accounting for $80 \%$ of funding for a project must be matched with a local or community contribution equal to $20 \%$ of the project's cost. Therefore, an initial monetary or in-kind community contribution must be available to be awarded state or federal funds. From the onset, communities must demonstrate their existing assets to make a project sustainable. Research that can demonstrate the importance and need for strong relationships between community-based nonprofits and local government in rail-trail and greenway development is needed to help communities methodically move forward in 
funding endeavors.

Most of the research conducted on rail-trails is somewhat dated and more quantitative in nature. Emerging in the 1980s and 1990s, research on Rail-Trails focuses on assessing the impacts of rail-trails on property owners (Moore et al., 1992), determining user expectation (Minnesota DNR, 1980), and discovering the recreation benefits of Rail-Trails (Sederelis \& Moore, 1995). Most methods include user sample surveys assessing demographics, frequency, and satisfaction of trail use (Sederelis \& Moore, 1995). One of the most significant hurdles in rail-trail development is the oppositional force of landowners whose property lies adjacent to proposed trails. Research suggests that most resistant adjacent landowners experience a positive change in attitude toward the existence of rail-trails once trails are developed (Moore \& Graefe, 1993; Turco et al., 1998). Other studies explore economic impacts of rail-trails, and are especially useful in securing the support of state and local funds (Farber, 1999; Farber, Argueta, \& Hughes, 2003). Most of these studies examine existing rail-trail use and associated conflicts, but do little to describe the process as it applies to partnerships or collaborative efforts in rail-trail and greenway development.

Studies that incorporate planning principles and ideas like smart growth and sustainability speak to the importance of accommodating for amenities like greenways that enhance opportunities for recreation, create healthier living environments, and increase community connectivity (Lindsey, 2003; Shafer, Lee, \& Turner, 2000) Drawing attention to the importance of greenways specifically, Shafer, Lee, and Turner (2000), insist that:

...facilities of any type, including trails, should be planned and designed for a balance among the economic, environmental, and social characteristics of an area so that its residents can lead healthy, productive, and enjoyable lives. (p.165)

Since greenway plans are usually initiated at the local or regional level and are the result of grassroots efforts (Ahern, 1995), there are many diverse groups and individuals who contribute to the planning and design processes, contributing to quality of life characteristics like resident-led processes, establishing sense of place, and increasing opportunities for face-to-face encounters (Shafer et al., 2000).

Accounting for community involvement is also necessary when incorporating quality of life determinants with community planning and design. The authors of "Sprawl, Smart Growth, and Sustainability" observe that Americans from all walks of life are coming together to address land-use issues, including community amenities like rail- 
trails and greenways:

These days, it's not all that surprising to see environmentalists sitting at the same table as farmers and suburbanites, developers and builders, public health advocates and fiscally conservative elected officials.

(Tregoning, Agyeman, \& Shenot, 2002: p. 242)

The authors' statement illuminates the need for more consideration to be placed on how different community members come together on the same issues in order to work toward a common goal. This "coming together" is the first step in implementing change, or starting a project.

\section{Partnerships, Collaboration, and Community Involvement}

Some of the literature pertaining to greenways and rail-trails explores the nature of community action and implementation. In a study of an urban greenway in the City of Vancouver, Moura Quayle (1995) poses the ultimate question: "how do we make things happen in the public realm?" Quayle (1995) refers to a management model called "groping along," used to describe how public managers approach issues based on a broad goal, willing to informally experiment with new ideas; 'making things happen' comes from a process of trial and error, but public ideas are better communicated in a way that helps managers grope toward their implementation.

In her case study of Vancouver, Quayle explains that a task force was formed to examine greenway potential in the city, reporting its findings to the Mayor and City Council. Public meetings and surveys revealed some of the constraints associated with "implementing ideas in the city," with the top four barriers being: (1) the culture and conformity of compliance; (2) fear of change and the unknown; (3) visual, social, and ecological literacy; and (4) the lack of a sustainable vision for the city (Quayle, 1995). The national Rails-to-Trails Conservancy also recognizes the hurdles that groups must face in dealing with public officials. In most communities few public officials will be either visionary or reactionary, however a majority of elected officials are hesitant to lose public support by endorsing a project but eager to be associated with a project that has strong community backing (Ryan \& Winterich, n.d.). Whether that majority is more compelled by fear and change of the unknown, or simply lacking a vision for their community, Quayle (1995) suggests strategies to "encourage positive groping along" that include restoring citizenship and building partnerships. The implications in Quayle's study of Vancouver are suggestive of partnerships, and are significant in the discussion of alliances formed between community-based nonprofits and local governing bodies. 
Pincetl's (2003) research on the role of nonprofits in park provisions in Los Angeles, CA echoes Quayle's study in citizen-led movements and partnership building. Her work refers to the study of urban regime theories, or ideas about how local governments and "private-sector agents," like community-based nonprofits, work together to create economic development opportunities. Urban regime theory demonstrates the shift apparent in local governance, from politics "dominated by an elite cadre of public and private actors including corporate and community leaders" to a more diverse representation of community-based organizations that partner with governing bodies and introduce different points of view (Martin, 2004, p. 394). According to Martin (2004), this shift in governance to include community-based organizations reflects the lack of trust that is inherent in modern day governmental decision-making processes, and the ideals of democratic decision-making being more effective at the grassroots level.

The paradigm shifts that coalesce to form a new kind of urban regime is apparent in Pincetl's (2003) recognition of the importance of "civil society institutions," like nonprofit organizations, in contributing to building community amenities like parks:

Much like business coalitions, [civil society institutions] lobby local elected officials, work with local bureaucracies, and mobilize to both influence state-level political bodies and to divert public support for projects... Those places lacking this civil society infrastructure tend to be less well equipped in parks and other amenities....all part of creating an economically thriving community, indeed an entrepreneurial city. (p. 981)

Since rail-trail and greenways can be considered "linear parks" (Little, 1990) this statement speaks volumes on the importance of community-led planning efforts. The formation of grassroots groups that partner with local governments to implement "community-driven place making" also suggests the importance and prevalent role of "civil society forces in the making of the public realm" (Hou \& Rios, 2003, p. 19).

Alliances between agents working to solve problems or develop projects and programs are often referred to as partnerships or collaborations. Research on partnerships and collaborations emerging from the fields of planning (Hoover \& Shannon, 1995; Hou \& Rios, 2003), recreation (Selin \& Myers, 1995), conservation (Collins et al., 1998), and public administration (Milne, lyer, \& Gooding-Williams, 1996) provide a way of exploring the potential for cooperative arrangements and participatory democracy in rail-trail and greenway planning.

The expectations of stakeholders that enter into alliances may help to determine 
or label the type of alliance, although definitions of terms like 'partnerships' and 'collaborations' are often used interchangeably (James, 1999). In order to distinguish the two, I draw from James' (1999) review of partnerships and collaborations, noting that partnership expectations rely on the mutual understanding and identifying of specified needs in an on-going agreement, while a collaborations exist when "none of the stakeholders has a full understanding of the issues that generate the alliance...hop[ing] that 'two heads are better than one' (p. 38). Therefore, partnerships stem from formal agreements to manage an identified task or project, while collaborations must accommodate and allow for the development of ideas and suggestions that might contribute to an eventual outcome.

The distinction of the two becomes important when involved parties do not have a clear understanding of which type of alliance applies to their specific situation; a member of a collaboration might have expectations congruent to a partnership, and vise versa (James, 1999). Examples of the two concepts are apparent in my study. The Mon River Rail-Trail system in Morgantown, WV is managed under a partnership between the City of Morgantown, Monongalia County, and the Mon River Trails Conservancy. These three entities share an agreement to manage the trail system. In Charleston, WV, recent efforts to create a greenway plan for portions of the city was a collaborative effort in which a local nonprofit, with support from the National Park Service's River, Trails, and Conservation Assistance (RTCA) program spearheaded community workshops to develop a plan that was presented to the City of Charleston in hopes of gaining their support (The Greater Charleston Greenway Initiative: A Vision for Greenspace, Connectivity, and Pedestrian Community, 2006).

Partnerships can exist between and among government entities, the nonprofit sector, and commercial businesses. In the 1970s, as the nonprofit sector began to grow, the development of public-private partnerships (PPP) increased as partnerships were built across sectors as a result of "limited government resources call[ing] for a greater contribution of time, money, and services from community institutions" (Gates, 1999, p. 261). However, the sometimes complex demands on agencies and organizations to maintain healthy partnerships creates a strain on those partners that do not have the capacity to devote as much time, staff, and other resources. Frisby, Thibault, and Kikulis (2004) address the issue of "under-managed partnerships" as it applies to leisure service departments in local governments, reporting that reducing or increasing the number of partners in a project should be based on organizational 
capacity, which may be enhanced by providing employees with the time and training needed to ensure good communication and work relations between partners. Publicprivate partnerships between nonprofits, local government leisure service departments, and the business sector can be enhanced by assessing organizational capacity and partnership management plans to determine where and to what extent human and fiscal resources should be spent (Frisby, Thibault, \& Kikulis, 2004).

In their study of a leisure service broad-based regional partnership, Selin and Myers (1995) observed how members of a partnership perceive the effectiveness of their alliance. Findings suggest that partners report a sense of satisfaction and perceive partnership effectiveness to rely on a number of correlates that include "administrative support, level of trust, sense of belonging, and strong leadership" (Selin \& Myers, 1995, p. 38). Randolph and Bauer (1999) suggest similar conditions are also evident in effective collaborative environmental decision-making alliances. Prerequisites for successful collaboration include:

- Good information;

- Time to participate, to build trust, to learn, to resolve disputes, to create solutions;

- Commitment of participants;

- Willingness to learn;

- Responsibility to affect and implement decision; and

- Resolution of the problem is the goal

(Randolph \& Bauer, 1999, p. 177).

These factors are reflective of what Randolph and Bauer (1999) consider to be "successful collaborative environmental decision-making (CED)" (p. 177). While most CED alliances may be aimed at resolving conflict over environmental land management issues, the principles for building effective collaborations is applicable to rail-trail and greenway development since they are also a type of public land.

Another important component of partnerships and collaborations is community involvement or public participation. Oftentimes, local residents make up the contingency of volunteer-based nonprofit organizations and grassroots groups that form to address specific community based issues like rail-trail and greenway development. Some community groups like neighborhood associations consist of individuals who devote time and energy focusing on enhancing quality of life in a particular geographic area (Swindell, 2000). Such place-based initiatives can be an important part of collective efforts that contribute to the 'coproduction' concept that "consists of citizen involvement or participation...in the provision of services" (Brudney \& England, 1983, p. 63). 
Encouraging citizen participation is a method of coproduction that may ultimately provide "the underpinnings for partnerships" (Mohan \& Mohan, 2002, p. 202). Brundey and England (1983) suggest that resident involvement in service provisions or management processes results in a local constituency that is "more knowledgeable of the content, costs, and limitations of municipal services and their joint responsibility with service agents for their delivery" (p. 62). Coproduction is also suggestive of the participatory democracy theory that citizens who hold the temporary role of policy-makers, are "given a stake in the policy process, and, consequently, feel a sense of ownership regarding the outcome" (Hoover \& Shannon, 1995, p. 436). Therefore, community involvement can be critical in creating awareness and gaining public support for local projects, and residents involved in the planning processes may demonstrate ownership that facilitates long-term project management and care.

Community involvement or public participation can not, however, be viewed as a panacea for promoting successful planning efforts or partnership/collaboration development. Realizing that public participation has become a "highly bureaucratic and standardized process," Hou and Rios (2003) contend that there are many factors that can inhibit public participation in place-based initiatives:

This institutionalization has resulted in narrowly defined boundaries and problems to avoid conflict and make channels of control clear...many projects take a considerable time to be implemented [therefore] citizens often lose interest and commitment...[and] frustration grows when commitments to public priorities are not implemented due to cost overruns, backroom deal making, or de facto decision making. (p. 20)

These factors must be considered in concert with the types of relationships that form during community involvement processes. The social networks that are created through partnerships, collaboration, and coproduction efforts should be appropriately structured and continually reinforced to assure for equitable community representation. Swindell (2000) acknowledges that equitable representation in neighborhood associations, which government officials may perceive as contributors to participatory democracy, may be inadequate in low income areas. Similarly, local governments in alliance with community groups or nonprofits that are engaged in rail-trail and greenway development and maintenance need to assess the collective level of representation in order to assure that the trails are accessible and provide opportunities for the wide spectrum of potential users.

There is a regional nature that is associated with these linear parks and they 
typically travel along the natural features of the landscape. Since "established human boundaries frequently do not parallel natural formations" rail-trails and greenways tend to "cross jurisdictional borders" (Hoover \& Shannon, 1995, p. 435). Rail-trails and greenways, existing as regional amenities, become inherent producers of partnerships and collaborations; multiple communities and stakeholders from the public, nonprofit, and private business sectors are potential members of alliances formed in rail-trail and greenway development and maintenance. An awareness and understanding of the literature on the public and nonprofit sector coupled with research on partnerships, collaboration, and community involvement efforts are essential to building and fostering these alliances.

\section{Nonprofit Organizations and Local Government}

"The most basic force [of the voluntary sector] is that of ordinary people who decide to take matters into their own hands and organize to improve their conditions or to seek basic rights." -Lester Salamon (1994)

The history of nonprofit organizations in the United States is extensive and well documented, dating back to the American Revolution and including impacts of twentieth century initiatives like the New Deal and the social movements of the 1960s (Salamon, 1995). However, the third sector did not garner significant public attention until the 1980s, since federal programs and policies dominated public discourse for the better part of the twentieth century. Encompassing a vast array of public services, nonprofits are classified by the US Internal Revenue Service with the code, 501(c)3. Referred to in terms of "third sector" or the "voluntary sector," nonprofit organizations are classified as such because of their independence from government entities and their distinction from the business sector as organizations that are able to receive tax-deductible donations, and are relieved from paying government-imposed taxes (Salamon, 1995).

My exploration of the nonprofit sector is somewhat contextual; I focus on community-based organizations that are involved in rail-trail and greenway building efforts, but each organization is unique in structure, mission, and levels of funding. Since trail advocacy groups are not the only nonprofit players in the field of rail-trail and greenway development, a multi-faceted representation of organizations is vital to the foundation of my analysis. The types of organizations included in my study are a mix of community-based nonprofit organizations including: citizen-led trail support groups, neighborhood associations, health initiative groups, land trusts, and community development organizations. These community based organizations work together in 
order to accomplish a wide variety of goals by implementing many different projects and programs. On a very large scale, nonprofits serve the "welfare state," offering public services and support as the government relies more and more on their ability to meet human needs (Salamon, 1994). Along these lines, there is a plethora of existing literature on nonprofit organizations. I chose to focus my review of the literature on research highlighting relationships between nonprofit organizations and local government entities to develop a framework for assessing the potential of relationships that develop in rail-trail and greenway project planning and administration.

The concept of devolution emanates the literature on nonprofit and local government relations. Snavely and Desai (2001) assert that the national and state decentralization to local government, along with the increasing empowerment of the nonprofit sector, are two significant factors that are becoming "increasingly important to the general welfare of communities" (p. 247). In the United States, local governments and nonprofit organizations are faced with finding solutions for the country's growing societal and economic pains, with an attentive focus on the role of the nonprofit sector:

In this new era of devolution, many policy makers are looking to nongovernmental entities, particularly at the local level to assume a larger role in building the human, economic, and social capital necessary to bring about change. (De Vita, 1999, p. 216)

Since the nonprofit sector is not constrained by the bureaucracies required in government policy making or project and program implementation, relationships between the two sectors allow nonprofit organizations to explore more accommodating alternatives to government problems (Clarke, 2001). The emergence of the nonprofit sector has certainly changed the way in which local governments operate. Attentiveness to their role in society reveals that nonprofits and local governments operate under a very close and similar sphere where responsibilities and actions often overlap and a better understanding of community development exists (Snavely \& Desai, 2000).

As in the case of partnerships and collaboration, relationships between nonprofits and local governments should not be mistaken as a panacea to solve the problems of communities. Nonprofit organizations, by their nature face the difficulties that arise in balancing flexibility with effectiveness, and confirming accountability while also allowing for a sense of grass-roots control (Clarke, 2001; Salamon, 1994). Nonprofits are also constrained by factors that affect their organizational capacity including fiscal challenges, staff shortages, and human resource needs (Salamon, 2003). The fact that most nonprofit organizations are funded by government entities is a sometimes forgotten 
inextricable tie that binds nonprofits, constricting the amount of flexibility allowed to third sector parties (Clarke, 2001).

Despite the limitations imposed on nonprofit organizations, partnerships and collaborations among different nonprofits and between local government entities allow for the third sector to become have a substantial voice in local policy making. The "distinct mechanism of interorganizational and interpersonal coordination" that is a defining characteristic of the third sector allows nonprofits to influence the policy making process by working together with similar organizations, and to influence the way policy is implemented when working with government actors (Milne et al., 1996). Since the makeup nonprofits is most often representative of grass-roots efforts and inclusive of community members that are outside the political realm, groups like neighborhood associations and other community-based nonprofits are able to "weave neighbors together socially around local policy issues, such as safety, streets, and recreation," allowing for the practice of participatory democracy, and an "increase[d] public confidence in what can be accomplished through collective activity" (Reid, 1999, p. 301, 292).

\section{Social Capital Theory Implications}

When nonprofit organizations and local governments work together, the alliances formed have the potential to promote economic development, stimulate policy-making dialogue, and produce social capital (Snavely \& Desai, 2000). In his book, Bowling Alone: The Collapse and Revival of American Community, Robert Putnam (2000) refers to the term "social capital" as "connections among individuals - social networks and the norms of reciprocity and trustworthiness that arise from them" (p. 19). Putnam's defining text has become the cornerstone of modern dialogue about social capital, focusing on the individual-level of social capital, or how the interconnected social networks that result from civic engagement affect individuals. Others have furthered Putnam's concept of social capital to theorize on the importance of social networks at the organizational level, particularly the promotion of social capital in the development of relationships between nonprofit organizations and government entities (Clarke, 2001; Smith, Stoker, \& Maloney, 2004; Snavely \& Desai, 2000).

While the first section of Bowling Alone explores trends in social capital, the second section presses the question: "why, beginning in the 1960s and 1970s and accelerating in the 1980s and 1990s, did the fabric of American community life begin to 
unravel?" (Putnam, 2000, p. 184). Putnam proposes several reasons for the shift in social capital trends, including the pressures of time and money, mobility and sprawl, technology and mass media, and changes in generational attitudes and beliefs. Not one of these factors is solely responsible for the deterioration of social networks in the United States; they are all very interrelated. Recognizing the negative changes that result from auto-dependency and suburban sprawl, Putnam (2000) quotes from Kenneth T. Jackson, a noted historian on suburban America:

The real shift, however, is the way in which our lives are now centered inside the house, rather than on the neighborhood or the community. With increased use of automobiles, the life of the sidewalk and the front yard has largely disappeared, and the social intercourse that used to be the main characteristic of urban life has vanished...There are few places as desolate and lonely as a suburban street on a hot afternoon. (p. 211)

Considering rail-trails and greenways in the context of social capital is especially applicable to examining community life in America and the issues of residential mobility and suburban sprawl.

In the article "Sprawl, Politics, and Participation: A Preliminary Analysis," Thad Williamson stresses the importance of "building social capital and reviving community in making the case for pedestrian-friendly places" (2002, p. 235). The existence of railtrails and greenways allow for more opportunities for pedestrian and bicycle transportation. Communities that develop more trails create pedestrian and bicyclefriendly places, implying that mobility is less about being dependent on the use of automobiles. These factors associate rail-trails and greenways with characteristics that are synonymous with walkable communities.

The connection between social capital and walkable communities is positively correlated in Kevin Leyden's study, "Social Capital and the Built Environment: The Importance of Walkable Neighborhoods" (2003). The study was conducted in Ireland's fastest growing city, Galway. Surveys were administered to measure social capital and its relationship to the built environment. Findings suggest that:

...the more places respondents report being able to walk to in their neighborhood, the higher their level of social capital. This relationship suggests that walkable, mixed-use neighborhoods are better generators of social capital that are modern, car-dependent suburbs. (Leyden, 2003, p. 1549)

Rail-trails and greenways located in urban or densely populated areas not only provide pedestrian friendly environments, they also offer alternative transportation routes. 
Communities that accommodate pedestrians and bicyclists are creating more transportation options; residents can use the amenities to reduce the amount of trips taken by or time spent in automobiles. To echo Leyden's claims, Freeman's (2001) research looks at the connection between social ties and the amount of time spent driving. The study concludes with disturbing evidence that "Every $1 \%$ increase in the proportion of individuals driving to work is associated with a $73 \%$ decrease in the odds of an individual having a neighborhood social tie" (Freeman, 2001, p. 74). Both studies support the positive relationship between social capital and walkable communities. Under these premises, "making the case" for walkable communities and pedestrian friendly places may be enhanced by the prevalence of social capital, and infrastructure (like rail-trails, greenways, and sidewalks) that creates opportunities to increase social interaction may increase social capital. In other words, walkable communities may increase social capital, and social capital may provide a means for supporting the development of rail-trails and greenways, which enhance walkability.

Opportunities for enhancing social capital through infrastructure (building more multi-use trails, creating policy that enables planning and building walkable communities, etc.) are referred to on an individual-level basis. The physical, built environment lends itself to discussing social capital at the individual-level, but the different community groups, nonprofits, and government entities that are involved in planning processes and continued management of rail-trails and greenways offer an avenue for the exploration of social capital at the organizational level. Hou and Rios (2003) explain that:

The rising influence of NPOs and the growing practice of communitydriven place making signals a need to reexamine the practice of community planning and design and the role of civil society forces in the making of the public realm. (p. 19)

Potapchuck, Crocker, and Schechter (1997) also suggest that a broader concept of social capital is necessary in examining the relationships of individuals, organizations, or groups involved in community initiatives, asserting that "While social capital at all levels of the community hinges on the webs of affiliations that exist among individuals, generalized social capital also involves the more intangible relationships among larger groups and organizations" (p.129). Considering social capital as a 'civil society force' is congruent with the work of Putnam (2000), but placing it in a realm that extends beyond the traditional individual level social capital theory is a relatively new way of including inter-organizational dynamics into the greater sphere of how social capital exists and grows in and among communities. 
Putnam (2000) is consistent in referring to the phenomenon of social capital as occurring at the individual level, and notes that higher frequencies of civic organizations is positively correlated to the presence of social capital. Since nonprofit organizations are not individual people, the Putnam school of social capital does not extend the notion of social capital to the organizational level:

...Putnam dismisses the prospect for accruing social capital through nonprofit organizations. To Putnam, these organizations are corporate entities that lack the face-to-face interactions that build trust, reciprocity, and stocks of social capital. (Clarke, 2001, p. 134)

Others that take a broader approach to social capital challenge this position, proposing the idea of social capital as something that is produced through nonprofit and local government interactions (Smith et al., 2004; Snavely \& Desai, 2000), and developing a new term for social capital that encompasses its horizontal (between sectors) and vertical (between divisions) nature (Rydin \& Holman, 2004).

Smith, et al. (2004) support the notion of connecting social capital with collective action to illustrate how relationships at the organizational level promote project success:

Social capital inheres in relations between actors and is a resource that is drawn upon to facilitate collaborative activities. It is the shared knowledge, norms and sense of trust that is brought to activity that in turn makes that activity more likely to succeed. (Smith et al., 2004, p. 510)

This connection reinforces the need to examine social capital on the organizational level, and supports others that theorize on the importance of nonprofit and local government alliances as proponents of social capital. Snavely and Desai (2001) suggest that "where local government and NGOs [non-governmental organizations] intersect on [the] dimension of individual/group expression, we find the creation of social capital" (p. 251), and Mohan and Mohan (2002) assert that the beneficial effects of social capital are realized at the individual level and to communities, stating that it "...cannot simply be appropriated by individuals or particular groups" (p. 193).

The collective action of individuals and groups, whether they are affiliated with a nonprofit organization, or part of a local governing mechanism, are the symbiosis of railtrail and greenway development. Using the concepts of social capital furthers the understanding of how and why nonprofit organizations and local government become allied, and the sheer nature of their association:

As people over time interact consistently through groups, they build up a repository of trust and norms of reciprocity, meaning they are obligated to promote their common interests. Both the contributions of NGOs to civil 
society and of local government to enhancement of grassroots democracy, help build social capital. The organizational efforts of both sectors bring people together to interact, to learn more about each other, to collaborate in community development activities, and to voice opinions. Presumably, citizens begin to develop a closer common identity, learn effective civic engagement, and learn how to compromise. (Snavely \& Desai, 2000, p. 251)

A ladder of community building developed by Potapchuk et al. (1997) demonstrates the complexity of basic localized social capital that allows for community organization, a significant factor in civic infrastructure. The authors explain that the success and failures of community organization often determines community ability to "mobilize its civic infrastructure to deal with a range of issues...[and] decisions that have to be made in civic life" and further this claim to distinguish the worth of what could be interpreted as individual (localized) and organizational (generalized) social capital:

It is the strength of community organizations in the form of localized social capital and their ability to work together drawing on generalized social capital that often determines the success of community problem-solving initiatives. (Potapchuk et al., 1997, paragraph 17)

Broadening the examination of social capital as it applies to nonprofit organizations and local governments involved in rail-trail and greenway development, gives more depth to the exploration of how these relationships form and function.

As more attention focuses on alternative forms of transportation and healthy lifestyles, rail-trails increase in popularity, valued for accommodating unique recreational opportunities and enabling non-motorized travel (Pathways to the Future: The West Virginia Statewide Trail Plan, 2002; Flink et al., 2001). Nonprofit organizations in community development fields play a critical role in the development of rail-trails and greenways. Currently, there is a gap in empirical research that specifically targets nonprofit and local government relations in rail-trail and greenway development. Qualitative research based on the factors that contribute to rail-trail and greenway development is needed to help aid and further discourse between community-based nonprofit organizations and local government entities. I developed this study to contribute to the body of work on rail-trails and greenways, while also building on existing research of alliance formation between nonprofit organizations and local government entities and the evidence that supports social capital as being at the foundation of community initiatives like rail-trail and greenway development. 


\section{Methodology}

\section{Chapter III}

\section{Qualitative Research Design}

Some guide books and websites ${ }^{5}$ give brief descriptions of rail-trails and greenways in the state, providing excellent descriptions of a trail's natural surroundings, warning users of challenging topography or terrain, and suggesting convenient rest stops. The more I walked, ran, or biked on my local rail-trail, I wanted to know more than the brochure and website provided. I wanted to learn about the people who built the trail, from the seedling of an idea, to the 51 mile system I use today. If I want to learn and understand more about the history of rail-trail projects in the state, I need to talk to the people involved.

Using qualitative research methods gives me the opportunity to "understand a phenomenon, uncover the meaning a situation has for those involved, or delineate process" (Merriam, 2002, p. 11). I decided to use qualitative methods because I wanted to understand a phenomenon (the development of rail-trails and greenways in West Virginia), uncover the meaning behind the situation (who assists in trail development, and under what circumstances are those particular individuals interested and involved), and delineate process (relationship building between actors involved in trail development).

My research involves a dialogue centered approach to learning more about railtrail and greenway development in West Virginia. Although information like the West Virginia Statewide Trail Plan (2002) and the West Virginia Statewide Comprehensive Outdoor Recreation Plan (2002) provide evidence suggesting the need and desire for more trail development in the state, there is little information documenting the progress of rail-trail and greenway development efforts in the state since projects are primarily held as local knowledge and discourse. Most of the research relating to rail-trails and greenways is quantitative in nature, including scholarly work (Moore \& Graefe, 1993, 1994; Sederelis \& Moore, 1995; Turco et al., 1998), economic feasibility studies (Farber, 1999), and user surveys (Farber et al., 2003; Moore et al., 1992; Resources, 1980) providing a gap in the research that could be filled or enhanced with qualitative studies,

\footnotetext{
${ }^{5}$ The national Rails-to-Trails Conservancy (RTC) publishes guidebooks for specific regions of the United States (Noe, 2000) and maintains a website with a rail-trail and greenway clearinghouse: (need website) The West Virginia Rails-to-Trails Council also publishes guides (Hartman et al., 1995) and maintains a website devoted to rail-trails in the state.
} 
particularly examining the relationship between actors involved in rail-trail and greenway development.

Qualitative research methods provide opportunity for theories to emerge from the data inductively, meaning that observations of a specific phenomenon are the foundation of emerging general patterns and themes (Patton, 2002). I chose to apply qualitative methods as a way of illuminating some of the issues facing West Virginia communities involved in rail-trail and greenway building efforts because qualitative research methods allow for information rich data, adding depth to explanations of phenomena and processes that are context-based (McKie, 2002), focusing less on "what happened," and instead probing further to understand "the significance of the event" (Lawler, 2002).

I know that there are rail-trails and greenways built all over the country. While I am still interested in the process of the event itself (rail-trail and greenway development), using qualitative methods allows further probing in examining how relationships between nonprofits and local governments aid in trail development and how those relationships, and the addition of the physical amenities, affect communities or illustrate "the significance of the event." Qualitative research based on the factors that contribute to relationship building between nonprofits and local governments involved in rail-trail and greenway development is needed as these two groups continue to work together to create happier, healthier, and more connected communities.

\section{Reflexivity in Research}

Sharan Merriam (2002) explains that "a research study begins with your being curious about something, and that 'something' is usually related to your work, your family, your community, or yourself" (p. 11). A qualitative study not only begins with that curiosity, but it becomes integrated with the researcher's questions and experience in an inextricable way. My own interest in rail-trail and greenway development sparked late in my undergraduate years. I started walking on a paved path that was adjacent to the river; I didn't know that this 'path' had a name, or that it was formerly a railroad line. At the same time, my parents gained a new interest in bicycling and started exploring railtrails in West Virginia. Shortly after, I returned to Morgantown to pursue a graduate degree in Recreation, Parks, and Tourism and began working with different community groups that were interested in expanding trails and greenways. The rail-trail in town renewed my interest in running, and my parents visited with their bikes so that I could explore more of the expansive rail-trail system. The 'something' that I became curious 
about is indeed related to my work, my family, my community, and myself.

The ideas, values, and beliefs that I carry with me throughout my research become an inherent aspect of the way I formulated my research design, conducted interviews, and synthesized findings. Accountability in qualitative research must include provision for reflexivity, or awareness of self: "To be reflexive, then, is to undertake an ongoing examination of what I know and how I know it" (Patton, 2002, p. 64). Therefore, the personal paradigms that I bring to my research may affect the presence of bias.

Previous research conducted in the spring of 2005 provides some context to the formation of this thesis. I interviewed local government and nonprofit representatives for a qualitative study that examined the knowledge, attitudes, and beliefs of participants as it pertained to the Mon River Rail-Trail System (Pack, unpublished, 2005). Since I had been involved in a community greenway planning initiative in Charleston that same year, I had formed opinions about the way local governments and community-based nonprofits interact. My experience led me to believe that the commitment level of local government regarding rail-trail and greenway development was relatively low. I saw individual community members that had formed or worked for community-based nonprofit organizations as the true catalyst for development. However, after interviewing several individuals from nonprofit and government sectors involved in the development of the Mon River Rail-Trail System, I learned that several groups, including the City of Morgantown, the Mon River Trail Conservancy, and the Morgantown Chamber of Commerce worked together very closely to build the rail-trail.

Conducting in-depth interviews sparked my interest in the way people perceived connections among and between the various agencies and organizations that stimulate trail development. Delving deeper into the issues of relationship building, I continued to acknowledge and account for bias as it might manifest in my research. I sought to maintain diversity and balance in my sampling techniques by relying on primary interview participants to generate referral lists, and selecting from those lists an equal representation of participants from the nonprofit and local government sectors.

The preliminary study conducted in 2005 provided me a broader understanding of the relationships and networks that foster rail-trail and greenway development. Previous assumptions that I made about levels of commitment from local governments and nonprofit organizations were challenged. As I began conducting research and interviews for this thesis, I was more aware of how social constructs are formed between individuals and among groups or organizations that are involved in rail-trail and 
greenway development. This background, along with my understanding of previous research, provided me with the language needed to ask questions that would contribute to my research goals.

\section{Grounded Theory Framework of Analysis}

Grounded theory is a way of "generating a theory from data mean[ing] that most hypothesis and concepts not only come from the data, but are systematically worked out in relation to the data during the course of the research" (Glaser \& Strauss, 1967).

Although I do not seek to use this thesis as a means of creating theory, I used grounded theory as a framework for data analysis. Strauss and Corbin (1998) describe grounded theory as an opportunity for the researcher to fuse science and art in analysis, exercising creative ability "to aptly name categories, ask stimulating questions, make comparisons, and extract an innovative, integrated, realistic scheme from masses of unorganized raw data" (p. 13). Raw data was collected by conducting semi-structured, open-ended interviews with an interview guide and using probes when necessary (Patton, 2002). Interview data was analyzed and supplemented with a document analysis of newspaper articles, organization and departmental reports and master plans, and records of city council meeting minutes. Instead of beginning with a theory and attempting to prove it, these data provided me, as the researcher, the opportunity to "begin with an area of study and what is relevant to that area [will be] allowed to emerge" (Strauss \& Corbin, 1990, p.12).

In their book, Basics of Qualitative Research, Strauss and Corbin (1998) lay the groundwork for analyzing qualitative data called "coding", involving different levels (open, axial, and selective coding) that provide a hierarchical approach to forming theory. Microanalysis, or "line-by-line" analysis of raw data facilitates the coding process (Strauss \& Corbin, 1998). Open coding is the first analytic step in the coding process, used to develop labels that correspond to "events and actions in the data" in order to "compare them with one another and decide which belong together" (Harry, Sturges, \& Klingner, 2005).

Axial coding, while not confined to a linear coding process, can be used to further develop emerging categories from open coding. The categories created in open coding are in essence a set of phenomena; axial coding "relates categories to subcategories to form...complete explanations about phenomena;" in other words, the subcategories answer questions about "what is going on" (Strauss \& Corbin, 1998, p. 125). Harry, et 
al. (2005) link the coding process with a hierarchical data analysis map representing the different levels of analysis that begins with open coding, moves to developing categories (axial coding) and themes (selective coding), and goes further to test themes, interrelate explanations, and form theory.

Tuler and Webler (1999) used a grounded theory approach in their study of the public participation process involved in the conservation efforts of the Northern Forest Lands Council in New England. Open coding comparative analysis of the interview data produced a set of categories of principles related to effective public participation. In a similar way, I analyzed interview data using open and axial coding. Like Tuler and Webler (1999), I aim to identify principles that relate to the process of rail-trail and greenway development as it applies to the interactions of nonprofit organizations and local government; I am not attempting to theorize. In order to generate categories and principles, I employed the "basic elements of grounded theory" by "constantly comparing incident with incident," (Merriam, 2002, p. 143) allowing cross-comparison to generate conceptual categories serve as the foundation of my findings.

The complex nature of associations between nonprofit organizations and local governments involved in these endeavors requires a highly contextual form of analysis, since each situation, organization, and governing body is highly unique. Each participant involved in the interview process carries her or his own set of paradigms, or a ways of making sense of the "complexities of the real world" (Patton 2002). This thesis presents a synopsis of the way that certain people in certain situations interpret their experiences of community building through the development of rail-trails and greenways. Using a grounded theory framework for analysis, their related experiences were synthesized in order to form a better understanding of how small, community-based organizations develop relationships with local government entities. Patton (2002) explains that:

...there is a very practical side to qualitative methods that simply involves asking open-ended questions of people and observing matters of interest in real-world settings in order to solve problems, improve programs, or develop policies. (p. 136)

Engaging in dialogue with community leaders and officials is not only a learning process by which I gain knowledge of a particular process or phenomenon, it is also a means by which I can apply grounded theory methods and begin to understand how problems are solved, programs are improved, and policies are developed. 


\section{Site Selection}

Sites for my research were determined through purposeful sampling. Interview participants were selected from three West Virginia cities: Charleston, Morgantown, and Wheeling. These three sites were chosen based on each city's existing rail-trail development, as well as planning efforts for proposed trails and greenways. Throughout this thesis, I refer to "local government" specifically as it applies to these municipalities. The local government respondents interviewed were all representative of city governments, as I did not extend my participant selection to include county or regional government officials.

With an overall population of $1,816,856^{6}$ West Virginia is traditionally known for its rural communities. The representative cities in this study were chosen because of their more urban nature. In addition to being three of the most populous cities in the state ${ }^{7}$ each of the three cities have existing trail development on or near a riverfront, areas that are being revitalized as community assets that can enhance quality of life for local residents while also drawing in traditional tourists and "visitors from nearby areas the regional tourists" (Breen \& Rigby, 1996, p. 16). More attention to waterfront planning has also increased venues for public discussion and participation that enable community pride and ownership (Sanoff, 2005). The community profiles in Chapter IV highlight each city's experience with trail development and convey the importance of the rivers' role as expressed by interview participants.

\section{Participant Selection}

Using different sampling methods, I chose interview participants based on their involvement with a related nonprofit group or by being referenced as an important point of contact by primary participants (Patton 2002). Purposeful sampling is a way of gathering data from participants whose role in a phenomena is unique due to their expertise in an area or their position as a "privileged witness to an event" (Maxwell, 2005, p.88). The criteria for selecting interview participants is based upon an individual being a "privileged witness"; interviews were conducted with people who are part of or associated with nonprofit organizations and local government entities that are or have previously been involved in rail-trail and greenway development.

\footnotetext{
${ }^{6}$ Current 2005 estimate from the US Census Bureau (www.census.gov)

${ }^{7}$ According to 2000 US Census data, Charleston is the largest city in WV, with a population of 53,421 , Wheeling ranks forth with a population of 31,419 , and Morgantown is the fifth largest city in WV with a population of 26,809 . However, the population in Morgantown fluctuates due to the student population generated by West Virginia University.
} 
The final sample group grew out of a combination of snowball and purposeful sampling. The snowball sampling strategy is most commonly used to as a means of identifying "hidden populations" associated with sensitive subjects like homelessness and drug addiction (Faugier \& Sargeant, 1997). While my research does not examine a "sensitive subject" per say, snowball sampling is an excellent way to pinpoint participants through a "series of referrals that are made within a circle of people who know one another" (Faugier \& Sargeant, 1997, p.792). Essentially, I wanted to start with "subjects who feature the necessary characteristics and, through their recommendations, find other subjects with the same characteristics" (Gobo, 2004, p. 442). A list of primary participants generated from the West Virginia Statewide Trail Plan (2002) was used as a purposeful sample of those directly involved with trail-related issues. As primary participants, those individuals were asked to provide a list of other key informants, or "people who are particularly knowledgeable about the inquiry setting... whose insights can prove particularly useful in helping an observer understand what is happening and why" (Patton, 2002). The primary participants suggested other individuals from the nonprofit sector and local government entities whose knowledge could contribute to my study based on an explanation of my research goals and selection criteria.

Interview participants included a diverse set of people involved with development efforts, and were not limited to participation based upon membership or employment status. Drawing from previous research (Leach, 2002) I assume that a study based on the opinions of only city council and nonprofit board executives may not be representative of the experiences of all those involved in rail-trail and greenway development. Participants associated with nonprofit organizations included representatives from: trail advocacy groups, neighborhood associations, chambers of commerce, local health initiatives, and land trusts. Interview participants from local government included members of city councils, planning departments, economic and development authorities, and parks and recreation boards. Table 1 includes a description of participants' involvement in rail-trail and greenway development and is designated as either a representative from the nonprofit sector or local government. 
Table 1. Interview Participants

\begin{tabular}{|c|c|c|c|c|}
\hline Position & Type of Organization & $\begin{array}{l}\text { Years } \\
\text { Experience }\end{array}$ & Location & *Sector \\
\hline $\begin{array}{l}\text { President/ } \\
\text { Member }\end{array}$ & $\begin{array}{l}\text { Neighborhood Association/ } \\
\text { Trail Advocacy Group \& } \\
\text { bicycle club }\end{array}$ & $>10$ years & Charleston & NPO \\
\hline Director & $\begin{array}{l}\text { Community Development } \\
\text { Alliance }\end{array}$ & $>5$ years & Charleston & NPO \\
\hline Director & City Planning Department & 6 years & Charleston & LG \\
\hline Council Member & City Council & 11 years & Charleston & $\mathrm{LG}$ \\
\hline Associate & Land Trust & $>2$ years & Charleston & $\mathrm{NPO}$ \\
\hline Director & $\begin{array}{l}\text { Community and Economic } \\
\text { Development }\end{array}$ & 5 years & Charleston & LG \\
\hline $\begin{array}{l}\text { Administrative } \\
\text { assistant/event } \\
\text { coordinator }\end{array}$ & $\begin{array}{l}\text { Trail Advocacy Group/ } \\
\text { Community health initiative } \\
\text { group }\end{array}$ & $\begin{array}{l}4 \text { years/ } \\
1 \text { year }\end{array}$ & Charleston & NPO \\
\hline Founding member & $\begin{array}{l}\text { Trail and parks advocacy } \\
\text { group }\end{array}$ & $>15$ years & Morgantown & NPO \\
\hline $\begin{array}{l}\text { Former president and } \\
\text { board member }\end{array}$ & Trail advocacy group & 9 years & Morgantown & NPO \\
\hline $\begin{array}{l}\text { Director/ } \\
\text { board member }\end{array}$ & $\begin{array}{l}\text { Parks and recreation } \\
\text { commission/trail advocacy } \\
\text { group }\end{array}$ & $\begin{array}{l}4 \text { years/ } \\
>10 \text { years }\end{array}$ & Morgantown & LG/NPO \\
\hline Council member & City Council & $>10$ years & Morgantown & $\mathrm{LG}$ \\
\hline City Manager & City Government & 14 years & Morgantown & LG \\
\hline Executive Director & Trail Advocacy Group & $>5$ years & Morgantown & NPO \\
\hline $\begin{array}{l}\text { Former mayor/ } \\
\text { council member }\end{array}$ & $\begin{array}{l}\text { City government/ } \\
\text { city council }\end{array}$ & $\begin{array}{l}15 \text { years } \\
\text { combined }\end{array}$ & Morgantown & LG \\
\hline $\begin{array}{l}\text { President/ } \\
\text { former president/ } \\
\text { former mayor }\end{array}$ & $\begin{array}{l}\text { Trail advocacy group/ } \\
\text { Chamber of Commerce/ } \\
\text { City government }\end{array}$ & $\begin{array}{l}1 \text { year/ } \\
>20 \text { years/ } \\
>10 \text { years }\end{array}$ & Morgantown & $\mathrm{NPO} / \mathrm{LG}$ \\
\hline $\begin{array}{l}\text { Developer and } \\
\text { organizer }\end{array}$ & $\begin{array}{l}\text { Community health initiative } \\
\text { group }\end{array}$ & $>5$ years & Wheeling & NPO \\
\hline Member & $\begin{array}{l}\text { Task force formed from } \\
\text { health initiative group }\end{array}$ & $>1$ year & Wheeling & NPO \\
\hline Council Member & City Council & 12 years & Wheeling & LG \\
\hline Director & $\begin{array}{l}\text { Community and Economic } \\
\text { Development }\end{array}$ & 4 years & Wheeling & LG \\
\hline Member & $\begin{array}{l}\text { Task force formed from } \\
\text { health initiative group }\end{array}$ & $>1$ year & Wheeling & NPO \\
\hline Member & Trail advocacy group & $>1$ year & Wheeling & $\mathrm{NPO}$ \\
\hline City Manager & City government & 4.5 years & Wheeling & $\mathrm{LG}$ \\
\hline Program Manager & $\begin{array}{l}\text { Community heritage } \\
\text { organization }\end{array}$ & 1 year & Wheeling & NPO \\
\hline
\end{tabular}

*The Sector column identifies which group the participants' belong. The following abbreviations are used:

NPO = Nonprofit Organization

LG = Local Government 
Although Table 1 represents the final sample representative of this study, my initial sample included 29 participants. Six individuals contacted for an interview were either unavailable due to schedule conflicts, or did not respond to my emails and followup phone calls. I take into account "the gap...between the initial sample (all individuals about whom [I] want[ed] to collect information) and the final sample (the cases [I] managed to get information on)" by reporting nonresponse (Gobo, 2004, p.441). The six individuals that represent nonresponse in my study may have provided additional, novel information and their absence should not be overlooked.

The depth of my research did not allow for the inclusion of every person referenced by other participants. By using purposeful sampling, I limited my sample selection to 23 participants and felt that saturation had been reached as referrals were continuously repeated by participants.

\section{Data Collection}

After identifying my principal participants in the three examined communities, I began face-to-face interviews from a small sample selection. I contacted individuals by email or telephone, explaining the nature of my study and introducing my research questions as a way to better illustrate why selected participants were important to building the knowledge base of my analysis. Most of the participants were eager to meet with me, and responded immediately to my initial inquiry. Others were hesitant to be interviewed; one participant explained in an email: "I truly don't know how much I can add to your project. I am only slightly involved with trail/greenway development." However, it was important for me to gather information from individuals across both nonprofit and local government sectors, and I found that every participant, whether they perceived themselves as knowledgeable on the subject or not, added depth to my research. Rail-trails and greenways are not developed and maintained exclusively by identifiable and definable groups, many people, associated with diverse organizations and entities, constitute community based efforts to create environments that are rail-trail and greenway friendly.

As I met with more people, my sample size increased because I relied on initial participants to refer others who might contribute to the understanding of my research questions. All interviews were audio taped and later transcribed, yielding over 100 pages of raw data. I assured all participants that confidentiality would be maintained, and names are changed to protect the identity of those interviewed. Although my topic 
is not sensitive in nature (I received exemption from the Internal Review Board) I must assure for privacy protection of participants and feel that some were more open in their responses based on ensured confidentiality.

I used an interview guide to serve as a reference for conducting semi-structured interviews. I contacted participants and conducted interviews in the spring of 2006, with conversations ranging in length from 30-90 minutes. I did not restrict my questioning to the interview guide, allowing me to use other probing questions to elicit more complete responses, or to modify my inquiries when participants needed clarification based on personal experiences. Some interviews were constrained by time limitations, in which case I used the interview guide as much as possible, but relied more on the participants' responses to guide our conversation.

The questions I chose to include in my interview guide (Appendix A) stemmed from my understanding of current research. On their study of a public participation process, Tuler and Webler (1999) asked participants to describe the process in order "gauge their familiarity with the process, to identify patterns of misperceptions or misunderstandings, and to help understand the case" (p. 440). Similarly, I wanted to understand how the process of rail-trail and greenway development was perceived by participants, asking them to describe their involvement with trail projects as well as their perceived relationship with the other sector. Responses to these questions helped me assess familiarity and recognize if there were misunderstandings related to the nature of existing relationships. Selin and Myers (1995) noted that empirical research on partnerships "suggest that many factors either contribute to or constrain the effectiveness of partnerships" (p. 39). To learn more about the perceived nature of relationships between the two sectors, I asked questions regarding the constraints and facilitating factors of building effective relationships. I hoped that responses to barrier/facilitating factor questions might illuminate where gaps exist in communication or logistic operations in building effective relationships. Asking participants about rail-trail and greenway development in other communities allowed me to compare the perceptions of other initiatives, and probed speculation on why some communities have more extensive trail development than others. Other questions were asked to gather opinions on relationship building, perhaps contributing to forming implications for building effective relationships in rail-trail and greenway development endeavors in West Virginia communities. 


\section{Data Analysis}

Throughout the interview process, and while transcribing, I began to build preliminary categories and themes using a grounded theory framework. While aware of my own experiences and guiding interests, I began immediate analysis of the data as I participated in conversations with interview participants. Charmaz (2004) notes the importance of being actively involved with data, making comparisons, and being open to categories and themes as they emerge throughout the research process:

From the beginning, the researcher actively constructs the data in concert with his or her participants...categories reflect the interaction between the observer and the observed...[g]rounded theorists attempt to use their background assumptions, proclivities, and interests to sensitize them to look for certain issues and processes in their data. (p. 501)

Throughout data collection, I was actively engaged in the analysis process, simultaneously using new data to enhance subsequent interviews. As findings emerged, I was able to consider using different probing questions in order to illuminate or gain alternate perspectives on surfacing issues and themes.

I used a grounded theory framework to analyze my data. As previously mentioned, grounded theory is "derived from data, systematically gathered and analyzed through the research process" (Strauss \& Corbin, 1998, p. 12) and is inductive in nature because it "involves discovering patterns, themes, and categories in one's data" (Patton, 2002, p. 453). In order to understand the process of data analysis using a grounded theory framework, I turned to the groundwork of Glaser and Strauss (1967), and more recent developments of Strauss and Corbin (1998) and Charmaz (2003; 2004).

In the beginning of by data collection and analysis, I found myself asking the same question posed by Charmaz (2003): "How do we do grounded theory?"; I learned that Charmaz's answer was to be heeded: "Analysis begins early. We grounded theorists code our emerging data as we collect it" (p. 258). I began taking field notes during interviews the moment I began to audiotape. Those notes supplemented the resulting transcripts by providing me with a guide to the original thoughts I formed as I conversed with participants.

Arai and Pedlar (2001) cite Taylor and Bogdan (1984) in describing data analysis as having three phases, "the on-going discovery phase, coding the data, and...attempts to discount the data" (p. 173). The initial phase of 'on-going discovery' is focused on "identifying themes and developing concepts and propositions" (Arai \& Pedlar, 2001, p. 173). As I interviewed participants, I constantly referred to my initial field notes from 
previous interviews, compared responses, and developed additional probing questions that would yield more information related to my research questions. After interviews were transcribed, I began the coding process accompanied by the field notes.

\section{Coding Data}

\section{Open Coding}

Coding my data involved the initial open coding process of line-by-line analysis, through which I labeled emerging categories or themes. Tuler and Webler (1999) describe coding as a process where "data are categorized with respect to relevant similar characteristics" (p. 440). I used the same approach, and soon realized that the multitude of identified categories needed to be reexamined and redefined through an extensive cross-comparative process. Strauss and Corbin (1998) explain that comparative analysis is, at it's most basic, a way to examine distinct incidents, and on a more complex level is used "to stimulate our thinking about properties and dimensions" by making theoretical comparisons (p. 78).

Through the open coding process, I developed a multitude of categories and themes. For example, I noticed that several participants referred to individual community members or political officials who are specifically committed to rail-trail and greenway development as 'champions' or 'torch-carriers.' Initially, I recognized "community champions" as a major category that could be placed under the major theme of "Political Environment". I continued working with the data, creating new codes as more ideas surfaced. Soon, I had a separate set of codes that led to forming a new category dealing with the specific role of a city mayor or manager in community initiative like rail-trail and greenway development. The "role of city mayor/manager" category could also be linked to "community champions" category because the individuals referred to, whether from the nonprofit sector or the local government, used their abilities to provide direction for rail-trail and greenway projects. This observation led me to present "Community Champions" and "Role of City Mayor/Manager" as subcategories of the larger category, "Leadership."

In order to begin making conceptual sense of the emergent categories and themes, I re-read every transcript and reviewed my preliminary labels or codes, and ultimately placed coded data on note cards so that individual quotes could be categorized, subcategorized, and re-categorized as I moved into the next level of analysis, axial coding. 


\section{Axial Coding}

Theoretical comparison enables relational patterns to emerge, as well as the variation between patterns:

It is not just one form of a category or pattern in which we are interested but also how that pattern varies dimensionally, which is discerned through a comparison of properties and dimensions under different conditions. (Strauss \& Corbin, 1998, p. 67)

Categories are related to other subcategories in the process of axial coding, given that name because it "reflect[s] the idea of clustering the open codes around specific 'axes' or points of intersection" (Harry et al., 2005, p. 5).

The role of the researcher is critical throughout the analysis process, and should be accounted for in the representation of findings. Patton (2002) points out that "no ways exist of perfectly replicating the researcher's analytical thought process" (p. 433). For example, one of my preliminary categories "Planning Process" was a subcategory developed under "Community Involvement" because I thought of planning processes as one component or type of community involvement. The more I consulted the data and was involved in axial coding, I realized that "Planning Process" was best represented as a category of one of the main conceptual themes, "Built Environment" because participants referred to planning processes to describe the logistics of developing a trail, and transitioned to discussing the implications of planning principles like smart growth and new urbanism. All of these ideas related more specifically to the built environment, or the way infrastructure is developed and exists in a community.

Through the processes of open and axial coding, I became completely immersed in the data. The codes that I developed, and later used to create a framework for displaying my findings, remain as my own interpretation of the data. As the sole researcher, I was the only person involved in data collection and analysis. Regarding data analysis, Patton (2002) describes the fine line between using guidelines and personal judgment or creativity:

Because each qualitative study is unique, the analytical approach used will be unique...qualitative analysis ultimately depends on the analytical intellect and style of the analyst. The human factor is the great strength and fundamental weakness of qualitative inquiry and analysis - a scientific two-edged sword. (p. 433)

Indeed the findings, implications, and conclusions drawn from the data I collected and analyzed should be regarded as a result of my interpretation. Through my research design, I attempted to collect data that would be representative of the phenomenon 
explored and used a grounded theory framework as a guide for analysis. Strauss and Corbin (1998) illuminate the unique "interplay between researchers and data":

There are procedures to help provide some standardization and rigor to the process [of analysis]. However, these procedures were designed not to be followed dogmatically but rather to be used creatively and flexibly by researchers as they deem appropriate. (p. 13)

In the same vain, my analysis cannot be totally objective, even though I strived to maintain consistency in my analysis to accurately produce findings that are essentially grounded in the data.

\section{Developing themes and categories and moving toward theorization}

From the onset of my research, I began the process of memo writing. I started with a series of "Researcher Identity Memos" to help organize my thoughts and move toward developed research goals and questions (Maxwell, 2005). I also took field notes while interviewing participants and wrote reflective memos after interviews were complete. Coffey (2002) explains that:

Field notes and journals are an obvious and longstanding form of embracing the self in the products of qualitative research, though they are often overlooked as such. These are the building blocks of qualitative research, a place for accumulation of data and reflections. (p. 317)

The memos, used actively in open and axial coding, helped me form a conceptual design. I could refer to my initial reactions and thoughts during an interview, constantly comparing those ideas to subsequent reflections and raw data:

[Memo writing] helps to spark our thinking and encourages us to look at our data and codes in new ways. Memo writing leads us to explore our codes; we expand upon the processes they identify or suggest. Thus our codes take on substance as well as a structure for sorting data.

(Charmaz, 2003, p.261)

The conceptual model that emerged from my analysis of the data is a visual representation of how categories and subcategories are connected to overall themes, as well as the interrelation of main themes.

The concept map is simply a way to demonstrate the different dimensions that surfaced through analysis. Exemplary key quotes were determined through coding procedures and are the building blocks of the conceptual foundation presented. I did not attempt to develop my research through the theoretical level, although the framework offers a way of condensing my findings into a useful model for how nonprofit organizations and local governments form and maintain relationships in the course of 
rail-trail and greenway development.

\section{Study Completion}

I concluded data collection after contacting 29 individuals and completing 23 interviews. As mentioned previously, time is a major consideration in the limitation of my study. The data collected and analyzed represents my interpretation of the views and ideological constructs of the 23 participants interviewed, at this moment in time. More time could yield several more interviews from individuals who were referred by participants, but not included in this study. For the purpose of this thesis I tried to maintain a balance between the number of participants that represented each community as well as a fairly equal number of participants from the nonprofit and local government sectors. Including all of the referrals as interview participants would have yielded a disproportionate amount of representatives for each community and sector.

The first phase of data analysis ended once concrete themes, categories, subcategories, and relative connections matured into a more comprehensive conceptual model. The second phase was the development of a rich, descriptive narrative in the form of exemplary quotations that support my interpretation of the data. Patton (2002) draws from the work of Denzin (1989) to convey the importance of "thick interpretation" as "connecting individual cases to larger public issues and to the programs that serve as the linkage between individual troubles and public concerns" (p. 503). Using thick interpretation allowed me to connect my understanding of empirical research with the findings produced from my analysis to form recommendations relevant to the phenomenon studied. 


\section{Findings}

\section{Chapter IV}

Although the three communities examined can be highlighted through the investigation of US Census Bureau information, other state or federal documents, and local resources, there is a distinct need to understand the dynamics of community participation in rail-trial and greenway development as reported by interview participants. Before delving into findings about nonprofit/local government relationships that emerged in the interview data, a brief description of Charleston, Morgantown, and Wheeling, an account of their respective experiences in rail-trail and greenway development is necessary, and a summary of the form of government under which each municipality operates.

\section{Community Profiles}

\section{Charleston}

"Mayor Danny Jones... said he would like to see foot traffic replace much of the vehicle traffic along Kanawha Boulevard. 'I want green space,' Jones said, 'a wider walking path and bike paths. Not concrete. Not cars. People."'

- Jake Stump, Charleston Daily Mail, May 4, 2005

Located in Kanawha County, Charleston is the state capital and the most populous city in West Virginia. Located at the confluence of the Kanawha and Elk Rivers, Charleston is home to a waning chemical industry, once the largest in the nation. Many of the railway lines are still active, serving the city's chemical industry and supporting the state's transportation of coal.

In the early 1990s, there was a small movement to develop a rail-trail that would begin in Charleston and extend over 100 miles to the north. Attempts to purchase a 24mile rail corridor that would begin to connect Charleston to other northern communities failed when a local businessman bought the property for the future use of reactivating the rail line for coal transport. Instead, a local group partnered with the city to build a one mile section of trail on an old county road parallel to the newly purchased rail line. Located in a Kanawha County park, the trail became the Elk River Rail-Trail, and is recognized as West Virginia's only 'rail with trail,' and one of the state's first successful rail-trail projects, albeit a small one. Aside from the one-mile Elk River Rail-Trail, Charleston has a four mile paved multi-use path on the north side of the Kanawha River, passing by the state capital building and downtown commercial district. 
Both existing trails provide local residents with recreation opportunities, but there are growing efforts to build a larger network of rail-trails and greenways in the Charleston area. One participant explained that he was involved in rail-trail and greenway planning efforts in Charleston "because we're the largest metropolitan area in the state and everybody has a rail-trail or a linear greenway in their city except Charleston, and it's frustrating in that respect." The various individual efforts addressing rail-trail and greenway development in Charleston are linked by supporters that sit on various committees formed by the city and a small group of nonprofit organizations.

- The City of Charleston - In 2004, the mayor of Charleston and City Council formed the Charleston Riverfront Development Committee to develop a vision and framework for riverfront development that included a public participation campaign. Working with the nonprofit Charleston Area Alliance (an umbrella organization that houses the Chamber of Commerce), the City engaged in public workshops and meetings resulting in the support of a "riverfront plan that prioritized public greenspace, enhanced and added public amenities at the water, and carefully considered a mixed-use approach to any riverfront development" (Charleston Riverfront Master Plan, 2006). In 2005, a private planning firm was hired by the city to develop a master plan for Charleston's riverfront consistent with the input from the Riverfront Committee and the outcomes of the public participation process. Sasaki Associates, Inc. released the "Charleston Riverfront Master Plan" in early 2006.

- Greater Charleston Greenway Project - The Greater Charleston Greenway Steering Committee, formed by the West Virginia Land Trust with assistance from the National Park Service's Rivers and Trails Conservation Assistance Program (RTCA), consists of community members representing organizations like the Charleston West Side Neighborhood Association and the West Virginia Trails Coalition. The Steering Committee hosted a series of community workshops in spring 2005 to address the potential for trails, greenways, and greenspace in the area of Charleston lying south of the Kanawha River. Partnering with the Regional Intergovernmental Council (designated as the Metropolitan Planning Organization for the greater Charleston area), the Steering Committee developed a map to reflect the outcome of the community workshops, which highlights existing, planned, and proposed trails and greenways in Charleston's south side. Prior to the Steering Committee's 
development of a map and plan for the south side, the West Virginia Land Trust solicited support from the City of Charleston Planning Commission resulting in a resolution ("City of Charleston Municipal Planning Commission Resolution in Support of the Kanawha Valley Greenway Initiative," 2004). The Steering Committee's final master plan and map will be presented to the City of Charleston upon completion as a supplement to the existing Riverfront Development project plans.

- The Kanawha Trestle Rail-Trail Project - A proposed rail-trail project in downtown Charleston is an endeavor headed by the West Virginia Trails Coalition and the Charleston West Side Neighborhood Association. The West Virginia Trails Coalition is a Charleston-based nonprofit organization dedicated to developing local, regional, and statewide trails in West Virginia, and the West Side Neighborhood Association is a nonprofit that serves as a representative body for the west side of Charleston. These two organizations are working with the local government entities like the City of Charleston, and the Kanawha County Commission, and nonprofit organizations like the Charleston Area Alliance and the West Virginia Land Trust to secure funding and develop a plan for a rail-trail that will extend across an unused rail road bridge. At the end of 2004, the Trails Coalition and the West Side Neighborhood Association were implemental in helping the city receive $\$ 800,000$ in federally appropriated funds lobbied by the US congresswoman serving the congressional district that includes Charleston. The City is currently working with the other project organizers to get matching funds to supplement the $\$ 800,000$ award and to negotiate acquirement agreements with the rail line company.

\section{Form of Government}

The West Virginia State Code (Section 8-3-2) specifies the various organizational plans that constitute the form of government municipalities can assume and designates what positions maintain administrative authority in local governance. Charleston operates under a "Strong-Mayor Plan." As the name suggests, a significant amount of authority is granted to an elected mayor in this plan. An elected city council serves as the governing body for the municipality, and city officers and employees are appointed by the mayor, and approved by the council. Charleston has 21 wards (geographical districts), with one representative on council from each ward. There are also six council 
members that are representatives at-large, totaling a 27 member city council.

\section{Morgantown}

"It's almost heaven for walkers and bicyclists. Monongalia County - that includes Morgantown... is a bona-fide, gold-star mecca for rail-trail buffs."

-Bob Downing, Sunday Gazette-Mail, April 17, 2005

Situated on the Monongahela River in Monongalia County, Morgantown is located in north central West Virginia. Mining and manufacturing industries dominated the area until the 1960s and 1970s, creating an economy that heavily relied on the extraction and transport of natural resources like coal (Vision 2000: Greater Morgantown Project, 1992). The economy has since changed, largely as the presence of West Virginia University grew in Morgantown. West Virginia University (WVU) is the state's largest university and Morgantown's largest employer. Contributing to the city's reported 26,809 residents (US Census Data, 2000) WVU currently reports a student population of $26,051^{8}$. Enrollment at WVU has been steadily increasing, and plans to increase enrollment to $30,000^{9}$ by 2010 is an explicit goal of University administration. As a result, the entire population of Morgantown and surrounding area is increasing.

In 2000, the greater Morgantown area reached the population threshold criteria of 50,000 residents, enabling the creation of a Metropolitan Planning Organization (MPO) that works to develop a long-range comprehensive transportation plan for Morgantown and Monongalia County. Part of the MPO directive is to form a Citizen's Advisory Committee, comprised of local residents that "provides recommendations on community issues and concerns" to the Policy Board addressing transit, non-motorized transportation, and roadway developments. The MPO also holds public meetings to gather community input to incorporate into the Plan. The most recent Transportation Plan Update Map recognizes the need for enhanced pedestrian and bicycle accommodations, and addresses a need to create linkages from current roadway systems to the rail-trail.

The Mon River Rail-Trail System includes 8 miles of paved trail within Morgantown city limits (The Caperton Trail and a portion of The Deckers Creek Trail), and 43 miles of crushed limestone surface extends along the Monongahela River and

\footnotetext{
${ }^{8}$ A 2006 press release from the WVU News and Information Services reported the current enrollment in a statement highlighting the recent enrollment growth. http://www.nis.wvu.edu/2006/spring enrollment.htm

9 The University released a comprehensive strategic plan in September 2005, outlining the administration's goals and objectives for the remainder of the decade. ("West Virginia University's 2010 Plan: Building the Foundation for Academic Excellence": http://www.wvu.edu/ 2010plan/documents/2010plan.pdf)
} 
into Preston County via Deckers Creek. The Mon River Trail North is developed just four miles short of the West Virginia/Pennsylvania state line, and the Mon River Trail South travels outside of Monongalia County to Prickett's Fort State Park in Marion County. The entire trail system encompasses three counties, Monongalia, Preston, and Marion. The trail system has received national attention as the RTC Trail of the Month in August 2004 and was recently designated a National Recreation Trail by the U.S. Department of the Interior.

Much of my knowledge of the Mon River Rail-Trail System came from preliminary research conducted in the spring of 2005. Interviews with members from the Mon River Trails Conservancy (MRTC), as well as city government officials and personnel provided insight into how the seedling of an idea that brought together a group of community members dedicated to trail development led to a 51 mile trail system. MRTC members shared some of the history of the organization:

It started in Morgantown because the railroad announced that they were pulling out. And the community got together and said, 'well, we need to try to preserve this right-of-way, and Rails-to-Trails is a good way to do that'. A committee was formed here in Morgantown as a central point because the trail system takes in Preston County, Marion County, and Mon County, so we agreed to meet in Morgantown we formed a board with representatives from all three counties.

...the organization (MRTC) really started in 1991, and that was just a group of people getting together to talk about the fact that CSX was looking at abandoning the corridor...so it started with a very small grassroots bunch of people in a living room talking about how to make this happen.

So, in '91 the group (MRTC) incorporated. In '96, they acquired the 51 miles, and that was with a sizable donation from Ruby McQuain...The city also put up a considerable amount of money for [the purchase of the corridor], so they went outside their boundaries to make sure that it was secure.

The MRTC worked with the City of Morgantown and the Morgantown Chamber of Commerce to pursue funding sources in order to purchase the rail corridor from CSX. The $\$ 800,000$ state allocated Transportation Enhancement grant was matched with a $\$ 200,000$ donation from the local Hazel Ruby McQuain Foundation for the initial cost of purchasing the corridor. A city official told me that all in all, the city was able to leverage four million dollars in state and federal grants for the purchase and construction of the trail.

The first section of the trail was built in 1998, outside of the city limits on the 
Deckers Creek Trail. The funds secured by the city were the key to the rapid construction of the trail system, but as one MRTC member pointed out, the vision began with a group of "persistent and courageous people" who were visionary because they were "meet[ing] constantly, with no budget, and looking at something [they] didn't have ownership of." The large sections of trail that are outside of city were managed by the MRTC until 2005, when the organization entered into a license agreement with the Morgantown Board of Parks and Recreation Commissioners (BOPARC). BOPARC oversees the maintenance of the entire trail system, which receives city and county monies to fund a full time employee for the trail. This new arrangement entailed a restructuring of the MRTC board of directors. Previously a 25 member all volunteer board, the make-up now consists of three representatives each from the City of Morgantown, Monongalia County, and MRTC. MRTC maintains a base of over 500 local members who continue to volunteer time or contribute funds for the trail system.

\section{Form of Government}

Morgantown operates under the "Manager Plan" for municipalities. As defined by state code, this plan consists of a council body that must be represented by as few as five and as many as eleven elected members. Council serves as the governing body, elects a mayor from its membership, and appoints a city manager. The mayor assumes the position of presiding officer, and the manager holds administrative authority, manages the affairs of the city, and appoints or employs city employees. Morgantown has a seven member city council.

\section{Wheeling}

"If you look at the trails now, they are being used. From a public health standpoint, this is just awesome. I can see why people would want to come here from far away to walk these trails." - Dr.William Mercer, quoted in the Wheeling Intellegincer, June 13, 2006

A city with a deep historical connection to the railroad industry and a distinctive bond to the river that flows through it, Wheeling has changed with the times, and is a significant part of West Virginia's cultural narrative. Designated as a National Heritage Area ${ }^{10}$ by the U.S. Congress in 2000 , Wheeling is recognized for its "dramatic setting, resources, and history, including its role as the birthplace of West Virginia during the

\footnotetext{
${ }^{10}$ National Heritage Areas are assisted by the National Park Service, designated by Congress for "their capacity to describe nationally important stories about the evolution of our nation" and are managed by partnerships among federal, state, and local governments and the private sector.

(http://www.cr.nps.gov/heritageareas/)
} 
Civil War" (Management Plan for the Wheeling National Heritage Area, 2004, p. 1). The National Road and iconic suspension bridge in Wheeling served as a link to the west, making Wheeling the "northernmost navigable port on the Ohio River" and became a hub for industrial trade and transportation for manufacturers of iron, steel, nails, glass, textiles, tobacco, and other goods (Management Plan for the Wheeling National Heritage Area, 2004)

A decline in industry has significantly altered the economy and population of Wheeling, and the city faces the challenge of addressing abandoned and underutilized infrastructure. The efforts of local government and the Wheeling National Heritage Area Corporation to direct attention to the city's historical, cultural, and geographic assets, include the 13 mile Wheeling Heritage Rail Trail.

The City of Wheeling was the first city in West Virginia to receive a Transportation Enhancement grant to develop a rail-trail. The initiative to assess the potential for rail-trail development came from members of city council and other city personnel. The 13 mile corridor extends north-south along the Ohio River and east-west along Wheeling Creek and was purchased by the city from a private landowner. The acquisition of the rail corridor right-of-way provided the $20 \%$ match of in-kind funds needed to leverage federal and state dollars.

During the initial planning and first phases of trail construction, there was a small community group founded by a city employee that was working with City Council to solicit grants. The group never incorporated and dissipated after trail construction was complete. Since the City of Wheeling is entirely responsible for management and maintenance of the trail, there has been little engagement from the public or citizen-led groups to adopt trail-related projects. The Wheeling National Heritage Area Corporation (WNHAC), a nonprofit organization that "leads community efforts to recognize, communicate, and preserve Wheeling's heritage," was implemental in the development of Heritage Port, an outdoor riverside amphitheater. WNHAC recognizes the Wheeling Heritage Rail-Trail as a vital component to the area, and considers how the trail contributes to the area in its management plan (Management Plan for the Wheeling National Heritage Area, 2004).

Recently, a group of residents organized a plan to assess the potential for expansion of the rail-trail. Several miles of abandoned rail line spurs owned by the city are under consideration in the group's plan. The Trail Expansion Committee is not an incorporated nonprofit, but its members came together through their affiliation with the 
Walkable Wheeling Task Force, which spawned from the local health initiative campaign, Wheeling Walks ${ }^{11}$. To date, the group has presented a detailed plan for trail expansion to the Wheeling city manager and the Wheeling Council Development Committee in order to gain the city's approval for their proposal.

\section{Form of Government}

Wheeling operates under a "Manager-Mayor Plan" as specified by the state code. This form of government shares most of the characteristics of the "Manager Plan," but differs in the appointment of the mayor, who is elected by the voters of the municipality rather than by the members of council. Under this plan, the manager, who is appointed by city council, holds administrative authority and manages the affairs of the city. Wheeling has a mayor and six council members.

\section{Summary of Findings}

The community experiences contribute to the summary of findings by giving context to the following narrative that was formed from interview responses. The three communities are unique in their historical and socioeconomic background and all have varying levels of existing rail-trail and greenway development or planning efforts. In order to make the data representative of each participant's background and experience, I labeled quotations with the following indicators for location and sector involvement:

\section{Location \\ $\mathrm{W}=$ Wheeling \\ $\mathrm{C}=$ Charleston \\ $\mathrm{M}=$ Morgantown}

Sector Involvement

$\mathrm{NPO}=$ nonprofit organization respondent

$\mathrm{LG}=$ local government respondent

$\mathrm{NPO} / \mathrm{LG}=$ nonprofit and local government respondent

Indicators were also used in order to assure for anonymity, as I guaranteed that confidentiality would be maintained throughout the thesis.

I used a grounded theory framework in data analysis to develop overarching themes that emerged in the data. Although I aim to contribute to existing research and theories regarding rail-trails, greenways, and nonprofit/local government relationships, I do not intend to propose new theory. The results of my synthesis produced practical

\footnotetext{
${ }^{11}$ Wheeling Walks is a public health campaign that strategically employs the use of participatory planning to develop a wide-reaching media effort encouraging people to walk 30 minutes daily. The program was so successful that it was replicated in Morgantown and has plans to launch in the Kanawha/Putnam County area. The program, supported by state and private funds, was highlighted in a 2004 Rails-to-Trails Conservancy case study report (Creating Active Communities: Ten Case Studies of Programs and Partnerships, 2004).
} 
implications that may help inform decision- and policy-making regarding rail-trails and greenways, while also extending an understanding of how government and nonprofit relations are evolving dynamically over time.

The summary of findings that follows is purposefully organized in respond to my research questions. When I began collecting data, I wanted to know more about how relationships between nonprofits and local governments form and function, what factors constrain or facilitate effective relationship building, how those involved in rail-trail and greenway development perceived the benefits of their labor, and why community efforts to build rail-trails and greenways vary in West Virginia cities and towns. Four of the main categories, "Perceived Benefits and Costs", "Built Environment", "Political Environment", and "Social Capital" were formed in order to display the interrelated nature of emerging themes and sub themes and to show that the theoretical implications provide a solid foundation for "Practical Implications," discussed in Chapter V: Summary, Conclusions, and Recommendations.

The concept map below (Figure 1) exhibits the structure of my findings, and provides a framework for the concluding discussion of implications and need for further research. A detailed outline of findings is provided as Appendix $B$.
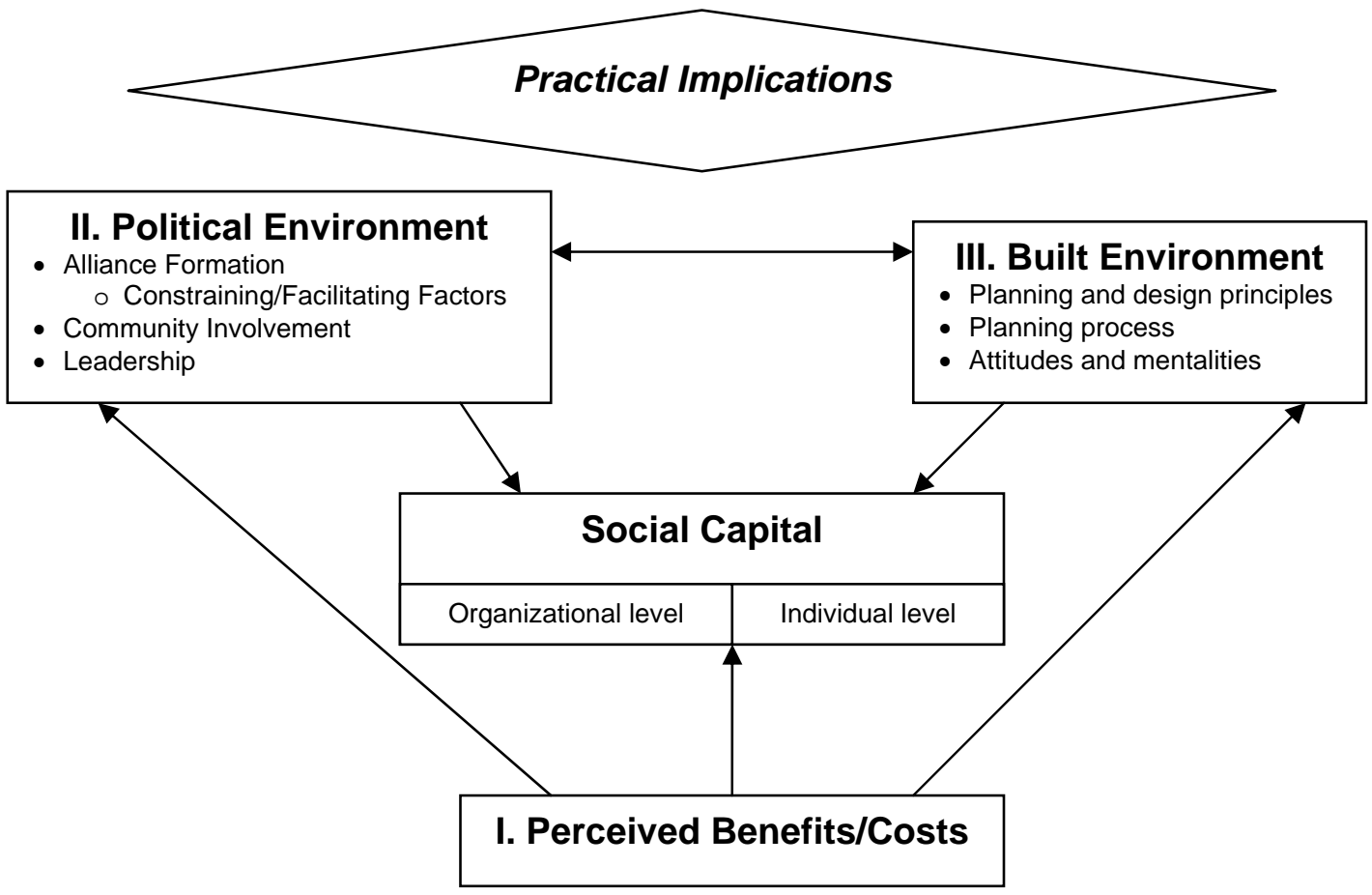

Figure 1. Categories in the Findings 
The "Perceived Benefits/Costs" category offers a background of how the participants of each sector assess the importance of rail-trails and greenways in their communities or the costs that are associated with their development, and illuminates the different aspects on which alliances are formed. These motivating conditions to establish rail-trails also assist in understanding why nonprofit organizations and local governments enter into relationships, what ideas and values they share, and how their differences contribute to the way relationships function and grow. "Perceived Benefits/Costs" is also reflective of how rail-trails and greenways help shape or change the built environment, or the actual infrastructure systems in a community. Linking "Perceived Benefits/Costs" to the other three categories also reveals that respondents viewed the development of rail-trails and greenways as contributing to the "Political Environment," the "Built Environment," and "Social Capital."

One of my research questions was: how do relationships between nonprofit organizations and local governments form and function? The Merriam-Webster Online Dictionary ${ }^{12}$ provides one definition of "politics" as: "the total complex of relations between people living in society." Since these alliances form out of how civil society and government coalesce, one of the main categories, "Political Environment," is used to describe the nature of relationships between nonprofits and local government. "Political Environment" consists of themes that became apparent during data analysis, including "Alliance Formation," "Community Involvement," and "Leadership." A sub theme included in the "Political Environment" category provides insight into the constraining and facilitating factors that contribute to effective relationship building between nonprofits and local governments involved in rail-trail and greenway development.

Another main category deals with the formation of the "Built Environment" by highlighting themes that emerged regarding opposition to building rail-trails and greenways, as well as the role of these multi-use trails in planning and design principles, and planning processes. As shown in the diagram, the political environment and the built environment are influenced by one another; alliances might form in the political environment in order to address infrastructure issues, while perceptions and knowledge of the built environment shape policies and determine whether or not the political environment will institute programs and support projects like rail-trails and greenways.

At the nexus of these categories are two variants of social capital theory, the

\footnotetext{
12 http://www.m-w.com/dictionary/politics
} 
individual level and the organizational level. Ideas linked to social capital, like geographic and social connectivity, are included in the reported perceived benefits. Themes that are represented in the "Political Environment" category are also suggestive of the production of organizational social capital, while themes like "planning and design principles" and "planning processes" indicate the presence of concepts indicative of individual level social. The three themes described at length ("Perceived Benefits and Costs", "Political Environment" and "Built Environment") include an analysis of social capital implications as an integrated component to each theme.

Each piece of interview data represented was synthesized to form a larger narrative. The conversations I had with each of the participants are extensions of a broader community dialogue that engage many different individuals, groups, and organizations who will always be striving to improve their communities.

\section{Perceived Benefits and Costs}

"Everybody has a different reason for wanting [a] rail-trail, but those are all good reasons to bring them in." (M-NP 11)

\section{Perceived Benefits}

Although there were varying degrees of reported benefits (one participant listed seven benefits, and another only listed one), overall, responses from both sectors maintained a strikingly similar quality when asked "What are the benefits of rail-trails and greenways to a community?" Table 2 shows how participants responded, and the frequency among designated nonprofit participants (NPO), local government participants (LG), participants that could be identified as being involved in a nonprofit organization and local government (NPO/LG), and a summation of overall responses for each reported benefit. 
Table 2.

Perceived Benefits of Rail-Trails and Greenways Ranked by Response

\begin{tabular}{lccrr} 
& \multicolumn{3}{c}{ Respondent Indicators } & \\
\cline { 2 - 3 } Reported Benefit & NPO & LG & NPO/LG & \\
\cline { 2 - 3 } Wellness & 7 & 3 & 1 & Total \\
\hline Economic & 5 & 4 & 1 & 9 \\
Safety & 7 & 0 & 0 & 7 \\
Recreation & 4 & 2 & 1 & 7 \\
Quality of Life & 2 & 5 & 0 & 7 \\
Alternative Transportation & 4 & 2 & 1 & 7 \\
Environmental & 4 & 1 & 1 & 6 \\
Topography/Accessibility & 3 & 2 & 1 & 6 \\
Connectivity & 5 & 0 & 1 & 6 \\
Social & 2 & 1 & 0 & 3 \\
Tourism & 0 & 2 & 0 & 2 \\
Planning/design & 0 & 1 & 1 & 2 \\
Education & 1 & 0 & 0 & 1 \\
Community Revitalization & 1 & 0 & 0 & 1 \\
\hline
\end{tabular}

I was curious about how participants would respond to this question, and assumed that local government might mention the potential for economic development that rail-trails and greenways might offer, and that nonprofit representatives would focus more on the social and environmental benefits of having rail-trails and greenways. Frequency of responses varied slightly, with more nonprofit participants citing "connectivity" and "wellness" as beneficial result of rail-trails and greenways. More local government respondents referred to rail-trails and greenways as enhancing "quality of life," which could be a more comprehensive phrase used to include more specific benefits like wellness, connectivity, and safety. One local government official suggested:

We want to be in a place that gives us opportunity to keep ourselves healthy and happy by recreating and the rail-trail is just a perfect example of that... [We want] quality of life in the broadest sense, and that includes housing, quality housing. See all of this, it's like one big crossword puzzle, or jigsaw puzzle, where you put one piece in and you say, 'oh my, I didn't realize.' And then before you know it, pieces just start fitting in over here and the whole picture. (M-LG) 
Using the phrase 'quality of life' could be suggestive of local government representatives' need to speak of benefits that are all-inclusive, rather than categorizing benefits more specifically. A participant noted that:

.... lot of times, people you'll be working with just don't demonstrate a lot of sensitivity to both sides of the project, and they just make assumptions that somebody doesn't want to help, or that they're difficult, or that they don't care. And it's not that, it's just that [local government representatives] have to care about everybody's everything. You have to find ways to, in facilitating, find ways to demonstrate to public officials and to government how your project is having a positive impact on the largest number of constituents. Because that's what they will respond to - how many people does this help. (C-NP)

This particular statement demonstrates how nonprofits that spearhead community initiatives might be frustrated that local governments do not 'see' the value in developing projects like rail-trails, when in fact the values need only to be presented in a manner that will illustrate that the project will yield the maximum benefits to a majority of the population.

A participant involved in a current rail-trail expansion project explained how individuals from nonprofit and local government sectors might view rail-trail and greenway development differently, but essentially want the same thing:

...this [rail-trail] is not for me...this is for my grandkids and the future and the quality of life. So there in itself is the motivation to say, 'you're on the government side of this area, and we're on the project wanting-to-have-ithappen side, we're talking the same thing here, we both want grandkids to have a better quality of life, we're talking the same thing here....we're on the same page, just different sentences.' (W-NP)

My assumption that more local government representatives would account for economic development incentives as a primary benefit was also dispelled. Again, participants from both sectors identified the economic benefits related to trail development in almost equal proportion, indicating that members from both sectors are indeed "on the same page" and might be closer to the same sentences than presumed. When asked to name benefits of rail-trails and greenways, participants mentioned the economic benefits:

Economics, the standard of your property values goes up a notch along the trestle. People want to live next to a park, and that's basically what a trail is, it's a linear park. (C-NP)

...the trail literally brings people to the area, and wherever you have people and those interchanges, there's economic development opportunity...it just continues to grow and creates jobs, services...it's becoming an economic engine. (M-LG) 
...parks and public open spaces are just so, so important. And I think that even links back into things like economic development. People are more likely to want to do things in communities that are pleasant... and then for employers...the healthier their employees are, the better off they are. So if these opportunities are available to them, I think its just more likely for it to happen. (W-NP)

One of the major differences in response to the question of benefits revolved around the issue of safety. Several of the nonprofit representatives cited trails as enhancing pedestrian and bicycle safety, while none of the local government representatives connected rail-trails and greenways with increasing community safety. Some of the nonprofit participants spoke of the actual increased physical safety that trails provide users:

[Where I grew up], finding safe places to play or ride were simple...I moved to Morgantown and realized pretty quickly that it wasn't the hills that got in the way, it was safe corridors. (M-NP)

It's safe, it's safe with less traffic. (C-NP)

...you know, safe, alternate routes for walking, creating walkable communities. (C-NP)

I think it gives people an opportunity to do these physical activity things with their family in a protective fashion, and it's just generally going to make it easier. (W-NP)

Others mentioned safety, but with more of a focus on the overall community safety that rail-trails and greenways provide as public spaces where once abandoned areas are receiving increased attention:

But what happens if you put a trail where a rail used to be, you do what you call 'daylighting'. Basically what you do is you bring people, and clear out the old tires and cut down the water weed and you open it up. And now something that was once very limitedly used....becomes a community greenway. (W-NP)

You know, the more people you have out there using [the trail], the more eyes you have down on the street. And we still have some pockets in this area that need to have more eyes on the street, and I think greenways, that's one way to be able to solve that. (C-NP)

Many of the categories that I developed from the data for "perceived benefits" are interrelated, and many participants immediately combined several benefits, although more specific in nature, usually related back to general quality of life: 
I think there's a number of reasons [that rail-trails and greenways benefit the community]. First of all for the overall health and vitality of the community. I think it encourages people to move and exercise without the use of their car. I think it makes them, by being on foot, appreciate the natural beauty of their community. In this case, the water, historical building, the mountains. And I think that then feeds into a higher opinion of where you live and a sense of well-being. (C-LG)

This participant first mentioned wellness, then referenced alternative transportation, and finally linked environmental to the overall quality of life, described as "a higher opinion of where you live and a sense of well-being." Another nonprofit participant responded similarly to the question of benefits:

The benefits? Sort of healthy lifestyles, to get people out and exercising and get them in touch with their outdoors, alternative transportation routes, which we certainly have a lot of problems [here] with traffic...families can take little kids out and it's a safe place to recreate. And a little bit of conservation. (M-NPO)

Again, the response to the question of benefits was somewhat similar between sectors. The nonprofit representative quoted above also mentioned wellness and alternative transportation, and further described potential safety and environmental benefits created through rail-trail and greenway development.

I interpreted the difference in response rate to be congruent with the nature of relationships developed between nonprofit organizations and local governments involved in rail-trail and greenway development. While more local government participants shifted their focus to the more generalized but explicit "quality of life" benefit that railtrails and greenways provide, nonprofit participants went further in developing specific "quality of life" benefits like "connectivity":

Particularly since these trails intersect so many small communities and neighborhoods, they provide a link from community to community. (M-NPO/LG)

Rail-trails in particular create great connectivity because that's what they were built for in the first place, connecting places where there were a lot of people and a lot of things going on. (C-NPO)

The coolest thing about rail-trails is in their connectedness...I mean, here's a park that almost everyone in the community lives within a half a mile of, and that's phenomenal. (W-NPO)

Most participants that mentioned "connectivity" as a benefit referred to the ability of railtrails and greenway to physically connect specific geographic locations, neighborhoods connected to other neighborhoods, parks and schools connected to neighborhoods, and 
areas of commerce connected to more residential areas.

Another type of connectivity mentioned was social connectivity. Comparing the rail-trail in Morgantown to a more traditional public gathering "commons," one participant explained that the rail-trail created "a public space where people could gather for all kinds of purposes" (M-LG). A Wheeling participant also spoke of social connectivity:

You hook a trail up, you have people on one ed of this town, passing the same familiar face, every other week or so, we start having social benefits of connecting those neighborhoods. (W-NPO)

Explicitly defining these social benefits as increasing social capital, a participant explained how rail-trails and greenways are social capital contributors:

...I see examples of social capital in both those communities. The more people are out, mingling with each other, the more they're going to trust each other, the more they are going to feel a commitment to the community, the more they're going to feel a link with that community. So, you see that all the time here on the trail as people are sharing pleasantries, they're getting to interact with each other. (W-NPO)

These participants speak of social connectivity and social capital on an individual level. Other participants also mentioned to existence of walking, running, and biking clubs and associations that frequently use the rail-trail, or are active in supporting rail-trail development. This evidence indicates a connection between rail-trails and greenways and social capital indicators like the prevalence of social groups that use the trails as a meeting place.

Connectivity could also be linked to quality of life, but I chose to separate the two because each was mentioned explicitly, and because I also wanted to demonstrate the specific aspects of "quality of life" as they were reported independently of one another. As revealed in the data, nonprofit organizations tend to engage in relationships with local governments and promote the development of rail-trails and greenways in the political realm by using more definable and distinct issues to demonstrate how rail-trails and greenways benefit people, the economy, and the environment. Local government respondents in this study reported benefits on a broader level, illustrating their position as "everybody's everything" and as being most respondent to projects that have a "positive impact on the largest number of people" (C-NPO).

\section{Perceived Costs}

Another factor that is revealing of why nonprofits and local governments form relationships, and the surrounding obstacles that they may have to face together when 
trying to develop or maintain a rail-trail, is how the players interpret the community's idea of the perceived cost of project development. Most respondents thought that community opposition or concern (perceived costs) related to the financial endeavor of trail construction and the lengthiness of projects:

One of the things we did...was to preach patience. There was an incredible impatience around the rail-trail. You know, these grants had come in, and people didn't understand why it takes so long, you know, 'they gave you $\$ 600,000$ ! Can't you start building the trail?' Well, no. (M-NPO)

The same participant went on to describe the skepticism that was present in the early stages of the trail planning process:

I mean, people thought that rail-trails were just silly. There's one local guy, a bit of a political and economic powerhouse locally, and he called it 'cotton candy'. When he talked to city council members about the rail-trail back then... he said, 'how much cotton candy do the people need to have?' Getting the money to build quality trails is tough and getting people to understand why you're building such a massive trail is hard too. (M-NPO)

This participant spoke particularly of the experience in Morgantown. Two local government representatives echoed his claims:

I know 15 years ago the whole concept of turning an abandoned rail line into a trail was not commonly accepted. There was a lot of skepticism, and some of those early projects really struggled. In fact, here in Morgantown, when we started ours...there was a lot of skepticism about the trail and its potential benefits. (M-LG)

City council in Morgantown tool a big risk with [the rail-trail] project... derisively, people said 'how many snowcones do you think you're going to sell down there on that river?' And Council risked really looking stupid and wasting precious dollars.... But it's yielded returns many times over. (M-LG)

If community members in Morgantown were uncertain about the idea of building a railtrail, they were soon reassured. The Mon River Rail-Trail system has become a success story, and has incited interest in rail-trails throughout the state. One Morgantown city council member noted that:

Morgantown has been so very successful, more than almost anywhere in the state of West Virginia. It's almost an island by itself... at one point, the city manager [of Clarksburg, WV] approached me and wanted to know, he would like the rail-trail to go through there. So it's an awakening, people are seeing what's going on in Morgantown. (M-LG)

A nonprofit representative from Charleston also noted the attention that Morgantown 
receives for the rail-trail. She described how Morgantown's experience with trail development could affect the way people in other communities view the benefits and costs of rail-trails and greenways:

I've noticed the way that what Morgantown has done is challenging Charleston to get up and be as good or better than Morgantown, on a variety of levels.... But if enough time passes and you're like, 'everybody is so crazy about the rail-trail in Morgantown', and it's just a huge community draw. (C-NPO)

In Wheeling, a different obstacle surfaced during a trail expansion project - the controversial issue of eminent domain. A Wheeling City Council member explained that "local government officials do not like to [use eminent domain], and they only do it as a last resort" (W-LG 17). The city eventually used eminent domain to acquire a small piece of property from a private land owner that was necessary in completing a section of the Wheeling Heritage Rail-Trail. One interview participant was involved in the eminent domain decision making process:

I testified in front of council regarding the value of eminent domain. [The] mayor said, 'very rarely do we have anybody coming in here saying that they want eminent domain. But...we did it. (W-NPO)

As both participants noted, local government is hesitant to get involved in the process of eminent domain. Since some rail-trail and greenway projects might require the acquisition of privately owned land, or a shift in thinking about the current land use and zoning issues, this comes as an obstacle that can be viewed as a cost.

However, local nonprofit groups are becoming involved in planning processes in order to educate local government leaders and community members about the benefits of rail-trails and greenways, sometimes working to diffuse concerns and opposition:

There's skepticism out there, you know, the cost, whether you could really do it, and blah, blah, blah, but we've been really successful at answering those questions and taking care of any kind of controversy that's come up around it. (C-NPO)

The same participant spoke at length about his continuous efforts to draw attention to the need for a rail-trail or greenway in Charleston. He also spoke of community opposition and the concern of project cost:

...there was an editorial in the paper a couple of years ago that said, 'it's nice that Andy ${ }^{13}$ wants to build a trail for his kids and his friends to ride on, but it's a big undertaking that will only benefit him and a few of his friends.' And that was the attitude. (C-NPO)

\footnotetext{
${ }^{13}$ Names have been changed to maintain participants' anonymity
} 
Reported perceived costs and benefits reveal how and why nonprofit organizations and local government develop relationships to further trail development efforts. Just as the above participant mentioned, community residents are often concerned about the cost of rail-trail and greenway projects. Local governments absorb those concerns, but sometimes rely on supportive nonprofit organizations to become community educators and to draw awareness to trail development.

The data supporting the findings in the following theme, "Political Environment" further develop the roles assumed and relationships built by nonprofit organizations and local governments in rail-trail and greenway development. Usually, I asked participants to describe the benefits of rail-trails and greenways at the beginning of the interview. This provided me with more of a context of the different dimensions of each person's experience and personal opinions about rail-trail and greenway development in their community. As I mentioned previously, this background illuminates the different aspects on which alliances are formed by attempting to clarifying why and how nonprofits and local governments form alliances.

\section{Political Environment}

Two of my central research questions were:

- What is the nature of relationships between nonprofit organizations and local governments? How do relationships form and function?

- What factors facilitate or constrain developing constructive relationships and in turn, the ability to complete rail-trail and greenway projects?

The theme of "Political Environment" is indicative of how, why, and under what circumstances relationships are formed between the nonprofit and local government sectors involved in rail-trail and greenway development. The emerging categories and subcategories related to the "Political Environment" theme represent a substantial portion of the entire findings section because they address two of my central research questions in depth.

\section{Alliance Formation}

One of the things apparent in all three communities was the willingness of local government to receive assistance from outside groups:

Oh, [nonprofit organizations] are very essential, we work with them all the time, we're always open to working with any type of group, totally open to working with any type of group who would want to get involved with the 
trail or anything else. (M-LG)

[A local health initiative group] that's available, they've helped us. They helped us tremendously when we just completed a gap project on the trail system. (W-LG)

... [certain individuals from nonprofits] have been great, they've been patient, you gotta have patience....and they have never been antagonistic, it's always been, 'let's sit down and figure this out.' (C-LG)

Participants from the nonprofit sector also displayed an understanding for the depth of responsibility that places restrictions in government processes that sometimes delay or prohibit project development:

Part of the problem in government is that you can no longer focus quite as much, and so now you have to answer all initiatives...I think some people can express themselves through a formal governmental structure, and others can do just as much, if not more, by staying outside of government. (W-NP)

You know, there's always been those who feel like the city has been slow to act on [enhancing pedestrian and bicycle transportation]. We have problems with our sidewalks and our crosswalks...I think the city is aware of these types of problems...I think most of their budget goes to roads and parking facilities which is all too typical of what happens in a city. But Morgantown has invested in that 51 mile trail and you also see that they're working with other nonprofits to make those neighborhood parks work better. (M-NPO)

These expressions of willingness and understanding from both sectors, for the most part, describe the general attitudes and opinions that nonprofits and local governments held with regard to their relationship. After speaking with all 23 participants, I sensed that relationships between the two sectors were generally amicable in all three communities. Since there seemed to be no language that would indicate conflict or hostility between the two groups, I began to examine the data to assess what reported factors facilitate or constrain the two sectors' ability to engage in partnerships and build effective relationships.

\section{Constraining and Facilitating Factors in Building Relationships}

Initially, when assessing the data that was coded to represent

"Constraining/Facilitating Factors," I attempted to place form subcategories that could be defined as either a 'constraining factor' or a 'facilitating factor.' After carefully reviewing the data and studying the emerging subcategories from coding processes, I realized that I would not be able to group subcategories into definable factors. In fact, I found that 
many of the subcategories were inextricably linked.

For example, I used "Nonprofit Organizational Capacity" to group findings suggesting that the organizational capacity of nonprofits was reported as being inadequate in some instances. Therefore, I linked "Nonprofit Organizational Capacity" to "Constraining Factors." However, the data that constructed another subcategory, "Nonprofit Ability vs. Constraints of Government Processes" indicated that nonprofit organizations often have the capacity to mobilize and gain support for project implementation because nonprofits are not required to operate under the same system that regulates local government processes. Consequently, I decided to present findings that contribute to the topic of "Constraining/Facilitating Factors" without distinctly categorizing factors.

\section{NPO as Educator and Resource Provider}

"Everyday goes by , more news gets put out about [the rail-trail project], more acceptance, then it's on their radar... we have put it on their radar, its in their subconscious... so it's an educational thing, time softens their stance just by sheer exposure of it all, whether by vicariously, or personally." (C-NPO)

One of the most commonly reported facilitating factors aiding relationship development dealt with the perception of nonprofit organizations as educators or resource providers. The following interview excerpt demonstrates how an affiliate of a nonprofit organization promoted trail project development by becoming an informational resource for local government officials and departments, effectively garnering political support for rail-trail and greenway projects:

...we could go to the city with our power point presentation and statistics and stories about how this happened in other places and say, 'we want you to help us make this happen in our community. And the only way any rail-trails get funded...is through transportation enhancement grants. That is funding that only government entities can apply.... So we had to convince the city, the city had to say we'll accept responsibility for following through with this. And you know, the leadership's been really farsighted on this, they really have. (C-NPO)

An interviewee that works for the City of Charleston planning department also noted the importance of educating local officials, and mentioned the vital role that nonprofits can play in disseminating information and creating awareness that might lead to action:

A lot of times [nonprofit organizations] are the ones doing a lot of the work, furthering these plans and having their support. They're out there creating that buzz on the street and talking to council members and mayors.... The educational component is going to get the politicians behind it. (C-LG) 
One Charleston nonprofit was also engaged in facilitating a series of 'think tanks' to generate public awareness regarding sustainable planning principles, and included a rail-trail specific workshop:

We've done a series of think tanks where we've covered, we had one on walkabiltiy... we had one on Smart Growth, which ultimately came back around to walkability. We did a rail-trail one, which tied back into, whether the public knew it or not, which tied back into the Smart Growth and the walkabilty ones that we've done over the past few years. So we've kind of wet people's appetites. (C-NPO)

Nonprofits that work to promote rail-trail and greenway development naturally elevate the awareness level of sustainable planning and design principles, since the two can be so easily linked. By educating the public and local government officials on these issues, programmatic efforts (i.e., workshops, think tanks, etc.) begin to affect the way people think about the built environment, and may effectively contribute to policy that positively enhances the built environment through infrastructure change reflecting sustainable design principles. Nonprofit participants explained the role of community nonprofits as they work in coordination with local government officials that might seem slow to accept or implement policy that contributes to trail development, or general walkability:

People, by and large, are doing the best they can, and so respect them, help to educate them. You know they say that there are two reasons why people don't do a good job. One is that they don't know what is expected of them, and two is they don't know how to do it. So we've got to help with the two. (W-NPO)

You just have to respect the fact that [local government representatives] are doing their job the best way they know how. And you know, just give them time to look at it and answer questions if they have any. Be there as a resource for them because they don't have to time to look that all up or the interest. (C-NPO)

The ability of nonprofits to act as educators to the public and resource providers to local officials emerged as one of the most critical facilitating factors relationship formation between nonprofits and local governments. Where nonprofits can assume the task of researching, analyzing, and presenting the benefits and costs of rail-trail or greenway development to a community, local government can be relieved of these often tedious tasks. My findings suggest that nonprofits as educators and resource providers, by supplying reliable information and consistent support, foster and strengthen relational ties with local government. 


\section{Nonprofit Organizational Capacity}

The nonprofit participants I interviewed came from a variety of backgrounds. Affiliations included organizations like rail-trail and park-specific advocacy groups, land trusts, neighborhood associations, and community health initiative groups. Each organization is devoted to a specific cause, whether it's advocating healthier lifestyles, or responding to the needs of a defined geographic location. All of the organizations represented in my study have different goals and objectives, but are similar in their dedication to creating more livable communities, which includes pursuing opportunities for rail-trail and greenway development.

As I discussed in the literature review, local governments increasingly rely on nonprofit organizations to assist in the development of programs and projects that provide for the general welfare of the public. When nonprofits have the organizational capacity to effectively carry out programs and assist with project development, their relationships with local government can continue to grow and develop. However, many nonprofit organizations do not have much financial backing, usually rely on the support of volunteers, and have little (if any) paid staff to dedicate to their cause. One participant noted that a barrier to fostering working relationships with nonprofits stems from insufficient capacity:

Sometimes I see prejudices toward nonprofits that are well intended organizations that have to struggle to produce a tangible product. And certainly very often, nonprofits do have fiscal constraints, they don't have all the money in the world like anybody else, but there's a prejudice that they just can't deliver the product in a timely way. (M-LG)

Another participant cited organizational capacity as a barrier to working with nonprofit groups, especially those that are primarily volunteer-driven:

So if you don't have a paid staff person and you have a lot of volunteers, a lot of times you don't know who you're taking direction from. Because you've got people calling in from that nonprofit group, telling you or asking you to do one thing, and you don't know if this person has the authorization to do that or not. (C-LG)

Participants from a Morgantown nonprofit mentioned a method in capacity building as a by-product of the actual structure of an organization and its administrative procedures:

Once you've created these boards and commissions, you need the resource of how to manage a nonprofit board as a business. It needs to be managed as such. There needs to be a plan for infusion of new board members, new blood.... I understand there's a mission you're after, but 
you've got to manage the group of people who are there. (M-NPO/LG)

We've held hard and fast to our bylaws since we incorporated...and I think that's been a testament to our success. If we allow someone, just because of their stature, to bypass the bylaws, we have the potential to crush ourselves. (M-NPO)

The concepts of nonprofit board or committee management and employing standardized administrative procedures seems to also relate to an organization's ability and capacity to successfully collaborate and engage in partnership with local government.

The current management agreement for the Mon River Rail Trail system was a result of the way the local trail conservancy maintained the capacity to build strong relationships with city and county governments. I use Morgantown as an exemplar of how a nonprofit's organizational capacity contributed to a formal public-private partnership to manage 51 miles of rail-trail, because it is the only instance of this type of relationship in my study, and in the state of West Virginia:

The city [of Morgantown] now, they maintain the stretch of trail that's within the city limits and then the outskirts, which is still 43 miles of trail, we have a partnership...that is a city and county and nonprofit agreement to help maintain the trail. And that's a very new development that has been incredibly crucial because as we started to get more and more miles, we couldn't maintain it with just volunteers. (M-NPO)

I think that the [Mon River Trails Conservancy] has always been on the forefront as modeling, how this might works, how might we take a nonprofit and combine it with city and local governments.... So we've actually developed a model that now serves as protocol for the rest of the state. (M-NPO)

The Mon River Trail Conservancy, by way of systematically and strategically forming a governing board and a set of by-laws were able to form solid relationships with local government. A working knowledge of local government processes was also mentioned as a vital component to building organizational capacity, as well as an understanding of how to extend partnerships beyond local government to achieve objectives:

...it's fine to get together a group of interested people, but if they don't know how the system works, they don't know about public meetings and council members and county commission members and how important it is to get their ear. (M-NPO/LG)

This participant went on to explain the dynamics of the MRTC board members:

From the beginning, there was always a core group of people who had a firm grasp on how public they needed to be and how involved they needed to be, how they needed to partner, not just necessarily with local 
government, but the chamber of commerce has been significant...the convention and visitor's bureau also. (M-NPO/LG)

Discussing the role of neighborhood associations, a local government representative also spoke to the value of a group's familiarity with government processes as enhancing their capacity for involvement in decision-making and other initiatives:

Neighborhood associations are really critical to making communities vital and sustainable. But in order for them to be an integral part of what's going on, they have to understand something about how city government works, they have to learn patience, they have to find leadership that will help them focus their initiatives and follow through. (M-LG)

This comment reflects the association between nonprofit organizational capacity and knowledge of local government processes. A city council member from Wheeling also noted the importance of local groups being involved in government processes, and explained the disconnect between a local group's effort to promote rail-trail expansion and local government awareness:

...maybe we should invite [nonprofits or affiliated community groups] them [to council meetings], or maybe they should invite themselves. But if they were acting in a quasi-government capacity, an advocacy capacity, and somehow reported to somebody so that they said, 'hey, here's this need that we perceive, and would you work it into your city plan,' it would be a lot easier. But frankly we don't know what they're doing. (W-LG)

The Wheeling Heritage Rail-Trail was purchased, developed, and is currently managed by the city, and there is not an existing trail advocacy nonprofit organization. The local group promoting trail expansion grew out of a task force affiliated with a health initiative nonprofit organization. The comment above reflects the trail expansion group's needed capacity to operate within the local government legislature.

Organizational capacity affects other factors that contribute to how relationships between nonprofits and local governments form and function. An organization's capacity might also affect its ability to strategically partner with local government or other nonprofits, which will be discussed later in more detail. Although organizational capacity could either be a facilitating or constraining factor to developing relationships, another factor, simply the ability of nonprofits to act outside of the constraints of government rules and regulations, becomes a very important facilitating factor in relationship building between nonprofits and local government. 


\section{NPO Ability vs. Constraints of Government Processes}

"I think one of the other unappreciated things about nonprofits is that they have considerable more flexibility than the government to accomplish public goods." (M-NPO)

The nature of government processes and structure as being confined to regulatory measures put in place to "safeguard public resources" (M-NPO) was also an evident factor in effective relationship building. Participants from both sectors mentioned the potential of nonprofit organizations to assist local government in advancing project progress. The consistent assistance that some nonprofit organizations can give local government is translated as the persistent, patient driving force necessary to see rail-trail and greenway projects completed:

Start building relationships and... always cultivate relationships and slowly building the trust with the facts and figures and your known commitment to the project. Because your project will die and lapse as soon as the promoters go away. You're never going to, and l've seen it happen before with other projects, people have a ground swell, they're just a bunch of volunteers, they bring the project to the City, and the city loves it, the county loves it, the community loves it. And they say we're going to do it, and then those people go away expecting the city to do it or the county to do it, and its never going to work that way. Those people are busy running their city, community, county, whatever. Albeit your project is wonderful, they've already told you that. They want you to hand it to them. And that's how it gets done. The volunteers never stop. And then once that first project's done, you show your capacity for success, you're excited because you're actually on it and using it, you see kids using it, then you go to the next one. (C-NPO)

This statement underscores the value of nonprofit organizations that have the ability to be consistently devoted to a project, through the planning, development, and continued management stages.

Local governments operate under an enormous amount of controls and regulations that sometimes restrict efficiency in decision-making and project implementation. One participant described how nonprofits' ability to act outside of regulatory measures was a facilitating factor in relationship building:

But the nonprofits do not have those limitations, so very often they can produce public and quasi-public programs and services in a much more efficient way. And because of that, there's a great opportunity for partnerships between the public and nonprofits to create these public goods and services. (M-LG)

When participants referred to the constraints of local government processes, I often asked probing questions to gain a better understanding of the different factors that 
contribute to the restrictive operational structure of local governments, and also asked participants to suggest methods that might alleviate those factors. The topic of public office turnover surfaced as a factor that contributes to facilitating or constraining relationships between local government and nonprofit organizations. A participant illuminated the strength that exists in a nonprofit's ability to remain consistent while government make-up always has to potential to change:

The great thing about [a downtown revitalization nonprofit organization], is that its consistent, it was always there, didn't matter who was the mayor or city council. ...to do that [a downtown rehabilitation project] you needed people that were year in year out advocating this. So the consistency of their message and over the long term you can, if you're diligent enough, you have to be patient, you can educate people, even people who come in cold. (C-LG)

Another nonprofit representative expressed the same need to maintain a consistent effort over time, explaining that "...year to year you're going to have different people elected, so you're always going to have to keep that communication going" (M-NPO). Completing projects while there are elected officials in office that are dedicated to enhancing communities is also a concern of individuals from both sectors involved in rail-trail and greenway initiatives:

The biggest problem is consistency. And if you have a strong mayor form of government in a city, you have people going in and out of who's mayor, then they each have their own different priorities. And my point is, that if you've got one guy in there, who's there for 8 years, 10 years...its easier to implement ambitious change of heart. (C-LG)

...it's like having the right people at the helm who are ready to make these decisions and to bring a lot of other people with them who have their own history of making good public decisions.... I can't tell you how many times people have said to me, 'we have to hurry up and get that done while [the current mayor] is mayor'...because people know when he's not there, you don't know, you can't count on it. (C-NPO)

These statements reflect that the ability and capacity of nonprofit organizations to act within government and build relationships may be dependent on who holds positions of power within local government. This notion is explored in greater depth under the category "Leadership."

Three different local government representatives also suggested 'home rule'14 as

\footnotetext{
${ }^{14}$ The Ohio Legislative Service Commission describes municipal "home rule" powers as including "the power of local self-government, the exercise of certain police powers, and the ownership and operation of public utilities." (http://www.Isc.state.oh.us/membersonly/124homerule.pdf) States like Ohio, that legislate for municipal "home rule" give more decision and policy-making power to individual communities. Currently,
} 
a change in state legislation that could enable municipalities to make decisions and implement policy that is more locally focused:

....in West Virginia, unlike many other parts of the country, local governments are severely constrained by state laws. The common phrase is home rule, and it's the absence of home rule in West Virginia that places a lot of barriers for public improvements. And at the core of home rule is the flexibility to finance these project, to be able to pick and chose revenue sources that make sense for the local area. (M-LG)

I'm a proponent of home rule, it's like [the state] enabling municipalities to do their own thing...it's to give more power to municipalities, or even counties to let them make decisions on issues. (M-LG)

I think the state of West Virginia could, by giving some prerogatives to cities, enhance a good it of what's happening locally. Because if a community feels like, if we have the opportunity to raise taxes for ourselves for certain initiatives, we could do that, rather than waiting for the legislature to make it possible. (M-LG)

These statements suggest that home rule could enhancing local governments' ability to aggressively pursue revenue sources and allow for policy that could enhance development initiatives and projects like rail-trails and greenways, perhaps affect the way in which local governments engage in partnerships or collaborate with nonprofit organizations.

\section{Strategic partnering and planning}

"...you need to connect with the people who are in place and say that this is an investment in what they care about, in what they're already doing.... And I do think that even just with a small group of people I think you can start to see the plan, and if you get the agencies involved, you've just increased your ability to make it happen..." (M-NPO)

One other emergent category related to factors that constrain or facilitate alliance formation involved the ability of both sectors to identify potential partners and strategically form relationships, and to methodically plan and prepare for project development. With regard to strategic partnering, participants expressed the need to identify potential partners that could contribute to their overall goals, whether it was between or among the nonprofit sector and local government sector. A member of the Mon River Trails Conservancy described the evolution of the group's partnership efforts:

We've always had a very involved and strong base with the city of Morgantown...initially, the nonprofit formed by starting to sit in and become involved in city meetings like the beautification committee, the transportation committee with the city. So we worked within that realm

West Virginia does legislate for municipal home rule. 
before the nonprofit formed, even the Convention and Visitor's Bureau was critical in purchasing the corridor. And then the nonprofit formed kind of as a result of how the city saw this working. (M-NPO)

Receiving a sizable grant from a local community foundation nonprofit was one of the needed funding catalysts for the development of the Mon River Rail Trail system. A local government representative mentioned the importance of considering all partnering possibilities:

Thoughtfully look at the community and what its strengths and assets are and where the real opportunities lie, and don't overlook a single potential partner. For example, don't overlook the nonprofits, don't overlook the private foundations. Private and state grants are not the total answer to everything. Cooperation and trust, good inventory, being creative, and willing to take a risk. (M-LG)

Another MRTC member also mentioned the significance of the foundation's grant in acquiring enough funds to begin rail-trail development, suggesting that "... if the local government doesn't have [the funding source], there are people out there, you just have to be really methodical about finding who those people are" (M-NPO).

An associate with a nonprofit in Charleston that spearheaded a greenway planning initiative and a city council member went on to discuss how relationships are strategically developed:

I think participation in their process to ask them rather than tell them what you want to do and maybe say, 'here's our big picture goal, tell me now how I can best use our relationship with local government to make that happen'...get some direction rather than always directing, I think is good. (C-NPO)

I always tell people, you want to be so integrated into city hall, county commission that you're almost viewed as a part of the city government... the best thing would be if you already have this committee is to sit down with the mayor or city manager, whatever type of government it is, county commissioner, and ask, 'we've got this initiative. Can you at least have someone from your administration come to our meetings?' Now if you meet every day, they're not going to be able to do it, but if its once a month for a couple hours, that's the way you get buy-in. (C-LG)

A trail expansion project spurred a local group in Wheeling to also consider how to logistically assess the depth of the project, and one participant explained that "we're not trying to get it all done at once, just piecemeal it together" (W-NPO). Although the group has extensively developed a plan for trail expansion, one city council member explained that they were not, to his knowledge, engaged in local government processes:

[The city council] never get minutes of their meetings, we don't know what 
they're doing unless they pop up and make a presentation, which we appreciate very much, but we have not been able to get them plugged into the process kind of as our needs assessor. (W-LG)

A city council member from Charleston also noticed the need for a local nonprofit working on greenway development to be more detailed and methodic in their efforts to present project proposals to city council and administration:

I think their intentions are good, I think where they're having a difficult time is articulating what they really want to try to accomplish...if they truly want to accomplish things they're going to have to really identify not only where potential trails are but how you bring them into being. (C-LG)

Both local government representatives demonstrate that nonprofits must, to the best of their ability, create a fully developed strategic plan for their proposed project. This suggests that strategic planning must accompany strategic partnering efforts in order to facilitate building effective relationships.

Participants from both sectors proposed the idea of 'trust' as a facilitating factor to building effective relationships. I interpreted their discussions of trust as it related to organizational social capital. Discussions about 'trust' could be inferred as an indicator of Putnam's theory of social capital, based more on an individual level. However, I saw a connection that was based more on organizational social capital, especially as it applies to strategic partnering.

When I asked participants to explain how effective relationships between sectors are built, some used phrases like "develop trust" (M-NPO/LG) and "build good will" (C-NPO), and suggested the importance of developing relationships through personal contact. Referring to local government's efforts building trust with other sectors, one participant advised:

...its just not easily done. It's common sense and it's fundamental, but you don't just walk up to somebody and say, trust me. You do it by deeds, and very often it's just one small deed after another that builds that relationship. It's like putting a penny in a penny bank. Well, a penny's not worth much, but you do it long enough, you're going to create something of value. (M-LG)

Nonprofit organizations that can become educators and resource providers to local government strategically partner and build effective relationship through those small deeds. A participant that is deeply involved in rail-trail and greenway development in Charleston discussed the different 'deeds' that lent to developing effective relationships. He described the outcome as being indicative of social capital by alluding to reciprocity: 
I've been seeing some good results [of efforts to cultivate relationships]. To where, when something comes up, [local government officials] come to us. It shows the maturity of the relationship when that happens. (C-NPO)

Factors that facilitate effective relationships between nonprofits and local government appear to contribute to organizational social capital, which in turn promotes and supports the development of projects like rail-trails and greenways. Having a unique dual perspective through his involvement with local government and the nonprofit sector, one participant extended the notion of social capital as positively contributing to project development:

If somebody walks in[to a room] and you know them, it's a lot easier than if somebody walks in and you've never seen them in your life. My job, I thought, as [a nonprofit] director was to get on a very personal basis with the governor, with the city manager, with the county commissioners...if you can call them and they'll take your call right away or see you right away, you're so much ahead than if they've never heard of you and that type of thing. So it's personal relations I think that is really major in accomplishing that type of thing. (M-NPO/LG)

Many of the participants mentioned building "personal relations" and alluded to one-onone interactions as being an important aspect of relationship building. Although these invoke characteristics of social capital on an individual level, the intent of individuals that represent a nonprofit or local government entity is to develop personal relations to further the goals and objectives of an organization:

The bottom line is, if nonprofits can trust city government, and government can operate in a way that enhances the public good in the broadest sense, then you've got a basis for taking things forward on almost every project. (M-LG)

\section{Community Involvement}

"It's a classic example of how government is supposed to work. You think of an idea, you announce to everybody, 'come and tell me what you think, I don't care how crazy.' Because you've got to hear the crazy ones so that you know the sane ones are sane." (C-NPO)

Most of the conversations I had with interview participants, at one point or another, focused on community involvement. Although most of my question were directed to address the larger social structures of government and organizations, participants responded by expressing the ideals of participatory democracy and Putnam's idea of social capital; civically engaged people produce good governance. The opening quote to this section reveals the importance of community involvement by 
explaining that it is "how government is supposed to work."

At the most basic level, community members are involved in supporting a rail-trail simply by becoming users. Sometimes, getting community support may not occur until the trail is built:

But we had any number of skeptics and the skeptics really outweighed the optimists really for a long, long time, even after [the rail-trail] was paved. But once you had it paved and people went down there with their bicycles or just to walk, and realized, oh look at this river, it's beautiful, then the work began to pass. And then you really begin to get community buy-in. It's not just buy-in, it's ownership. They take ownership of it. Success builds on success. (M-LG)

Community buy-in was also described as 'broad-based support' and positioned as a necessary component to enabling rail-trail and greenway development:

I think one of the major factors in promoting and enabling trail development in any community is a broad base of support. It's just important to have the community involved. And if you had the city council and the county commission wanting to do these things, they can only go so far as they have the community's support to go. And so I think that's just something that can never be overstated. (W-NPO)

When participants mentioned the importance of community support, I asked what methods were effective in receiving input and engaging community members.

Responses varied, including the ability to address community needs by relating how the variety of benefits of rail-trail and greenway development affects the range of diverse community members,:

I think the most important thing for the groups to do is to get local support by talking about how the thing they want to accomplish will help ordinary citizens in the town.... There are just so many things that other people will recognize as valuable. I think that people who feel strongly about one particular issue sometimes don't try to step back about it to see how other people could support the thing they care so strongly about. You won't get the support unless you do try to say, 'how can this be valuable to people who aren't like me?' (M-NPO)

actively recruiting a large variety of community members to participate in planning processes, while being conscious that support might dwindle, but remaining steadfast by continuing to involve as many people as possible,:

I would say, cast a really wide net when you first start, there's really no such thing as inviting too many people to the table. And then keep everybody informed, but be ok with the fact that not everybody is going to follow this all the way down the road, and that your most invested leaders will show themselves and its not a failure if you have a meeting and only five people come, but if you have five people and they're the right five 
people you can make decisions and put it back out to all the people who first said they were interested. (C-NPO)

and finally, engaging community members through a participatory planning process, where a group of interested individuals are involved in examining a particular issue through an organized forum over a period of time:

...I think if we can start out doing some participatory planning, we're just more likely to spawn the whole realization that people can get involved...through participatory planning, we're able to involve people beyond our reach and scope. (W-NPO)

Community involvement in rail-trail and greenway development varied between communities. In Morgantown a group of residents interested in rail-trail development pushed the issue in the community, formed a nonprofit organization to operate as an advocate for rail-trail development, and until recently, independently maintained and managed 43 miles of rail-trail outside of city limits through volunteer-led effort. The public-private partnership formed between the City of Morgantown, Monongalia County, and the MRTC is a new collaborative arrangement to manage the 51 miles of trail. The local government entities have dedicated funding, on a year to year basis, to maintain the rail-trail. One participant remarked that, despite the previous completely volunteerled effort to maintain the trail:

...[it] is somewhat hard to get good volunteers, there's a lot of, one of the downsides, I think, to getting money is a lot of people step back and say, 'county's taking care of it now, we're outta here!'...it would be nice to continue to have volunteers who say, well, l'll come out and work on this project...(M-NPO/LG)

The experience of Wheeling local government has been somewhat similar through out the entire process of planning, building, and managing the rail-trail. Since local government was totally responsible for the development of the Wheeling Heritage Rail-Trail, community involvement has not been as much of a necessary function of the trail's management. A Wheeling city council member explained that one of the benefits of the way the Heritage Rail-Trail was developed is that there is dedicated funding, since the city owns and manages the corridor. However, he mentioned a drawback to the trail's sustainability:

....in exchange for the sustainability, we gave up that stakeholder feeling and so nobody takes care of the trail, and nobody's asking for more.

(W-LG) 
Later in the interview, he explained that there was little community support for the trail in the beginning phases of construction, and he did not notice a change in the level of community involvement to date.

Another Wheeling participant that I spoke with had been involved in a citizen-led effort to promote the trail when it was first built. He explained that the group's effort waned after trail construction was complete:

But then like I say, it all dropped off. And I think part of it has to do with the fact that the trails are there, so nobody thinks they need [to be involved] anymore, you know, what do we need to do? Trails are there, we don't have to do anything, the city maintains them, nobody helps out. Why would we have to have a meeting about the trail? (W-NPO)

To contrast, the City of Charleston is taking a more active approach to involving local residents in planning efforts, and promoting awareness on issues like walkability. An interview participant from the planning department explained the city's efforts to become more involved in neighborhood associations:

I think with how we're getting more plugged into the community, we're doing a better job of that. And that's what we're trying to do with these walkable communities, sustainable communities, smart growth and these things is to start to preach these to the neighborhood associations and get them educated. So they're starting to have a better idea of what kind of design and activity they want. (C-LG)

The neighborhood associations mentioned are nonprofit organizations that were formed so that the city planning department could, as this participant explained, become "more plugged into the community."

Community involvement efforts stemming from local government and nonprofits promoting trail development were indicative of social capital. One nonprofit group realized the value in communicating their efforts with the variety of civic organizations in addition to local government: “...we went to neighborhood association meetings, we went to church group meetings... and city council meetings, and all of the [city] commissions" (M-NPO). Another participant expressed the importance of engaging the public in project development, and suggested that public participation and community involvement efforts were not simply methods of dissemination and education:

My colleague...makes the case that people don't join groups, they join people. And so it's those relationships that help people sometimes to leapfrog over the data. And so I think the data is important. But I also think that we must spend time developing relationships with people. (W-NPO) 
Another participant reflected the same idea when describing why community-led initiatives form by stating, "people want to belong to people" (M-NPO). Nonprofits and local government entities that can work together to provide opportunities for community involvement and public participation in rail-trail and greenway development may also be provide opportunities to increase social capital.

\section{Leadership}

Rail-trails and greenways would not exist if leaders did not emerge to guide the various phases of development. One participant remarked on a quality of leadership, attesting that "you need a catalyst kind of person, you need the entrepreneurial spirit to make things happen. If you don't have that spark, it's not going to happen" (W-NPO). Indeed, during most of the interviews, people spoke of individuals and groups with leadership characteristics as driving trail development; the qualities of individuals or groups that manage to "make things happen" were depicted as one of the most integral components of developing relationships between nonprofits and local government

Two reoccurring observations that formed the "Political Environment" theme and contribute to the idea of leadership were relatively individually based. The idea of leadership emerged when people referred to community-led efforts, or initiatives spearheaded by an individual or group from a nonprofit. When asked, "what are some of the key factors enabling trail development in your community?" responses revealed that leadership was an important element:

I think behind any effort you'll find individuals who are the torch carriers, so to speak...the difference between having [an abandoned rail line] being converted over [to a rail-trail] or not, may just be that there's no personality, or there's no group that is willing to go and take that on and finish it. (W-NPO)

First and foremost, you need a champion, and a group of champions. And those exist in every community and they don't always have to be the same people....but you do need some glue I think to make things happen. (W-NPO)

l'd have to say the people are number one. The volunteers, the people that serve on the board, they either make it happen or it doesn't. The city's money is important...but clearly the dogged volunteers who meet month after month after month...(M-NPO/LG)

Many conversations that I had sparked my curiosity about civic engagement and becoming politically involved. I wondered, do those who emerge as leaders on the nonprofit side of a project ever feel that their efforts would be more effective if they 
became formally involved in local government? I asked one nonprofit participant, who had been identified by others as a "champion" of rail-trail and greenway development (one participant even called him the "King of Greenways") if he ever considered stepping into a different leadership role by running for public office:

...the mayor's even asked me [if] I'm running [for public office], and I go, "no." Because if I ran, then I would run for council in my ward. The I would be devoted by the fact that I got elected by these few people, to take care of them. Now, I can go to [other neighborhoods] to do projects, I do projects downtown...[so] I would look at it as being very restrictive if I got elected. (C-NPO)

His comment reinforced the earlier emerging concept, that nonprofits often have increased ability to pursue rail-trail and greenway projects because they can be devoted to one particular cause. To this participant, changing leadership roles would be restrictive because he would have to represent a large number of constituents and focus on a very wide range of issues.

In addition to community champions, a participant also recognized that "having the governmental structure, the correct people in government... who can help make those things happen" helps support trail development (W-NPO). Distinct from the "champion" designation, the subject of city administration leadership was often brought up in regards to the personality of a mayor or city manager. A local government representative verified the significant role that mayors and city managers play in enabling trail-related projects:

It's going to vary from town to town, depends on who you talk to. It all depends on how the mayor or city manager structures their administration. Some of them, everything has to roll through their office, and others are more delegators, there's no golden rule. (W-NPO)

Operating under a "Strong Mayor" form of government, administrative authority is granted and carried out by a mayor elected through a popular vote. Charleston participants were also very vocal about the current mayor's leadership and support of community rail-trail and greenway initiatives:

...I was very excited that we got with this mayor who gets it, gets what communities can be, who is very widely traveled, a lot of this has to do with seeing what is happening in other parts of your country. [The mayor] gets it and understands it, intuitively and also through his travels. (C-NPO)

The biggest factor [enabling trail development] is the mayor. The mayor is such a strong leader in walkable communities... without his support, this [riverfront] planning wouldn't be here. (C-LG) 
Morgantown operates under a "Manager Plan" form of government. The leadership qualities of the Morgantown city manager were spoken of as a catalyst for the development of the rail-trail, especially in securing the funds necessary to purchase the corridor and begin construction:

Because it was [the city manager], very quiet, very efficient, very smart, very understanding of how municipalities work... and before you know it, here's $\$ 250,000$ from the [Hazel Ruby McQuain] Foundation that said, 'you can make this happen, we're behind you.' (M-LG)

I talked about [the city manager] being the individual who had the vision and the fiscal power and knowing how to parlay small grants into larger grants to get the maximum use of the money. So through [the city manager] and his support by city council, I think an awful lot of this trail system came into existence, he certainly deserves a lot of credit for it. (M-NPO/LG)

The importance of trust was reiterated with regard to the role of the city manager:

... [the city manager] said if we can not create trust in city government, we'll not accomplish anything. And that to me, well, it's a real eye opener and a very optimistic signal, because it was not simply about money or politics, it was about a very basic thing that makes communities come together and stay together, trust. (M-LG)

This complements other data suggesting social capital as a facilitating factor in building relationships. Those in leadership roles, whether in local government or the nonprofit sector, might have the ability to nurture relationships by social capital

Wheeling has a "Manager-Mayor Plan" of government. Like the city manager of Morgantown, the city manager of Wheeling holds administrative authority and manages the city's affairs. A participant working with a local group to address trail expansion spoke of the accessibility of the city manager:

I developed a relationship with [the city manager], and he's a great guy... [he] is just the kind of guy that if somebody is willing to do something, he's not going to deny them that, he's going to give them every opportunity....he's never pushed me, always encouraged me, and he's never been rude. (W-NPO)

Later, this participant explained that the city manager was critical to the trail expansion project because he was instrumental in convincing the city to maintain the rights-of-way of all abandoned rail corridors considered for trail development, rather than selling the property to generate revenue for the city. 
The idea of leadership was not strictly defined or described as stemming from local government administration, or community champions, but extended to include programmatic efforts. A program in Morgantown ${ }^{15}$ provided guidance for creating a vision and plan to foster community development. A former director of the program explained why the program was essential in developing cooperative, supportive relationships between all sectors of the society:

...the concept of the [visioning program] was that its important for a small community, or any community for that, to work together. And we found that individual nonprofits, or individual anything, by themselves couldn't accomplish too awfully much because they didn't have the financial resources, they didn't have the volunteers or the people power, and they couldn't achieve the kind of results that are happening in this community that have been achieved. Because through the cooperative efforts of nonprofits working together, and nonprofits working with the business sector, and nonprofit and business working with government, putting those three together...I think is really the reason for the results that we're having in the Morgantown area. (M-NPO/LG)

Familiar with the vision program implemented in Morgantown and the guidance it provided the community, a Wheeling participant observed it as a factor that set Morgantown apart from other cities:

Enough can't be said about Morgantown's Vision [program] and the trail project that came out of that initial project...Morgantown definitely has head and shoulders above other communities....in terms of their long term plan, their long term vision in getting everybody at least to play nicely together in the same sandbox. (W-NPO)

The collaborative visioning process enabled all sectors of the community to work together, to create a comprehensive plan for community development. This programmatic effort provides a venue for different leaders in the community to converge on the different issues they support, and in essence, find ways to partner and support each other. At least one participant from each community mentioned the value of visioning programs as providing leadership or a guidance. These types of efforts may even enhance the nonprofit sector's capacity, as organizations network, share resources, and become more "plugged in."

\footnotetext{
15 The Vision 2000 program was facilitated by the Morgantown Area Chamber of Commerce. Developed in the early 1990s, the program included the involvement of over 200 volunteers from the public, private, and nonprofit sector whose directive was to compile a set of objectives and recommendations to enhance community development as to make Morgantown a "showplace community." The project was so successful that it continues as a visioning tool for Morgantown (under the new name, Vision 2020) and other communities throughout the state.
} 


\section{Built Environment}

There were several ideas from the preceding major themes that are also reflected in the "Built Environment." For example, one of the most reported perceived benefits of rail-trails and greenways was "wellness." Participants discussed how railtrails and greenways provide places for people to recreate and exercise. The topography of West Virginia, as one participant explained, can be restrictive for people who are can not handle strenuous physical activity, but need to remain active nonetheless:

But in our communities it's so difficult to find a safe place to walk and ride because of the topography, lack of sidewalks. Even if you have sidewalks, just having an uninterrupted trail to walk on with a steady grade and it's not a steep hill, is much more attractive for a larger number of citizens... rail-trails are nice and flat, a lot more attractive. (M-NPO/LG)

Rail-trails and greenways are appealing to users at every level of physical fitness, especially those who need to incorporate physical activity for wellness, but are not able to strenuously exercise. A participant that developed a health initiative to use a media campaign to address the obesity and health epidemic in the state described a realization that he made during the program:

Through that campaign, it really helped me to better understand the relationship between public health programming and then policy and environment. I mean it just hit me smack in the face...we're promoting fitness and people are saying, 'hey, there's no place to walk in my neighborhood!'...We can only do things which the environment permits and reinforces. (W-NPO)

This participant suggests that if the built environment is prohibitive to pedestrians and bicyclists, people are less likely to walk and bike where they live.

Community involvement is critical to the development of the "Political Environment" theme because it describes the processes by which community members become civically engaged, and contribute to the processes of decision and policy making. Community involvement in rail-trail and greenway development is also linked to "Built Environment" because it is how the community contributes to "planning processes" and becomes informed about "planning principles and design."

One of the very first things that happens in the process of trail planning and construction is for someone, or a group of people, to be aware of their built environment. A person notices inactive rail lines and begin to think, "what if?" This attention to physical surroundings might encourage the person to ask questions and begin a mission 
to transform the underutilized resource into a community asset.

A Charleston participant commented that attention to the political geography of a place is essential in evaluating a course of action in rail-trail planning:

...from the outset...look around about where this trail is in the community and find out who is going to be impacted and start really with those people. Because if [the trail] is coming, you know somebody from [one community] decides that there needs to be a rail-trail through [another community], and doesn't include them in the planning, by the time they hear about it, they're going to be resistant from someone from the outside coming in and trying to change their community. (C-NPO)

This kind of consideration is necessary for nonprofits and local governments in the initial stages of trail development and is tied to relationship building factors. When nonprofits can be educators, researchers, resource providers, they can contribute to partnership building between local government entities, across political boundaries.

\section{Planning Processes}

The planning processes described by those that I interviewed revealed something about the extensive and lengthy nature of rail-trail and greenway development. One participant commented on the extensive process of corridor acquisition:

It does take a lot of, like even more than the construction money and time, it takes a lot of time just to make that purchase happen and get agreements from land owners if its going through private property and you really do need to have people with a legal understanding and a lot of time and patience to keep it going. (M-NPO)

Referring to the design considerations of greenway development, another participant affirmed:

Just trying to establish a greenway, it sounds very simple. You know, why don't you just go out and plant some green and tell people this is your greenway. Well, you know, it's not that simple. It's gotta be planned out, there's property, there's issues, there's down to the point of what kind of tree is going to grow in this kind of habitat? (C-NPO)

A local government representative from Charleston also commented on the city's plans for riverfront development as being rather lengthy, stating that the current master plan is "a 20 year vision," noting the lack of understanding and urgency revolving around the project and stating "we're all on different timetables" (C-LG).

People involved in planning processes must acknowledge and be prepared to account for time as a major factor in trail development. As one participant noted, 
"people have a hard time thinking incrementally" (C-LG). Completion of a project should not be the singular measure of success for communities engaged in trail development, as progress is often slow-going:

You need people who are willing to stay in the community, to keep it going, to not burn out because you're not seeing any progress right away. With my nonprofit, it took ten years before we had an actual any little bit of trail.

She continued talking about various phases of trail construction, and the time involved in the bidding for contractors to complete the work. She concluded by making a comment alluding to the capacity of nonprofits to spearhead such projects:

....all of those things take a toll as far as volunteer burnout. So sometimes it does work better if it's a city [managing the trail project] because you know that it's in their planning originally or a county agency. That's not going to go away like it could with a nonprofit.

Wrapping up her thoughts, she explained the phenomenon of trail development by confirming that "it does just take a long term commitment and I feel like that's not an easy thing. I think it's a miracle every time it happens, to be honest" (M-NPO).

One element that contributes to the "miracle" of rail-trail and greenway development is community involvement in planning processes. Methods of public participation and community involvement essentially bond the built environment with the political environment. Nonprofits and local government entities that facilitate public participation in planning efforts also create a forum for social interactions. One participant spoke of the benefits of rail-trails and greenways specifically as it relates to planning processes that involve public participation and discourse:

Well, I guess there's the benefit of the finished product and then there's the benefit of the planning process...you know people need to remember that the planning process in and of itself has value because of the way it helps a community dialogue with each other about connecting neighborhoods, 'oh, so and so lives there and [l'd] like to get there, I never knew that because I don't live there'. You know, it helps you see something beyond your own neighborhood, it helps you see the community in a bigger way, and I think it helps people work together, not just for their own little part of the world, but for the greater, well they're looking at their part of the world but they see it in a context of a bigger place, so that's great. (C-NPO)

Planning processes that help people "see something beyond their own neighborhood" might also facilitate in individual level social capital, as community members become more acquainted with one another, and perhaps build on systems of trust. The way 
residents view their built environment may also change, as they explore the possibilities of connecting people and places.

\section{Mentality and Attitudes}

"And everybody goes, 'what the heck are they building a trail for?' " (C-NP)

The more I talked to people that were involved in most phases of trail development, I realized that it was a miracle when a rail-trail was completely constructed. One of the reasons that it proved to be such a feat was because of the oppositional mentality and attitudes that could hinder development at every stage of the process. After accounting for many of the benefits that the local rail-trail provides Wheeling, a participant alluded to public attitudes:

There's a whole lot of neat social things that happen because of the trails. So how do you get more of that if you don't know about it, if you don't want it, if you don't understand it, if you don't use it, if you don't care and you're saying, 'you're going to use my dollars to do that?' (W-LG)

The subcategories of "Alliance Formation" illuminate the constraints placed on local government due to controls and regulations put in place to safeguard public resources. The built environment includes public resources like utilities, roadways, sidewalks, and parks. Rail-trails and greenways are other public resources that are being recognized as alternative transportation routes, but as one participant explained, that might not be enough of an incentive to get people to actually want or support trail development:

...there's no indication that the people are going to use [rail-trails or greenways] to go to work. America is simply not where it needs to be. In my opinion, what's holding America up from [using] alternative transportation is attitudes, not the availability of trails or bikeways. (M-NPO/LG)

A Charleston participant considered the difference between the Morgantown and Charleston in evaluating community support for rail-trails and connected the existence of auto-centric mentalities with levels of support:

....in a truly university city like Morgantown, kids or students are used to walking or riding [bicycles]... and here [in Charleston], we park right at the door, we use our cars.... So I don't know if there's a mindset, you know, it's younger there, its more recreation oriented and you've got an older population here. (C-LG)

Another Charleston representative supported her claims when explaining why some Charleston residents were opposed to riverfront development plans that considered 
eliminating a section of roadway for constructing greenways:

...yeah, there's an attitude here. There's a group of people, a very intelligent group of people, who just say, 'why should we change it? It's a nice road, it's 6 miles long, I can go fast and you can't create anything different anyway, what difference does it make?' (C-LG)

These bits of conversation led me to consider "mentality and attitudes" as a supporting subcategory for one of my central research questions: Why have some West Virginia communities seen the benefits of rail-trails and greenways while other communities with supportive infrastructures have yet to develop these amenities?

However, several participants alluded to the incomparability of communities in West Virginia when it comes to rail-trail and greenway planning. One Charleston native remarked:

I think if you compare for example Morgantown and Charleston, its always going to be apples and oranges. No, Charleston has not developed, in my view, its potential [for rail-trails and greenways], but over the last 20 years, we've built in this community an enormous performing arts hall and science center which cost 120 million dollars. (C-LG)

I realized that every community was different and had its own set of variables. However, participants also suggested that oppositional attitudes could shift if people experience how rail-trails and greenways function in other communities, or how implementing different design principles can have positive effects. Nonetheless, mentalities might be difficult to alter as suggested by this participant:

We need to get the general population out of West Virginia, because people just don't know what their missing...there are people that make up the vast majority of the population in our state who just aren't leaving the porch. I mean, they get up, they go to work, they hit Wal-Mart, they do their thing. (C-NP)

Comments like this made me wonder, "how do people make things happen in West Virginia communities? How do rail-trails and greenways actually come to be?" The phenomenon I was studying started to feel like a phenomenon in every sense of the word.

The more I spoke with people, the more my questions were answered. I started to understand that there are many different factors that facilitate rail-trail and greenway development. I knew the benefits of having a rail-trail in my community because I had one there. I understood how design principles contribute to walkability in a community, and I also saw the alternative transportation opportunities that rail-trail and greenways 
can create because I have used a rail-trail to as a route to work. My mentality about railtrails and greenways has been shaped through experience. I thought, if people can not experience what it would be like to have a rail-trail, how do their belief systems change? One participant suggested that "you have to make it human," and noted that some proponents of trail development are “...idealist [and] think about nature for nature's sake," and may not realize that "those arguments don't convince other people at all" (MNP 5). Other emerging concepts implicated ways to make trail development more "human;" one participant noted that:

....if there's one way to try to really encourage this area [to recognize] the importance of greenways and trail development [is to demonstrate] how that ties back into economic development. (C-NPO)

Economic development was often mentioned during interviews, especially as a factor used to persuade the public or local government to support rail-trails and greenways. I knew that economic development was important on many levels because it increases revenue and allows the city to spend more money on improvements. However, I continued to question: How do attitudes and values change? How can our relationship with the built environment be reconsidered?

\section{Planning principles and design}

As I read over my transcripts, I began to notice a large amount of "buzzwords" that are linked to certain schools of thought in the urban planning field. Participants talked about rail-trails and greenways as contributors to community "walkability," some mentioned the importance of "Smart Growth" and "New Urbanism," and others talked about how "sprawl" decreases connectivity in and amongst communities. A participant from the Charleston city planning department explained that these principles (although they have roots in our earliest forms of planning) were somewhat foreign to the public, but creating an awareness of how these concepts can be beneficial is:

...just something that happens slowly over time. They've seen so much bad design in their life and you can explain to them what good design is, and when they can start to see examples of it, it gets them motivated and excited about it. (C-LG)

Explaining some of the measures taken by the City of Charleston to introduce more sustainable design practices, one participant noticed that the public might not see the value in the enhanced design:

With the downtown streetscapes they've done, the curb-cuts and the attractive landscaping and things...the way they're trying to build the 
downtown so that your building can't be all closed on the front, it has to be open so that people aren't afraid to walk past. Eyes on the street. They're putting a great deal of effort into making Charleston walkable. But it's an uphill push for them, people don't understand it and appreciate it much at this time (C-NPO)

In the case of the three communities I studied, the built environment is influenced by a feature of the natural environment, rivers. Riverfront development is, as one local government representative explained, "a very common phrase in the vocabulary of most city administrators this day and age" (M-LG). Planning principles and design that help link a community with its river is imperative to the vitality and attractiveness of a city. Until the rail-trail was constructed, Morgantown's riverfront had been largely neglected:

You think of all the years the city literally turned its back on the river. There were abandoned warehouses, rusted fences, junked cars. People didn't go there, they didn't even look in that direction. We turned our back to it, when all along it was a very valuable asset that was locally unemployed. (M-LG)

In Wheeling, the construction of a large outdoor amphitheater adjacent to the Heritage Rail-Trail also helped reconnect the city with it's beautiful river. One participant said that the rail-trail in Wheeling "helped [the] community take back the waterfront" (W-NPO). Communities like Wheeling, Charleston, and Morgantown can especially benefit from attention to riverfront development as being a significant factor in trail development: "...river development, which is, and may not be describe[d] as such, but is trail development. It's development of a green corridor" (C-LG).

Planning principles that promote pedestrian and bicycle travel may also enhance social capital. One participant described the opportunities that rail-trails and greenways, as components of walkable communities, provide for social interaction:

...it gets them out of their car. They're zooming down the road at 30 miles per hour, windows up, the $\mathrm{AC}$ on, the radio blaring, or they're on their phone...even if they saw their neighbor, they go right by them...the neighbor didn't notice them except for the blur. But if they're walking or riding their bike, they will say hi. More than likely, they'll stop and say, ' what are you doing? Get your bike and ride to work with me tomorrow, or go to the park with me tomorrow, let's meet for a ride. (C-NPO)

His descriptive statement makes a case for the connection between social capital and the built environment. Rail-trails and greenways, as a component of planning principles and sustainable design can help strengthen neighborhood ties, and contribute to social capital by being places that invite people to interact and engage in conversation and activities with other members of their community. 
Nonprofits and local governments that work together to educate and inform the public in an attempt to plan for a more sustainable, community-centered built environment may provoke citizens to reexamine values. The data suggests that if mentalities and attitudes that are oppositional to trail developed can be changed through the political environment, more people will recognize the benefits of rail-trails and greenways and support their development. 


\section{Summary, Conclusions, and Recommendations}

\section{Chapter V}

\section{Summary}

There is little empirical research that attempts to explore nonprofit and government relations as it applies to rail-trail and greenway development. Most of the research conducted on rail-trails and greenways is relatively new, emerging over the past ten to fifteen years, providing evidence to support the benefits of rail-trails and greenways as reported by trail users, adjacent landowners, and community residents (Moore \& Graefe, 1993, 1994; Moore et al., 1992; Sederelis \& Moore, 1995; Shafer et al., 2000; Turco et al., 1998). These important studies helped build a field of knowledge being used to present a case for rail-trails and greenways.

In the early 1990s, federal legislation provided a new funding mechanism for trail projects through the Intermodal Surface Transportation Efficiency Act (ISTEA). Coupled with the increase of rail corridor abandonment, ISTEA provided communities across the country the opportunity to explore trail development. Fifteen years later, ISTEA is in its second reauthorization as the Safe, Accountable, Flexible, Efficient Transportation Equity Act: A Legacy for Users (SAFETE-LU). Currently, there are over 12,000 miles of developed rail-trails in the United States, with thousands of miles still under development. Becoming a more prevalent fixture in American communities, rail-trails and greenways are being recognized and honored for their contribution to improving social, economic, environmental, and human health conditions for an increased quality of life (Lindsey, 2003; Shafer et al., 2000).

Rail-trails and greenways are developed and managed under a wide range of authorities (Flink et al., 2001), including local government entities like municipalities. Few rail-trails are constructed and managed solely by nonprofit organizations like trail advocacy groups, but community-based nonprofits are often involved in some aspect of trail planning, construction, and maintenance. There is a plethora of existing research on the subject of nonprofit and government relations (De Vita, 1999; Lloyd, 1990; Milne et al., 1996; Salamon, 1995; Smith, 2003; Snavely \& Desai, 2000). However, there is virtually no available research attempting to connect rail-trail and greenway development with nonprofit and local government relations. Studies that could be considered important to an exploration of this new research topic include Quayle's (1995) look into community action and implementation in greenway development, Pincetl's (2003) 
examination of nonprofit and local government convergence in park planning, and Hou and Rios' (2003) study of participatory planning in park development.

Additionally, linking the concepts of individual and organizational social capital to the phenomenon of nonprofit and government relations in rail-trail and greenway development augment this study's ability to support theory that pursues connections between the built environment, the political environment, and social networks.

In the Introduction, I questioned how projects like rail-trail and greenways "happen." The West Virginia Statewide Trail Plan (2002) and the West Virginia Statewide Comprehensive Outdoor Recreation Plan (2002) called for an exploration of trail-related issues in West Virginia, as a result of their recognized popularity among residents. One trail-related issue involves exploring how trails happen, and more specifically how different entities of government work with community-based organizations to facilitate their development. Furthermore, understanding more about the factors that contribute to effective relationship between the two sectors is critical in conceptualizing the broader phenomenon of rail-trail and greenway development.

I wanted to explore the phenomenon by learning more about individual communities' efforts in rail-trail and greenway development, and particularly the relationships that exist between different nonprofit organizations and municipalities that enable trail development. My study was conducted using qualitative methods and a grounded theory framework. This allowed me to become personally engaged with my study participants and the resulting data. Using qualitative methods of face-to-face interviews allowed me to gather data that could provide a rich, descriptive narrative analysis of each community's struggles and triumphs. Reflecting the varying experience of 23 individuals involved in rail-trail and greenway development in three West Virginia cities may enhance the potential for increasing the state's infrastructure of trails and provide a significant framework for a deeper understanding the factors that contribute to effective relationships between nonprofit organizations and local government involved in rail-trail and greenway development.

\section{Conclusions}

The data collected yielded over one hundred pages of transcription, and a clear representation of the findings emerged during a lengthy analysis. After the interviews were conducted, I felt a deeper understanding of issues surrounding rail-trail and greenway development, as well as the factors that contribute to effective relationship 
building between nonprofits and local government. After data analysis, I felt entrenched in the issues, and sought a clear way of representing my findings. To reiterate, I was the sole researcher for this study, so a certain amount of bias is inevitable. I tried to account for any biases that might impede on my ability to provide a representative summary of the data by interviewing a relatively diverse, but equally proportioned group of individuals. My interview guide also helped me gain different responses from the same questions, enabling a comparative analysis.

Understanding the "values and beliefs that underpin the formation and enduring nature of linkages" between nonprofits and local government is necessary to developing the subject of nonprofit and government relations (Cousens, Barnes, Stevens, Mallen, \& Bradish, 2006, p.32). I asked participants to describe the benefits of rail-trails and greenways to a community, and their responses provided a glimpse into the values and beliefs that may also contribute to the nature of nonprofit and local government relations, and their potential for successfully creating or managing public goods. Participants from both sectors produced somewhat similar responses, indicating that a shared sense of the benefits of rail-trails and greenways might translate to the broader concept of shared values and beliefs. Since shared values and beliefs are linked to the potential for partnership success, the data revealed that the potential for nonprofit and local government relations to be effective in the three communities studied.

One variance that emerged in the "Perceived Benefits/Costs" theme was a higher response of generalized benefits by local government representatives and more specified benefits reported by nonprofit representatives. The response rate, combined with data representing the subcategory "Nonprofits as Educators and Resource Providers" may be indicative of devolution. The literature exploring devolution, or the decentralization of government, suggests that the public sector is increasingly relying on the nonprofit sector as a producer or provider of public goods and services (De Vita, 1999). On the whole, nonprofit representatives reported a wider range of benefits, and were more specific in their designations. Many of the nonprofit representatives I spoke with had assumed the role of educator or resource provider to the public and local government. A greater knowledge of the benefits of rail-trails and greenways amongst nonprofit representatives may be because of their role as educator, and must be able to more specifically cite the benefits of rail-trails and greenways in order to gain support from local government officials that want to provide the "greatest good for the greatest number over the long run" (Nalbandian, 1999, p. 188). 
The emerging theme of "Political Environment" also illustrated the increased role of nonprofit organizations in local government policy and program implementation, and the opportunity for social capital result from effective relationship building. Where nonprofits can be a resource of information for local government or enhance local governments' efforts in educating the public, there is potential to increase social capital. Concerted efforts by nonprofits and local government to incorporate community involvement in rail-trail and greenway planning initiatives "bring people together to interact, to learn more about each other, to collaborate...and to voice opinions" (Snavely \& Desai, 2000, p.251). This claim was supported by the relayed experiences of participants of my study. Local government representatives welcomed the presence of nonprofits in public participation events, and looked to them as a resource of information in their attempts to promote rail-trail and greenway development.

The complex system that supports relationships between the public, private, and nonprofit sectors is described by Goldsmith and Eggers (2004) as "governing by nonprofits to serve as distribution channels for public services and transactions" (p. 8). Certainly, the emerging data that supports the claim of nonprofits as educators and resource providers reflects how the third sector is a "distribution channel." The other category formed in my data that supports Goldsmith and Eggers' notion of governing by networks is "Nonprofit Organization Ability vs. Constraints of Government Processes"; the network model provides governing bodies with more flexibility. As government works with and through the private and nonprofit sector, their capacity to leverage public and private dollars increase, as well as their ability to "bypass procedures that slow...the acquisition of urgent materials or partners" (Goldsmith \& Eggers, 2004, p. 31). The participants I spoke with reflected this notion of "flexibility." Local government representatives expressed the importance of nonprofits as actors that could pursue the development of rail-trails and greenways without the regulatory measures that sometimes confine local government, also noting their consistent supportive role in a network.

Other categories and subcategories in the findings related to the "Political Environment" helped provide answers to my research questions and contribute to my objectives. I gained a better understanding of how relationships between nonprofits and local government form and function, and also learned a lot about how various forms of local government contribute to how relationships are built. "Strategic Partnering and Planning" was a concept that emerged as a facilitator of building effective relationships. 
Nonprofit participants that alluded to the importance of "strategic partnering and planning" frequently contributed to the "Leadership" concept as well. Some nonprofit representatives mentioned the importance of city administration, and would specifically contribute the main managing authority (mayor or city manager) as contributing to effective relationship building and suggested their role as social capital builders. Nalbandian (1999) also recognized the city manager as an increasingly important figure in municipalities, explaining their multiple roles as "community builders and enablers of democracy" (p. 187).

Smith et al. (2004) contend that trust in inter-organizational relations is a key component of social capital that feeds capacity for collective action. City managers and other local government administration that build relationships with other government entities, the private sector, and nonprofit organizations based on deeds that enable trust and reciprocity, exemplify how organizational social capital is produced. Participants in my study also expressed "trust building" as a leadership characteristic, describing the importance of personal interactions in developing effective relationships.

Another factor feeding the capacity for collective action emerged as "Community Involvement." As participants described different rail-trail and greenway initiatives that had or lacked a community involvement component, individual level social capital was again evoked. Community involvement and public participation opportunities were reported as opportunities for the public to become educated and informed on issues related to trail development. Also, where community members could come together for a planning effort, there was increased opportunity for social interaction that could contribute to developing social networks, and norms of reciprocity and trust (Putnam, 2000).

Some participants were facilitators of community involvement events that attempted to educate and inform the public on sustainable planning and design of the built environment. Although those events were noted by participants from both sectors as supplementing efforts to garner interest and support for amenities like rail-trails and greenways, the concept of mentalities and attitudes also emerged as a barrier to rail-trail and greenway development, and sometimes as a constraining factor to building relationships between nonprofits and local governments. This supports previous research that suggests that the consideration of personal attitudes needs to be a key component to research exploring planning efforts (Lund, 2003).

The findings produced from this study met my research objectives and questions. 
The value of qualitative methods in this type of research can not be overstated. Investigating the social processes involved in relationship building between the public and nonprofit sector is not an easily measurable topic (Harry et al., 2005). In-depth, face-to-face interviews allowed me to work with data and develop findings that could provide a thick description of how relationships between nonprofit organizations and local government involved in rail-trail and greenway development form and function. The framework and data represented in my findings begins to provide a basis for developing theory related to the phenomena of rail-trail and greenway development and nonprofit and government relations.

The emanating theory of social capital also helped guide my study because of its presence in the three major themes explored. Also, the emerging concepts related to social capital support the need to consider the differences between individual level and organizational level social capital. This study begins to illuminate "how these networks of relationships intersect," lending support to the concept of organizational social capital as a method for "understanding the improvement of democratic governance" (Smith et al., 2004, p.525). In addition, the data that emerged to form the "Built Environment" theme is also useful in supporting claims that link individual level social capital with built environments that are pedestrian-friendly (Leyden, 2003) and allow for "communitydriven place making" (Hou \& Rios, 2003, p.19). Addressing the need to "restore the American community" via social capital, Putnam (2000) suggests ways to increase civic participation, explicitly mentioning the role of the built environment:

Let us act to ensure that by 2010 Americans spend less time traveling and more time connecting with our neighbors that was do today, that we will live in more integrated and pedestrian-friendly areas, and that the design of our communities and the availability of public space will encourage more casual socializing with friends and neighbors. (p. 408)

Rail-trails and greenways are not a panacea for the afflictions of a society becoming more deprived of the social interactions that build networks based on reciprocity and trust. However, they are a component of creating communities that are healthier and more connected. This research makes a case for exploring rail-trails and greenways as they apply to individual level social capital and examining government and nonprofit relations through the lens of organizational social capital. 


\section{Recommendations}

"Then I just think the bigger picture too, of values...thinking more about the environment in which you live and all the choices that you make that have an impact on that. I think that once you start thinking about [rail-trail and greenway development] in one context like alternative transportation, you can't help but get your mind around other choices you make like recycling, anything you do that has an impact, choices you make that have an impact on the community. That's a little pie-in-the-sky, but I really feel that way about it." (C-NP 14)

The larger narratives that formed from this study are full of practical implications for practitioners of rail-trail and greenway development in West Virginia. I chose to limit the representation of data as it related specifically to municipalities, but many participants were vocal about the state's role in trail development. Several practical recommendations that are not reflected in the findings suggest implementing changes at the state level. Some participants mentioned the need to develop strong relationships with state legislative representatives, as it provides a lobbying force for funding at the state level. Also, participants with a greater knowledge of trail-related issues in the state talked about the role of the newly appointed State Trails Coordinator as a factor that could potentially enhance trail development since the position creates a new venue for communities to network and seek assistance. Another state-related recommendation indicated a need for more consistency and support from regional planning and development agencies. Others proposed that a dedicated state funding mechanism would be extremely helpful for communities that do not possess the financial capital to seriously consider rail-trail and greenway development.

Through data collection and analysis, I began to form my own recommendations that can be supported by the data. Theory that builds the body of knowledge relating to nonprofit and local government relations suggests that the nonprofit sector is playing a larger role in civil society. The public sector increasingly partners or collaborates with the nonprofit sector to carry out programs or complete projects. In rail-trail and greenway development, this shift of roles provides an opportunity for nonprofit organizations to become resource providers for local governments. Nonprofits that are advocates for trail development must know how to approach local government in order to partner effectively, and pursue their goals. In these instances, nonprofits need to know how to "package" rail-trails and greenways. Soliciting local government's support for rail-trails and greenway projects can be accomplished through presentation of community experiences along with a description of the benefits of rail-trails and greenways. In using other community cases to exemplify successful rail-trail and 
greenway stories, nonprofit representatives should research to find the communities that are demographically, economically, and geographically comparable to theirs. Also, where nonprofits seek to gain local government support for a trail project, they should compile data that exemplifies the wide range of benefits that trails provide. These considerations appeal to the government's need to provide resources that serve the greatest number of constituents.

Also, in order to maintain and build relationships with one another, nonprofits and local governments involved in rail-trail and greenway planning, or comprehensive community planning should enter into formal agreements that reflect the government's recognition of nonprofit efforts as enhancing their own. These agreements also serve as a record of support for nonprofits to reference when city administration, planning, or development offices change due to election turnover.

Local governments and nonprofits should also work together to provide ample community involvement and public participation opportunities during rail-trail and greenway development. The new State Trail Coordinator position might be a resource for communities to learn about effective community involvement strategies, or the regional planning and development councils might be able to improve their efforts by existing as more of a resource for communities that need support and guidance through public participation processes.

Finally, local government policy should be open and willing to working with community groups that are interested in pursuing trail development. Where applicable, planning departments could accommodate or city councils could legislate for more concerted efforts to connect with organized community groups like neighborhood associations. If planning and development departments could act as an umbrella for nonprofits that are involved in community development (trail advocacy groups, watershed associations, community beautification clubs, etc.) and actively recruit organizations, there would be more of a central place for neighborhood associations and other place-specific community groups to partner and receive information regarding different types of community development efforts. By creating a centralized way of connecting different community groups, more community members are aware and can become involved in initiatives that are important to them. Also, it provides a way for organizations to collaborate and communicate so that meeting times and events do not overlap with one another. 
Further research is needed to more fully extend and develop theory related to nonprofit and government relations in rail-trail and greenway development. My study is specific to the municipal level of local government, and could be enhanced by including relationships between nonprofits, municipalities, and county and state level government that evolve in rail-trail and greenway development. A larger sample size and increased site selection may also be useful in making more generalized comparisons. The use of more researchers could also increase the validity of this type of qualitative study by decreasing the opportunity for personal bias to affect research design and data analysis. Finally, quantitative research that follows Putnam's methods for determining factors that contribute to social capital may also capture supporting evidence for rail-trails and greenways as creators of social capital.

The quote at the beginning of this section clearly describes the reasons why I wanted to conduct this research. As a proponent an active user of rail-trails and greenways, I too believe in their ability change the way people view their environment and place in it. I also believe in the power of small, grassroots initiatives as a driving force for sustainable community development and change. This thesis gave me the unique opportunity to engage in dialogue with many different leaders in rail-trail and greenway development, across public and nonprofit sectors. Not only did I learn more about how these different groups work together to promote, plan, construct, and manage trails, I also gained a better understanding of political processes and the importance of civic engagement. I hope that this research extends the knowledge of how nonprofits and local governments work together, not only to develop rail-trails and greenways, but more basically to provide for the general welfare of the communities they serve. 


\section{References}

Vision 2000: Greater Morgantown Project. (1992). Morgantown, WV.

Pathways to the Future: The West Virginia Statewide Trail Plan. (2002) Charleston, WV.

Statewide Comprehensive Outdoor Recreation Plan. (2002). Charleston, WV:

The West Virginia Development Office.

City of Charleston Municipal Planning Commission Resolution in Support of the Kanawha Valley Greenway Initiative. (2004). City of Charleston, WV.

Creating Active Communities: Ten Case Studies of Programs and Partnerships. (2004). Washington, DC: Rails-to-Trails Conservancy.

Management Plan for the Wheeling National Heritage Area. (2004). Wheeling, WV: ICON Architecture, Inc.

Charleston Riverfront Master Plan. (2006). Charleston,WV: Sasaki Associates, Inc. Gannett Flemming, Inc.

The Greater Charleston Greenway Initiative: A Vision for Greenspace, Connectivity, and Pedestrian Community. (2006). Charleston, WV: West Virginia Land Trust.

Ahern, J. (1995). Greenways as a planning strategy. Landscape and Urban Planning, 33, 131-155.

Arai, S. M., \& Pedlar, A. M. (2001). Building Communities Through Leisure: Citizen Participation in a Healthy Communities Initiative. Journal of Leisure Research, 29(2), 167-182.

Breen, A., \& Rigby, D. (1996). The New Waterfront. New York: McGraw-Hill.

Brudney, J. L., \& England, R. E. (1983). Toward a Definition of the Coproduction Concept. Public Administration Review. January/February.

Charmaz, K. (2003). Grounded Theory: Objectivist and Constructivist Methods. In N. K. Denzin \& Y. S. Lincoln (Eds.), Strategies of Qualitative Inquiry (pp. 249-291). Thousand Oaks, CA: Sage Publications, Inc.

Charmaz, K. (2004). Grounded Theory. In S. N. Hesse-Biber \& P. Leavy (Eds.), Approaches to Qualitative Research: A Reader on Theory and Practice. New York: Oxford University Press.

Clarke, S. E. (2001). The Prospects for Loca-Democratic Governance: The Governance Roles of Nonprofit Organizations. Policy Studies Review, 18(4), 129-145.

Coffey, A. (2002). Ethnography and Self: Reflections and Representations. In T. May (Ed.), Qualitative Research in Action. London: Sage Publications, Ltd. 
Collins, A., Constantz, G., Hunter, S., \& Selin, S. (1998). Collaborative watershed planning: The West Virginia Experience. Conservation Voices, 1(2), 31-35.

Cousens, L., Barnes, M., Stevens, J., Mallen, C., \& Bradish, C. (2006). "Who's Your Partner? Who's Your Ally?" Exploring the Characteristics of Public, Private, and Voluntary Recreation Linkages. Journal of Park and Recreation Administration, 24(1), 32-55.

De Vita, C. J. (1999). Nonprofits and Devolution: What Do We Know? In E. T. Boris \& C. E. Steuerle (Eds.), Nonprofits and Government: Collaboration and Conflict (pp. 213-233). Washington, D.C.: The Urban Institute Press.

Denzin, N. K. (1989). Interpretive Interactionism. Newbury Park, CA: Sage.

Farber, S. (1999). An Economic Impact Study for the Allegheny Trail Alliance. Pittsburgh, PA: Pennsylvania Academy League, Inc.

Farber, S., Argueta, J., \& Hughes, S. (2003). 2002 User Survey for the Pennsylvania Allegheny Trail Alliance. Pittsburgh, PA: University Center for Social and Urban Research, University of Pittsburgh.

Faugier, J., \& Sargeant, M. (1997). Sampling hard to reach populations. Journal of Advanced Nursing, 26, 790-797.

Flink, C., Olka, K., \& Searns, R. (2001). Trails for the Twenty-First Century: Planning, Design, and Management Manual for Multi-Use Trails (2nd ed.). Washington, DC: Island Press.

Freeman, L. (2001). The Effects of Sprawl on Neighborhood Social Ties. Journal of the American Planning Association, 67(1), 69-77.

Frisby, W., Thibault, L., \& Kikulis, L. (2004). The organizational dynamics under-managed partnerships in leisure service departments. Leisure Studies, 23(2), 109-126.

Gates, C. T. (1999). Creating a Healthy Democracy. National Civic Review, 88(4), 259-264.

Glaser, B. G., \& Strauss, A. L. (1967). The Discovery of Grounded Theory: Strategies for Qualitative Research. Hawthorne, NY: Aldine Publishing Company.

Gobo, G. (2004). Sampling, representativeness and generalizability. In C. Seale, G. Gobo, J. F. Gubrium \& D. Silverman (Eds.), Qualitative Research Practice (pp. 435-456). London: Sage Publications Ltd.

Goldsmith, S., \& Eggers, W. D. (2004). Governing by Network: The New Shape of the Public Sector. Washington, DC: The Brookings Institute.

Harry, B., Sturges, K. M., \& Klingner, J. K. (2005). Mapping the Process: An Exemplar of Process and Challenge in Grounded Theory Analysis. Educational Researcher, 34(2), 3-13. 
Hartman, L., Proud, F. W., \& Weirick, M. (1995). Adventure Guide to West Virginia Rail-Trails. Charleston, WV: West Virginia Rails-to-Trails Council.

Hoover, A. P., \& Shannon, M. A. (1995). Building greenway policies within a participatory democracy framework. Landscape and Urban Planning, 33, 433-459.

Hou, J., \& Rios, M. (2003). Community-Driven Place Making: The Societal Practice of Participatory Design in the Making of Union Point Park. Journal of Architectural Education, 19-27.

Howser, B. M. (1997). Putting Value on Rail-Trails. Public Management, 79(4), 4-10.

James, K. (1999). Understanding Successful Partnerships and Collaborations. Parks and Recreation, 38-47.

Lawler, S. (2002). Narrative in Social Research. In T. May (Ed.), Qualitative Research in Action (pp. 242-258). London: Sage Publications, Ltd.

Leach, W. D. (2002). Surveying Diverse Stakeholder Groups. Society and Natural Resources, 15, 641-649.

Leyden, K. (2003). Social Capital and the Built Environment: The Importance of Walkable Neighborhoods. American Journal of Public Health, 93(9), 1546-1551.

Lindsey, G. (2003). Sustainability and Urban Greenways: Indicators in Indianapolis. Journal of the American Planning Association, 69(2), 165-180.

Little, C. E. (1990). Greenways for America. Baltimore: Johns Hopkins University Press.

Lloyd, P. C. (1990). The Relationship Between Voluntary Associations and the State Agencies in the Provision of Social Services at the Local Level. In H. K. Anheier \& W. Seibel (Eds.), The Third Sector: Comparative Studies of Nonprofit Organizations (pp. 241-253). Berlin, Germany: Walter de Gruyter \& Co.

Lund, H. (2003). Testing the Claims of New Urbanism: Local Access, Pedestrian Travel, and Neighboring Behaviors. Journal of the American Planning Association, 69(4), 414-429.

Martin, D. G. (2004). Nonprofit Foundations and Grassroots Organizing: Reshaping Urban Governance. The Professional Geographer, 56(3), 394-405.

Maxwell, J. A. (2005). Qualitative Research Design: An Interactive Approach (2nd ed.). Thousand Oaks, CA: Sage Publication.

McKie, L. (2002). Engagement and Evaluation in Qualitative Inquiry. In T. May (Ed.), Qualitative Research in Action (pp. 261-285). London: Sage Publications, Ltd.

Merriam, S. B. (2002). Qualitative Research in Practice: Examples for Discussion and Analysis. San Francisco, CA: Jossey-Bass. 
Milne, G. R., lyer, E. S., \& Gooding-Williams, S. (1996). Environmental Organization Alliance Relationships Within and Across Nonprofit, Business, and Government Sectors. Journal of Public Policy \& Marketing, 15(2), 203-215.

Minnesota Department of Natural Resources. (1980). Living along trails: What people expect and find. Saint Paul, MN: Minnesota Department of Natural Resources, Trails and Waterways Unit.

Mohan, G., \& Mohan, J. (2002). Placing social capital. Progress in Human Geography, 26(2), 191-210.

Moore, R. L., \& Graefe, A. R. (1993). Living Adjacent to Rail-Trails: Changes in Landowners' Experiences and Attitudes. Paper presented at the Northeast Recreation Research Symposium.

Moore, R. L., \& Graefe, A. R. (1994). Attachments to Recreation Settings: The Case of Rail-Trail Users. Leisure Sciences, 16, 17-31.

Moore, R. L., Graefe, A. R., Gitelson, R. J., \& Porter, E. (1992). The impacts of rail-trails: A study of the users and nearby property owners from three trails.

Washington, DC: National Park Service, Rivers \& Trails Conservation Program.

Nalbandian, J. (1999). Facilitating Community, Enabling Democracy: New Roles for Local Government Managers. Public Administration Review, 59(3), 187-197.

Noe, B. A. (2000). Rails-to-Trails: Maryland, Delaware, Virginia, West Virginia. Guilford, CT: The Globe Pequot Press.

Pack, K., unpublished, (2005). Making Connections: Knowledge, Attitudes, and Beliefs of the Mon River Rail-Trail System.

Patton, M. Q. (2002). Qualitative Research and Evaluation Methods (3rd ed.). Thousand Oaks, CA: Sage Publications, Inc.

Pincetl, S. (2003). Nonprofit and Park Provisions in Los Angeles: An Exploration of the Rise of Governance Approaches to the Provision of Local Services. Social Science Quarterly, 84(4), 979.

Potapchuk, W. R., Crocker, J. P., \& Schechter, W. H. (1997). Building community with social capital: Chits and chums or chats with change. National Civic Review, 86(2).

Putnam, R. (2000). Bowling Alone: The Collapse and Revival of American Community. New York: Simon \& Schuster.

Quayle, M. (1995). Urban greenways and public ways: realizing public ideas in a fragmented world. Landscape and Urban Planning, 33, 461-475.

Randolph, J., \& Bauer, M. (1999). Improving Environmental Decision-Making Through Collaborative Methods. Policy Studies Review, 16(3/4), 168-191. 
Reid, E. (1999). Nonprofit Advocacy and Political Participation. In E. T. Boris \& C. E. Steuerle (Eds.), Nonprofits and Government: Collaboration and Conflict (pp. 291-325). Washington, D.C.: The Urban Institute Press.

Replogle, M. (2006, May). New Law, New Questions, 'Missed Opportunities'. Planning, 6-9.

Ryan, K.-L., \& Winterich, J. A. (n.d.). Secrets of Successful Rail-Trails: An Acquisition and Organizing Manual for Converting Rails into Trails: Rails-to-Trails Conservancy and the National Park Service.

Rydin, Y., \& Holman, N. (2004). Re-evaluating the Contribution of Social Capital in Achieving Sustainable Development. Local Environment, 9(2), 117-133.

Salamon, L. M. (1994). The Rise of the Nonprofit Sector. Foreign Affairs, 73(4), 109-122.

Salamon, L. M. (1995). Partners in Public Service: Government-Nonprofit Relations in the Modern Welfare State. Baltimore: Johns Hopkins University Press.

Salamon, L. M. (2003). The Resilient Sector: The State of Nonprofit America. Washington, D.C.: Brookings Institution Press.

Sanoff, H. (2005). Community participation in riverfront development. CoDesign, 1(1), 61-78.

Sederelis, C., \& Moore, R. L. (1995). Outdoor Recreation Net Benefits of Rail-Trails. Journal of Leisure Research, 27(4), 344-359.

Selin, S., \& Myers, N. (1995). Correlates of Partnership Effectiveness: The Coalition for Unified Recreation in the Eastern Sierra. Journal of Park and Recreation Administration, 13(4), 38-47.

Shafer, C. S., Lee, B. K., \& Turner, S. (2000). A tale of three greenway trails: User perceptions related to quality of life. Landscape and Urban Planning, 49, 163-178.

Smith, G., Stoker, G., \& Maloney, W. (2004). Building Social Capital in City Politics: Scope and Limitations at the Inter-organisational Level. Political Studies, 52, 508-530.

Smith, S. R. (2003). Government and Nonprofits in the Modern Age. Society, 36-45.

Snavely, K., \& Desai, U. (2000). Mapping Local Government-Nongovernmental Organization Interactions: A Conceptual Framework. Journal of Public Administration Research and Theory, 11(2), 245-263.

Strauss, A. L., \& Corbin, J. (1990). Basics of Qualitative Research: Grounded Theory Procedures and Techniques.Newbury Park, CA: Sage Publications, Inc. 
Strauss, A. L., \& Corbin, J. (1998). Basics of Qualitative Research: Techniques and Procedures for Developing Grounded Theory (2nd ed.). Thousand Oaks, CA: Sage Publications, Inc.

Swindell, D. (2000). Issue Representation in Neighborhood Organizations: Questing for Democracy at the Grassroots. Journal of Urban Affairs, 22(2), 123-137.

Taylor, S. J., \& Bogdan, R. T. (1984). Introduction to Qualitative Research Methods: The Search for Meanings (2nd ed.). New York: John Wiley \& Sons.

Tregoning, H., Agyeman, J., \& Shenot, C. (2002). Sprawl, Smart Growth, and Sustainability. Local Environment.

Tuler, S., \& Webler, T. (1999). Voices from the Forest: What Participants Expect of a Public Participation Process. Society and Natural Resources, 12, 437-453.

Turco, D., Gallager, L., \& Lee, K. (1998). Resident Attitudes toward Rail-Trail Development. Parks and Recreation, 33(4), 48-53.

Williamson, T. (2002). Sprawl, Politics, and Participation: A Preliminary Analysis. National Civic Review, 91(3), 235-244. 


\section{Appendices}

\section{Appendix A}

\section{Interview Guide Questions}

The two sets of questions are identical, but I used "Nonprofit Organizations" and "Local Government" interchangeably to illicit perceptions about one group from another. The questions represented reflect those interchanges.

\section{Questions for participants representing nonprofit organizations:}

1. How were/are you involved with rail-trail/greenway development?

2. In your opinion, what are the benefits of a rail-trail/greenway to a community?

3. How would you describe your relationship with local government? How has this relationship changed over the years? How do you see the relationship evolving in the future?

4. What are some of the barriers or constraints to developing constructive relationships with local government? What are some of the facilitating factors?

5. How has local government contributed to the community in terms of railtrail/greenway development?

6. In the case of [name of city], what are some of the key factors or who are key players enabling trail development?

7. What policy changes and/or enabling legislation do you think is necessary for WV communities to utilize their potential for rail-trail/greenway development?

8. Why have some towns and cities in WV been able to build an infrastructure of trails while other communities with similar or supporting infrastructure have not?

9. What advice would you give to other nonprofit organizations in WV eager to work on similar projects? What factors are essential to building effective relationships with local government?

\section{Questions for participants representing local government:}

1. How were/are you involved with rail-trail/greenway development?

2. In your opinion, what are the benefits of a rail-trail/greenway to a community?

3. How would you describe your relationship with nonprofit organizations? How has this relationship changed over the years? How do you see the relationship evolving in the future?

4. What are some of the barriers or constraints to developing constructive relationships with nonprofit organizations? What are some of the facilitating factors?

5. How have nonprofit organizations contributed to the community in terms of railtrail/greenway development?

6. In the case of [name of city], what are some of the key factors or who are key players enabling trail development?

7. What policy changes and/or enabling legislation do you think is necessary for WV communities to utilize their potential for rail-trail/greenway development?

8. Why have some towns and cities in WV been able to build an infrastructure of trails while other communities with similar or supporting infrastructure have not?

9. What advice would you give to other local governments in WV eager to work on similar projects? What factors are essential to building effective relationships with nonprofit organizations? 


\section{Appendix B}

\section{Themes, Categories, and Subcategories within the Findings}

I. Perceived Benefits and Costs (theme)

a. Benefits (category)

b. Costs

\section{Political Environment}

a. Alliance Formation

i. Constraining and Facilitating Factors (subcategory)

1. NPO as educator and resource provider

2. Nonprofit Organizational Capacity

3. NPO abilities vs. constraints of government processes

4. Strategic partnering and planning

b. Community Involvement

c. Leadership

i. Community Champions

ii. Role of City Mayor/Manager

III. Built Environment

a. Planning and design principles

i. Walkability, Smart Growth, and New Urbanism

ii. Riverfront Development

b. Planning Processes

c. Attitudes/Mentalities 


\section{Curriculum Vita}

\section{Kelly L. Pack}

Research Thesis Topic: Relationships between Nonprofit Organizations and Local Governments in Rail-Trail and

Interests Greenway Development

Other Research Interests: Community Development and Land Use Planning, Qualitative Research, Social

Capital Theory, Pedestrian and Bicycle Transportation

Skills - Proficient in writing literature reviews, social assessment reports, and web-based content.

- Strong background in qualitative research methods, including interview techniques and data management and analysis.

- Experience with volunteer management, and event planning and organizing.

- Computer proficiency with Microsoft Office, ArcView9, PageMaker, and Photoshop

Experience Graduate Research Assistant - WV Water Research Institute, Morgantown, WV $1 / 06-8 / 06$

- Work with staff to provide requested assistance to community organizations for grant searching and proposal writing related to brownfield redevelopment.

- Maintain communications with local officials and community group leaders.

- Develop content and work with partners to improve the educational, outreach, and technical assistance website, www.wvbrownfields.org.

- Design and produce informational displays, brochures, and Annual Report for the Northern West Virginia Brownfields Assistance Center.

Logistics Coordinator - Adventure West Virginia, Morgantown, WV

- Managed 250 student database for the outdoor education college freshmen orientation program.

- Conducted and maintained communication support for program staff, students, and parents.

- Compiled and organized emergency/risk management information.

Graduate Assistant - West Virginia University Outdoor Recreation Center, Morgantown, WV

$8 / 04-12 / 06$

- Organized and led backpacking and climbing trips in West Virginia and the U.S. southwest.

- Trained student employees and managed gear rental procedures and database.

Gallery Attendant/Educator - Avampato Discovery Museum, Charleston, WV

- Developed educational science demonstrations and conducted large group workshops.

- Worked closely with other staff to facilitate and organize large tour groups.

- Served as the Assistant Youth Volunteer Coordinator and docent for the Juliet Museum of Art.

Counselor/Instructor - Camp Green Cove, Tuxedo, NC

- Organized and led wilderness backpacking trips in southeast Appalachia.

$2000-2002$

- Ropes course leader, rock climbing instructor, camp music coordinator, swimming instructor.

Volunteer - Member of the Community Design Team for Wellsburg, WV (March 2005) and Point

Experience Marion, PA (April 2006). Worked with diverse staff of professionals and students to assist communities in visioning and planning processes.

- Assisted in the facilitation of community workshops for the Greater Charleston

Greenway Initiative in Charleston, WV. Developed presentation on Local

Greenway Opportunities (2005).

- Volunteer coordinator for Friends of Deckers Creek community event, CarpFest (2005).

Education $\quad$ M.S., Recreation, Parks, and Tourism Resources, West Virginia University, Morgantown, WV

$2004-2006$

B.A., English, West Virginia University, Morgantown, WV

$1999-2003$ 